UNIVERSIDADE DE SÃO PAULO

ESCOLA DE ENFERMAGEM DE RIBEIRÃO PRETO

FERNANDA GASPAR TORRATI

ANSIEDADE, DEPRESSÃO, SENSO DE COERÊNCIA E ESTRESSORES NOS PERÍODOS PRÉ E PÓS-OPERATÓRIO DE CIRURGIAS CARDÍACAS.

RIBEIRÃO PRETO 
FERNANDA GASPAR TORRATI

\section{ANSIEDADE, DEPRESSÃO, SENSO DE COERÊNCIA E ESTRESSORES NOS PERÍODOS PRÉ E PÓS-OPERATÓRIO DE CIRURGIAS CARDÍACAS.}

Dissertação apresentada ao Programa de Pós-Graduação em Enfermagem Fundamental da Escola de Enfermagem de Ribeirão Preto da Universidade de São Paulo para a obtenção do título de Mestre em Enfermagem

Linha de pesquisa: Processo de cuidar do adulto e idoso com doenças agudas e crônico-degenerativas.

Orientadora: Profa. Dra. Rosana Aparecida Spadoti Dantas.

Ribeirão Preto 
AUTORIZO A REPRODUÇÃO E A DIVULGAÇÃO TOTAL OU PARCIAL DESTE TARABALHO, POR QUALQUER MEIO CONVENCIONAL OU ELETRÔNICO, PARA FINS DE ESTUDO E PESQUISA, DESDE QUE CITADA A FONTE.

FICHA CATALOGRÁFICA

Torrati, Fernanda Gaspar, 1969

Ansiedade, depressão, senso de coerência e estressores nos períodos pré e pós-operatório de cirurgias cardíacas / Fernanda Gaspar Torrati .2009

n. de f. 110; altura $31 \mathrm{~cm}$.

Orientadora Rosana Aparecida Spadoti Dantas. - Ribeirão Preto,

Dissertação (Mestrado) - Programa de Pós-Graduação da Escola de Enfermagem de Ribeirão Preto da Universidade de São Paulo. Linha de pesquisa: Processo de cuidar do adulto e idoso com doenças agudas e crônico-degenerativas - Escola de Enfermagem de Ribeirão Preto da Universidade de São Paulo.

1. Ansiedade 2. Depressão 3. Enfrentamento 4. Estresse 5. Cirurgia Torácica I. Dantas, Rosana Aparecida Spadoti. II. Universidade de São Paulo. Escola de Enfermagem de Ribeirão Preto. III. Título. 


\section{FOLHA DE APROVAÇÃO}

Fernanda Gaspar Torrati

Relação entre depressão, ansiedade, senso de coerência e estresse nos períodos pré e pós operatório de cirurgias cardíacas

Dissertação apresentada ao Programa de PósGraduação em Enfermagem Fundamental da Escola de Enfermagem de Ribeirão Preto da Universidade de São Paulo para a obtenção do título de Mestre em Enfermagem

Linha de pesquisa: Processo de cuidar do adulto e idoso com doenças agudas e crônicodegenerativas.

Orientadora: Profa. Dra. Rosana Aparecida Spadoti Dantas.

Aprovado em:

Banca Examinadora

Prof. Dr.:

Instituição: Assinatura:

Prof. Dr.:

Instituição: Assinatura:

Prof. Dr.:

Instituição: Assinatura: 


\section{DEDICATÓRIA}

Dedico esta dissertação:

A meus filhos, Verônica, Paloma e Mateus, porque vocês são a razão do meu viver, meu amor eterno e motivação sempre.

A meu marido, Fabio, pelo amor e apoio que me impulsionam.

A minha mãe, Cida, pela vida e porque sou hoje o que ela me ensinou ontem.

A meu pai, Leonio (in memorian) pela vida. Saudades.

A todos os meus familiares e amigos, por toda a compreensão nesse período da minha vida.

Amo vocês. 


\section{AGRADECIMENTOS}

A Deus, por tudo o que sou e tudo o que tenho, especialmente à força para continuar nessa caminhada.

Em especial, à Prof. Dra. Rosana Aparecida Spadoti Dantas, minha orientadora, pelos ensinamentos, pelos conselhos, pela paciência, pela amizade, que me fizeram crescer e pelas horas de dedicação ao meu trabalho.

Às amigas Cecília e Cássia, por me incentivarem e estimularem, mesmo quando eu estava prestes a esmorecer e pela ajuda incondicional.

Às Profs. Dras. Lidia Ap. Rossi, Ana Maria Pimenta e Roberta Cunha M. Rodrigues, pela colaboração, discussões e dicas para o meu trabalho.

Às enfermeiras Cristiane e Viviane por compartilharem comigo uma parte desse trabalho.

Às colegas Carina, Flavia, Dulce, Rose, Fabíola, Cassandra, Madalena, Silvia, Filomena, Fátima, Ana Célia pela compreensão da distância que aconteceu tantas vezes em nosso trabalho.

A toda equipe de enfermagem da Unidade Pós Operatória de Cirurgia Torácica e Cardiovascular pelo apoio.

Aos pacientes que, mesmo estando em uma fase difícil da vida, contribuíram com carinho para esta pesquisa. 


\section{SUMÁRIO}

LISTA DE TABELAS

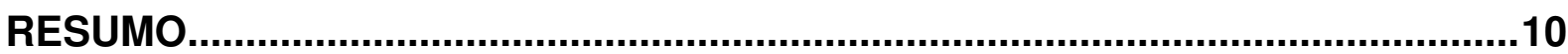

ABSTRACT

RESUMEN

1. INTRODUÇÃO

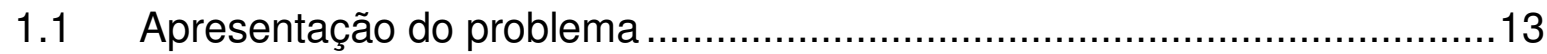

1.2 Referencial teórico e revisão da literatura............................................15

1.2.1 O início da cirurgia cardíaca no Brasil ...........................................15

1.2.2 Tipos e características da cirurgia cardíaca......................................16

1.2.3 Ansiedade e depressão: definições, caracterização clínica e métodos de avaliação. ..........................................................................19

1.2.4 Ansiedade e depressão no período perioperatório de cirurgia cardíaca ..25

1.2.5 Estresse e estressores em unidade de terapia intensiva.....................30

1.2.6 Senso de coerência...................................................................33

2. OBJETIVOS

3. CASUÍSTICA E MÉTODO

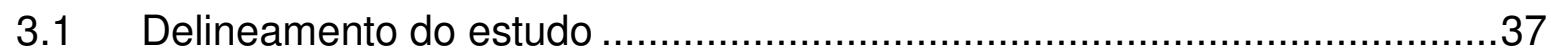

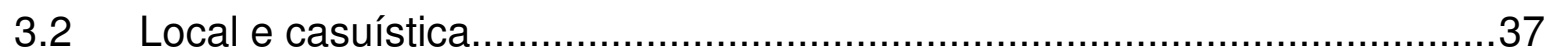

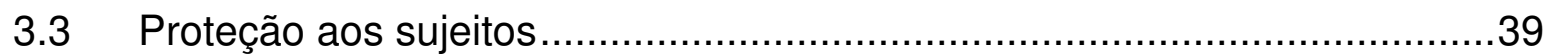

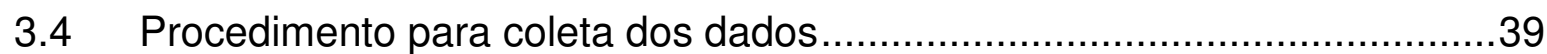

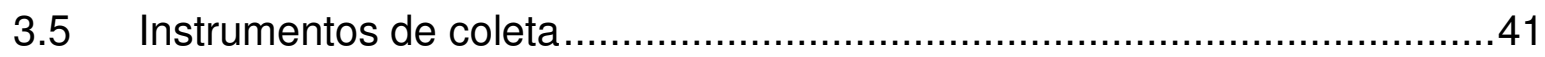

3.5.1 Instrumento de caracterização sócio-demográfica e clínica dos sujeitos....41

3.5.2 Instrumento de avaliação de ansiedade e depressão..........................43

3.5.3 Instrumento para avaliação do senso de coerência...............................44

3.5.4 Instrumento para avaliação dos estressores percebidos em

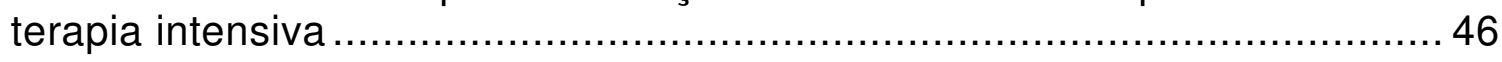

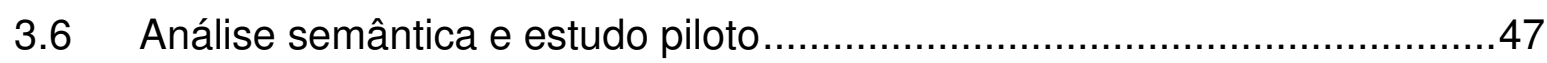

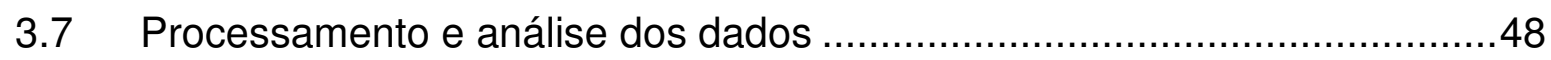


4. RESULTADOS

4.1 Relacionados à caracterização sócio-demográfica e clínica dos participantes do estudo.

4.2 Relacionados à avaliação de ansiedade, depressão e senso de coerência, no período pré-operatório.

4.3 Relacionados à avaliação de estressores pelos participantes no pósoperatório imediato.

4.4 Relacionados à correlação entre as variáveis ansiedade, depressão e senso de coerência com o estresse percebido pelos pacientes no pósoperatório da cirurgia cardíaca.

5. DISCUSSÃO

6. CONCLUSÕES

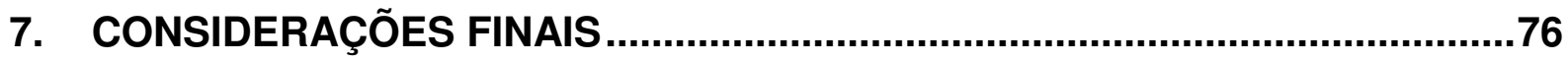

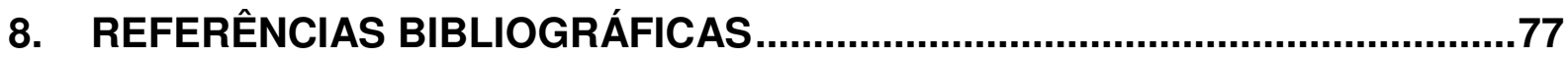

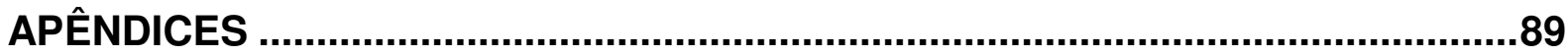

APÊNDICE A

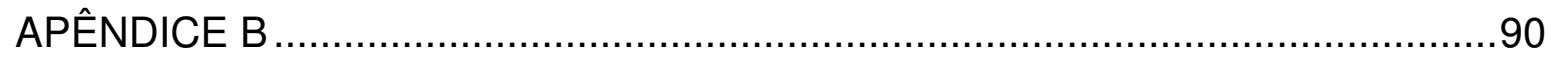

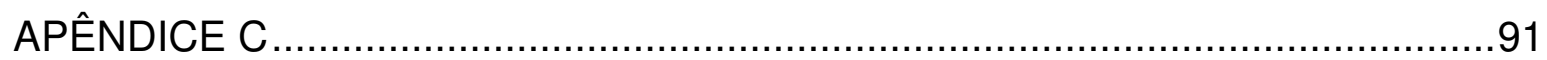

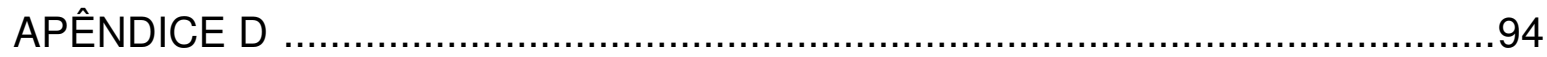

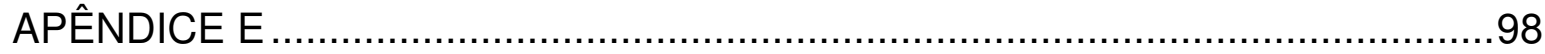

ANEXOS

ANEXO A

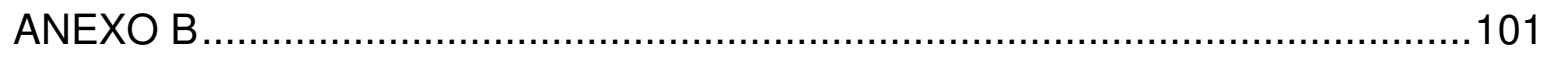

ANEXO C

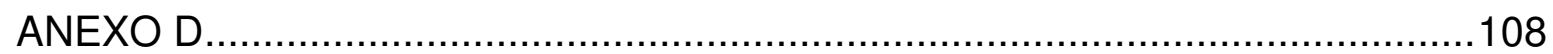




\section{LISTA DE TABELAS}

Tabela 1 - Distribuição dos 91 sujeitos do estudo segundo a caracterização sócio-demográfica. Ribeirão Preto, 2007 - 2008.

Tabela 2 - Caracterização do tratamento cirúrgico entre os 91 participantes do estudo. Ribeirão Preto, 2007 - 2008.

Tabela 3 - Estatística descritiva e consistência interna dos instrumentos usados na avaliação pré-operatória dos participantes. Ribeirão Preto, 2007-2008. 53

Tabela 4 - Coeficientes de correlação de Spearman entre as medidas de SC, ansiedade e depressão. Ribeirão Preto, 2007-2008.

Tabela 5 - Resultados dos testes de associação entre as medidas de HADansiedade e as variáveis: sexo, idade, escolaridade e tempo de pré-operatório. Ribeirão Preto, 2007-2008.

Tabela 6 - Resultados dos testes de associação entre as medidas de HADdepressão e as variáveis: sexo, idade, escolaridade e tempo de pré-operatório. Ribeirão Preto, 2007-2008.

Tabela 7 - Resultados dos testes de associação entre as medidas de senso de coerência e as variáveis: sexo, idade, escolaridade e tempo de pré-operatório. Ribeirão Preto, 2007-2008. 
Tabela 8 - Distribuição das médias das respostas para a Escala de Estressores em Terapia Intensiva (total e dos itens). Ribeirão Preto, 2007-2008 60

Tabela 9 - Distribuição dos pacientes segundo as respostas aos itens da Escala de Estressores em Terapia Intensiva (EETI). Ribeirão Preto, 2007-2008 (continua)

Tabela 10 - Resultados dos testes de associação entre as medidas da Escala de Estressores em Terapia Intensiva com as variáveis: sexo, idade, escolaridade e tempo de permanência na UTI. Ribeirão Preto, 2007-2008.

Tabela 11 - Coeficientes de correlação de Spearman entre as medidas de SC (QSCA), ansiedade (HAD ansiedade) e depressão (HAD-depressão) e estressores (EETI). Ribeirão Preto, 2007-2008. 


\section{RESUMO}

Torrati, F. G. Ansiedade, depressão, senso de coerência e estressores nos períodos pré e pós-operatório de cirurgias cardíacas. 2009. 110 f. Dissertação (Mestrado) Escola de Enfermagem de Ribeirão Preto, Universidade de São Paulo, Ribeirão Preto, 2009.

A cirurgia cardíaca é um evento estressante na vida de um paciente, especialmente durante a estadia na unidade de terapia intensiva, no período pós-operatório imediato, podendo ser agravado por fatores como ansiedade, depressão e a capacidade de enfrentamento. Entretanto alguns pacientes conseguem lidar melhor com esse estresse do que outros. Os objetivos deste estudo foram avaliar: as relações entre ansiedade, depressão e senso de coerência de pacientes no préoperatório de cirurgia cardíaca; as relações entre ansiedade, depressão e senso de coerência com as variáveis sexo, idade, escolaridade e tempo de pré-operatório e a relação das medidas de ansiedade, de depressão e de senso de coerência dos pacientes cardíacos, no período pré-operatório, com o estresse percebido no pósoperatório imediato. Os dados foram coletados por entrevistas individuais realizadas pela pesquisadora em dois momentos da internação: no período pré-operatório e no pós-operatório imediato. Para a primeira coleta foi utilizado um instrumento de caracterização sócio-demográfica e clínica; a versão adaptada da Hospital Anxiety and Depression Scale (avaliação da ansiedade e depressão) e a versão adaptada do Questionário de Senso de Coerência de Antonovsky (avaliação da capacidade de enfrentamento). Para a segunda coleta foi utilizada a versão adaptada da Escala de Estressores em Terapia Intensiva. Os dados foram analisados usando o coeficiente de correlação de Spearman, teste de Mann-Whitney e teste de Kruskal-Wallis. O nível de significância adotado foi de 0,05. Participaram da investigação, 91 sujeitos com idade média de 56,9 anos ( $D P=13,7), 52,7 \%$ eram mulheres; $45(49,5 \%)$ foram submetidos à cirurgia de revascularização do miocárdio. Houve correlações inversas e de moderada magnitude, entre senso de coerência e ansiedade $(r=-0,371 ; p=$ $0,000)$ e senso de coerência e depressão $(r=-0,516 ; p=0,000)$. As mulheres e os pacientes com menor escolaridade apresentaram maior pontuação para ansiedade $(M=8,1$ e $M=7,6$, respectivamente) e para depressão $(M=5,8$ e $M=5,7$, respectivamente). $\mathrm{O}$ tempo de internação pré-operatória foi associado à maior ansiedade $(p=0,03)$ e o nível e escolaridade foi associado à maior depressão ( $p=$ 0,01 ). Pacientes masculinos, acima de 60 anos, com maior grau de escolaridade obtiveram maior senso de coerência. A percepção dos estressores foi maior para os pacientes masculinos, com idade entre 41 e 59 anos, com escolaridade em nível médio ou superior e maior tempo de internação na UTI. Os itens da escala considerados mais estressantes foram "ter dor" e "não conseguir dormir". Concluiuse que houve correlação de moderada magnitude entre as medidas de estressores percebidos e ansiedade $(p=0,01)$ e depressão $(p=0,003)$ e correlação fraca entre as medidas de senso de coerência $(p=0,09)$ e estressores.

Palavras chave: Ansiedade, Depressão, Enfrentamento, Estresse, Cirurgia Torácica 


\begin{abstract}
Torrati, F. G. Anxiety, depression, sense of coherence and stressors in the pre- and postoperative periods of cardiac surgeries. 2009. 110 p. Master's Dissertation University of São Paulo at Ribeirão Preto College of Nursing, Ribeirão Preto, 2009.

Cardiac surgery is a stressful event in a patient's life, especially while at the intensive care unit in the immediate postoperative period, and can be aggravated by factors like anxiety, depression and coping capacity. Some patients, however, manage to deal with this stress better than others. This study aimed to assess: the relations between anxiety, depression and sense of coherence of patients in the preoperative period of cardiac surgery; the relations between anxiety, depression and sense of coherence and gender, age, education level and preoperative hospitalization time variables and the relation between preoperative measures of anxiety, depression and sense of coherence in cardiac patients with perceived immediate postoperative stress. Data were collected through individual interviews held by the research at two times during hospitalization: in the preoperative period and in the immediate postoperative period. For the first data collection, an instrument was used to survey sociodemographic and clinical characteristics; the adapted version of the Hospital Anxiety and Depression Scale (assessment of anxiety and depression) and the adapted version of Antonovsky's Sense of Coherence Questionnaire (assessment of coping capacity). For the second data collection, the adapted version of the Intensive Care Unit Environmental Stressor Scale was used. Spearman's correlation coefficient, Mann-Whitney's test and Kruskal-Wallis' test were used for data analysis. Significance was set at 0.05 . Study participants were 91 subjects with a mean age of 56.9 years $(S D=13.7) ; 52.7 \%$ were women; $45(49.5 \%)$ were submitted to coronary artery bypass graft surgery. Inverse and moderate correlations were found between sense of coherence and anxiety $(r=-0.371 ; p=0.000)$ and sense of coherence and depression $(r=-0.516 ; p=0.000)$. Women and patients with lower education levels presented higher anxiety ( $M=8.1$ and $M=7.6$, respectively) and depression scores $(M=5.8$ and $M=5.7$, respectively). Preoperative hospitalization time was associated with greater anxiety $(p=0.03)$ and education level was associated with greater depression $(p=0.01)$. Male patients older than 60 years with higher education levels obtained a higher sense of coherence. The perception of stressors was greater for male patients between 41 and 59 years old, with secondary or higher education level and longer ICU hospitalization time. The most stressful items on the scale were "feeling pain" and "not being able to sleep". It is concluded that a moderate correlation exists between perceived stress measures and anxiety $(p=0.01)$ and depression $(p=0.003)$, and a weak correlation between sense of coherence measures $(p=0.09)$ and stressors.
\end{abstract}

Key words: Anxiety, Depression, Coping, Stress, Thoracic Surgery 


\section{RESUMEN}

Torrati, F. G. Ansiedad, depresión, sentido de coherencia y estresantes en los períodos pre y post-operativo de cirugías cardíacas. 2009. 110 h. Dissertação (Mestrado) - Escola de Enfermagem de Ribeirão Preto, Universidade de São Paulo, Ribeirão Preto, 2009.

La cirugía cardíaca es un evento estresante en la vida de un paciente, especialmente durante la estadía en la unidad de terapia intensiva, en el período post-operativo inmediato, que puede ser agravado por factores como ansiedad, depresión y la capacidad de enfrentamiento. Sin embargo, algunos pacientes logran lidiar mejor con ese estrés que otros. Las finalidades de este estudio fueron evaluar: las relaciones entre ansiedad, depresión y sentido de coherencia de pacientes en el pre-operativo de cirugía cardíaca; las relaciones entre ansiedad, depresión y sentido de coherencia con las variables sexo, edad, escolaridad y tiempo de pre-operativo y la relación de las medidas de ansiedad, depresión y del sentido de coherencia de los pacientes cardíacos, en el período pre-operativo, con el estrés percibido en el postoperativo inmediato. Los datos fueron recolectados por entrevistas individuales realizadas por la investigadora en dos momentos de la hospitalización: en el período pre-operativo y en el post-operativo inmediato. Para la primera recolecta fue utilizado un instrumento de caracterización socio-demográfica y clínica; la versión adaptada de la Hospital Anxiety and Depression Scale (evaluación de ansiedad y depresión) y la versión adaptada del Cuestionario de Sentido de Coherencia de Antonovsky (evaluación de la capacidad de enfrentamiento). Para la segunda recolecta fue utilizada la versión adaptada de la Escala de Estresores en Terapia Intensiva. Los datos fueron analizados utilizándose el coeficiente de correlación de Spearman, test de Mann-Whitney y test de Kruskal-Wallis. El nivel de significancia adoptado fue de 0,05 . Participaron de la investigación 91 sujetos con edad promedia de 56,9 años $(\mathrm{DE}=13,7)$, el $52,7 \%$ era mujer; $45(49,5 \%)$ fueron sometidos a la cirugía de revascularización del miocardio. Fueron encontradas correlaciones inversas y de moderada magnitud entre sentido de coherencia y ansiedad $(r=-0,371 ; p=0,000)$ y sentido de coherencia y depresión $(r=-0,516 ; p=0,000)$. Las mujeres y los pacientes con menor escolaridad presentaron mayor puntuación para ansiedad ( $M=8,1$ y $M=$ 7,6 , respectivamente) y para depresión ( $M=5,8$ e $M=5,7$, respectivamente). El tiempo de internación pre-operativa fue asociado a mayor ansiedad $(p=0,03)$ y el nivel de escolaridad fue asociado a mayor depresión $(p=0,01)$. Pacientes masculinos, arriba de 60 años, con mayor grado de escolaridad obtuvieron mayor sentido de coherencia. La percepción de los estresores fue mayor para los pacientes masculinos, con edad entre 41 y 59 años, con escolaridad en nivel medio o superior y mayor tiempo de internación en la UTI. Los ítems de la escala considerados más estresantes fueron "sentir dolor" y "no lograr dormir". Se concluye existió correlación moderada entre las medidas de estresores percibidos y ansiedad $(p=0,01)$ y depresión $(p=0,003)$ y correlación débil entre las medidas de sentido de coherencia $(p=0,09)$ y estresores.

Palabras-clave: Ansiedad, Depresión, Enfrentamiento, Estrés, Cirugía Torácica 


\section{INTRODUÇÃO}

\subsection{Apresentação do problema}

Enquanto enfermeiras da unidade pós-operatória de cirurgia torácica de um hospital-escola temos, em nosso dia a dia, presenciado relatos de pacientes sobre como a experiência de ser submetido a uma cirurgia cardíaca pode ser estressante e causar ansiedade. Isso pode ser compreensível diante da complexidade dessa cirurgia, que é um acontecimento crítico na vida dos pacientes e de seus familiares.

Durante a internação, os pacientes se deparam com ambientes que podem ser fontes de estresse e ansiedade. Por exemplo, no período pré-operatório, eles referem preocupações e ansiedade relacionadas aos vários aspectos do tratamento como as expectativas e incertezas relacionadas ao ato anestésico-cirúrgico e ao ambiente da unidade de terapia intensiva.

No pós-operatório imediato, os pacientes são encaminhados para uma unidade especializada de terapia intensiva, permanecendo ali até que suas funções fisiológicas retornem ao normal, o que ocorre em torno de 40 horas. Durante a permanência nessa unidade, eles se encontram sob ventilação mecânica, monitorizados por vários aparelhos e com a presença de tubos em vários locais de seus corpos, dificultando a movimentação e comunicação verbal; encontram-se longe de seus familiares e com visitas reduzidas. Além disso, podem apresentar

distúrbios ou alterações físicas e psicológicas, o que irá comprometer a recuperação. Acreditamos que esse ambiente novo e as próprias condições, físicas 
e psicológicas, dos pacientes podem provocar o aumento da ansiedade. Temos observado o desconforto e surpresa dos pacientes, durante sua estadia na unidade pós-operatória. Também constatamos que alguns deles conseguem lidar melhor com esse acontecimento em suas vidas do que outros. Isso nos faz questionar o porquê dessas diferenças.

Assim, no presente estudo, temos como proposta a investigação do estado emocional (ansiedade e depressão) e do senso de coerência (uma medida de coping) em pacientes no pré-operatório de cirurgias cardíacas e verificar se essas variáveis tem relação com a percepção dos estressores presentes no pós-operatório imediato. 


\subsection{Referencial teórico e revisão da literatura}

\subsubsection{O início da cirurgia cardíaca no Brasil}

A história da cirurgia cardíaca no Brasil inicia-se em 1900, quando o Dr. Alfredo José Cardoso, natural de Piracicaba, defendeu, na Faculdade de Medicina e Farmácia do Rio de Janeiro, sua tese de doutorado sobre "Cirurgia do Coração" realizando uma revisão de literatura. Em 1905, aconteceu a primeira sutura cardíaca em nosso país, realizada por João Alves de Lima. No entanto, apenas em 1927, houve o primeiro caso bem-sucedido de sutura de ferida cardíaca por objeto cortante, a qual foi realizada por Silvio Brauner. A partir da inauguração do Hospital das Clínicas de São Paulo, em 1944, a cirurgia torácica apresentou um marcado desenvolvimento, sob a liderança do professor Euryclides Zerbini (COSTA, 1998). ${ }^{*}$

Nesse período, a cirurgia cardíaca na Europa e Estados Unidos avançava rapidamente e o Hospital das Clínicas recebeu a visita de vários especialistas estrangeiros dessa área cirúrgica que iniciaram a cirurgia cardíaca fechada no Brasil. Para as valvopatias, as correções se iniciaram em 1953 quando foi realizada a primeira dilatação de estenose aórtica, com auxílio do dilatador de Bailey, no Hospital São Paulo, ligado à Escola Paulista de Medicina. O procedimento ocorreu após a primeira correção de estenose aórtica ter sido feita na França, quando Tuffier realizou a pioneira tentativa para aliviar a obstrução aórtica, dilatando digitalmente a valva através de invaginação da parede da aorta (BRAILE e GODOY, 1996). Em 12

\footnotetext{
* De acordo com: normas ABNT.
} 
de novembro de 1956, Hugo Felipozzi realizou a primeira operação com circulação extracorpórea no Brasil, durante a correção de um defeito do septo atrial (PRATES, 1999).

\subsubsection{Tipos e características da cirurgia cardíaca}

Embora o tratamento clínico venha progredindo ano a ano e a abordagem minimamente invasiva se expandindo rapidamente, a cirurgia cardíaca é a intervenção de escolha em alguns casos de cardiopatias. São vários os tipos de cirurgia cardíaca utilizados para correção das mais variadas cardiopatias, entre elas: revascularização do miocárdio (popularmente conhecida como pontes de Safena), correção de doenças valvares, correção de doenças da artéria aorta, correção de cardiopatias congênitas, transplante cardíaco, implante de marcapasso cardíaco.

As cirurgias mais comuns em nosso serviço são a revascularização do miocárdio e correção de doenças valvares.

A doença arterial coronariana (DAC) resulta de um acúmulo de placas de ateroma, conhecido como aterosclerose, nas artérias coronárias. Na DAC ocorre um desequilíbrio no fornecimento e demanda de oxigênio resultando em inadequada perfusão do músculo cardíaco (miocárdio) e conseqüente isquemia. As lesões são mais comuns em bifurcações e ramificações das artérias, onde o fluxo sanguíneo é mais turbulento (WOODS; FROELICHER; MOTZER, 2005). As lesões nem sempre são grandes, mas uma lesão pequena pode progredir, chegando a diminuir o fluxo sanguíneo e levar ao quadro de angina (BRICK et al, 2004). 
Para determinar se o paciente é um candidato à cirurgia de revascularização do miocárdio, são avaliados a anatomia coronária, o grau de isquemia no teste de stress e a função ventricular do coração. Para essa cirurgia, um vaso sangüíneo, que pode ser a veia safena ou a artéria mamária interna ou, ainda, a artéria radial, é implantado no coração realizando uma ponte (bypass) para normalizar o fluxo sangüíneo (BOJAR, 1999). Estudos têm demonstrado que a cirurgia de revascularização miocárdica é cada vez mais comum em pacientes idosos, acima de 75 anos, possibilitando um aumento na expectativa de vida dessa população. Entretanto, os idosos apresentam um maior número de complicações cerebrais, renais e pulmonares no pós-operatório (LOBO FILHO ET AL, 2002).

As doenças de válvulas cardíacas podem ocorrer em uma ou mais válvulas do coração com uma variedade de etiologias: doença reumática, endocardite infecciosa, prolapso valvar ou malformação congênita (FINKELMEIER, 1995).

A estenose aórtica pode ocorrer por espessamento, calcificação ou fusão dos folhetos valvares que produz uma obstrução, dificultando o esvaziamento do ventrículo esquerdo. As indicações para cirurgia são: presença de angina, insuficiência cardíaca congestiva ou síncope. A estenose mitral ocorre, principalmente, como conseqüência de febre reumática. $\mathrm{O}$ espessamento dos folhetos valvares e o espessamento e encurtamento das cordoalhas tendíneas reduzem, gradualmente, o tamanho da valva mitral, dificultando a passagem do sangue e o enchimento do ventrículo esquerdo (BOJAR, 1999).

A regurgitação da valva ou válvula aórtica é resultado de anormalidades nos folhetos valvares decorrentes de deformidades após processo inflamatório, destruição por endocardite ou prolapso ou decorrentes da dilatação da raiz aórtica. A valva mitral pode ter regurgitação resultante de anormalidades no anel (dilatação), 
folhetos valvares (por doença reumática, endocardite), cordoalha tendínea (ruptura ou alongamento) ou músculos papilares. As indicações para essa correção cirúrgica são: insuficiência cardíaca congestiva aguda, endocardite (com comprometimento hemodinâmico, bacteremia ou sepse), sintomas de insuficiência cardíaca congestiva ou angina, evidências de descompensação do paciente como fração de ejeção menor que 55\%, dimensão diastólica final em torno de $70 \mathrm{~mm}$ ou dimensão sistólica final de $55 \mathrm{~mm}$ (BOJAR, 1999).

As valvas cardíacas podem ser trocadas ou reparadas. As próteses valvares podem ser de material biológico (tecido animal) ou fabricado a partir da liga de metais (metálicas).

Para a realização dos diferentes tipos de cirurgia cardíaca pode-se utilizar a circulação extracorpórea (CEC), que tem por finalidade propiciar um campo cirúrgico limpo e preservar as características funcionais do coração. Nesse procedimento, o sangue é desviado por meio de uma cânula colocada nas veias cavas do átrio direito e pulmões, passa por uma máquina que irá oxigená-lo e eliminar o gás carbônico e, em seguida o fará retornar ao paciente, entretanto esse procedimento deve ser mantido o tempo necessário para que se faça a correção da lesão cardíaca, dele dependendo a preservação da integridade morfológica e funcional de todos os órgãos do paciente. A CEC produz uma resposta inflamatória sistêmica com libera cão de substâncias que prejudicam a coagulação e a resposta imune; aumenta o tônus venoso; produz grande liberação de catecolaminas, alterações no fluido sanguíneo e estado eletrolítico; disfunção, lesão ou necrose celular do miocárdio e uma disfunção pulmonar branda. Essa resposta inflamatória, no período pósoperatório, leva a uma movimentação de fluídos do espaço intravascular para o intersticial devido às alterações na permeabilidade vascular e à diminuição na 
pressão oncótica, podendo causar alterações como: edema, disfunção pulmonar leve, aglutinação leucocitária e deposição na microcirculação pulmonar. Quanto maior o tempo de CEC, mais grave o desequilíbrio fisiológico (WOODS; FROELICHER; MOTZER, 2005).

Os cuidados médicos e de enfermagem após as cirurgias de revascularização do miocárdio e troca ou plastia de válvula são similares, pois os pacientes de ambos os procedimentos poderão apresentar disfunções cardiovasculares e/ou pulmonares.

\subsubsection{Ansiedade e depressão: definições, caracterização clínica e métodos de avaliação.}

Além dos aspectos fisiopatológicos apresentados, os pacientes também sofrem um impacto emocional intenso quando submetidos a uma cirurgia cardíaca. No período perioperatório desse tipo de cirurgia, os pacientes estão expostos às mais diversas emoções e sentimentos, sendo que há uma forte relação entre ansiedade e depressão com o ato anestésico-cirúrgico (DUITS et al, 1999).

Para Spielberger (1981), em nossa vida, existe uma seqüência temporal de eventos que são desencadeados ou desencadeiam outros eventos. Um estressor, ou tensor, é o estímulo ou situação que representa um grau de perigo físico ou psicológico percebido pela pessoa. Assim, uma situação tensa (um estressor) pode ser percebida como uma ameaça que levará a ansiedade. Os limites entre estresse

e ansiedade muitas vezes são indefinidos. Sentimentos de tensão, apreensão, nervosismo e preocupação e suas alterações fisiológicas e comportamentais como 
tremores, palpitações e vertigens podem ser sintomas de ansiedade. Situações simples do dia-a-dia podem, muitas vezes, desencadear o processo de ansiedade como ir ao dentista, fazer uma prova ou teste, uma entrevista para uma vaga de trabalho ou ser submetido a uma cirurgia. A reação a essas situações é influenciada tanto pelo perigo real que ela representa como pelas avaliações e interpretações que o próprio indivíduo faz (SPIELBERGER, 1981).

Quando os sintomas ansiosos são excessivos, ocorrendo na maior parte dos dias por um período de, pelo menos, seis meses, a ansiedade pode se transformar na síndrome da ansiedade generalizada, na qual a pessoa vive angustiada, tensa, preocupada, nervosa ou irritada. Os sintomas mais freqüentes são: insônia, dificuldade em relaxar, angústia constante, irritabilidade aumentada e dificuldade em concentrar-se. Os sintomas físicos também são comuns, tais como taquicardia, tontura, cefaléia, dores musculares, epigastralgias, sudorese fria (DALGALARRONDO, 2000).

Além da ansiedade generalizada, em algumas pessoas podem ocorrer crises intermitentes de ansiedade caracterizada sob a forma de crises do pânico. As crises de pânico são crises de ansiedade intensa, nas quais ocorre importante descarga do sistema nervoso autonômico, produzindo sintomas como: taquicardia, sudorese, tremores, dispnéia, náuseas, formigamentos em membros ou em lábios. Os pacientes podem experimentar diversos graus de despersonalização (corpo estranho, sensação de perda do controle, desrealização), além do medo importante de ter um infarto, de morrer ou enlouquecer. Essas crises são de início súbito e desencadeadas por certas situações como multidão e locais fechados (DALGALARRONDO, 2000). 
Embora os sintomas de ansiedade sejam essenciais para o diagnóstico dos transtornos de ansiedade, eles são encontrados com freqüência na depressão e devem ser também considerados parte integrante de seu quadro clínico (MAJ ; SARTORIUS, 2005).

A definição de depressão dada pela décima revisão da Classificação Internacional de Doenças (CID-10) divide-a em três graus, levando em consideração o número e a gravidade dos sintomas: leve, moderado ou grave. O paciente com depressão pode apresentar um rebaixamento do humor, redução da energia e diminuição da atividade. Existe alteração da capacidade de experimentar o prazer, perda de interesse, diminuição da capacidade de concentração associada, em geral, à fadiga importante, mesmo após um esforço mínimo, problemas do sono, diminuição do apetite e quase sempre uma diminuição da auto-estima e da autoconfiança, além de idéias de culpabilidade e/ou de indignidade, mesmo nas formas leves. O humor depressivo varia pouco, de um dia para outro, ou segundo as circunstâncias e pode se acompanhar de sintomas "somáticos" como, por exemplo, perda de interesse ou prazer, despertar matinal precoce, agravamento matinal da depressão, lentidão psicomotora importante, agitação, perda de apetite, perda de peso e perda da libido" (ORGANIZAÇÃO MUNDIAL DA SAÚDE, 2000).

Para Maj e Sartorius (2005) a depressão caracteriza-se pela presença de uma série de sintomas que podem mudar com o tempo. Esses sintomas podem variar infinitamente de indivíduo para indivíduo. Não existem, até agora, causas conhecidas e comuns que permitam uma classificação verdadeira de base etiológica da depressão. Ainda não se sabe se a depressão deve ser classificada por categoria ou dimensão, ou seja, se é possível dividir os transtornos em uma série de categorias distintas ou consigná-los à determinada dimensão. 
Dalgalarrondo (2000) refere que as síndromes e reações depressivas surgem com muita freqüência após perdas representativas, como de uma pessoa amada, um emprego, um bem material, o status socioeconômico. A pessoa com quadro depressivo apresenta um humor triste, que pode ser caracterizado por vários sintomas afetivos (tristeza, melancolia, choro fácil), instintivos e neurovegetativos (fadiga, cansaço fácil, desânimo, insônia ou hipersonia, perda ou aumento do apetite, diminuição da libido), ideativos (ideação negativa, pessimismo, idéias de culpa, idéias de morte, ideação ou atos suicidas), cognitivos (déficit de atenção e concentração, dificuldade de tomar decisões), alterações da autovaloração (sentimentos de baixa auto-estima, incapacidade, vergonha e autodepreciação), alterações da volição e da psicomotricidade (permanecer na cama todo o dia, aumento da latência entre as perguntas e as respostas, lentificação psicomotora, diminuição da fala, mutismo, negativismo). Podem estar presentes também sintomas psicóticos (idéias delirantes negativas, delírio de ruína ou miséria, delírio de culpa, alucinações, ilusões auditivas ou visuais) e marcadores biológicos não específicos (ausência de resposta ao teste de supressão do cortisol pela dexametasona).

Segundo Maj e Sartorius (2005) existe uma forte associação entre ansiedade e depressão. Essa relação se reflete na sobreposição de itens que avaliam sintomas depressivos e de ansiedade nas escalas de uso mais amplo para a mensuração da gravidade dos dois transtornos. Vários estudos têm demonstrado a co-ocorrência de depressão e ansiedade (BURKER et al., 1995; DUITS et al., 1999). Os sintomas ansiosos e depressivos comumente se sobrepõem, sendo difícil, muitas vezes, separá-los e, assim, realizar uma mensuração separadamente (GORENSTEIN; ANDRADE; ZUARDI, 2000). 
Uma das maneiras de se avaliar a ansiedade e a depressão é a utilização de instrumentos. Mensuração por escalas é uma forma sistematizada de observação, na qual os fenômenos a serem avaliados foram previamente definidos (NARDI, 1998). A ansiedade e a depressão podem ser medidas por escalas, inventários ou questionários que podem ser de auto-avaliação ou de avaliação clínica. Segundo Gorenstein, Andrade e Zuardi (2000) as escalas de depressão se diferenciam pelas categorias de sintomas depressivos que são incluídos nos itens. As principais categorias de sintomas são: vegetativos ou somáticos, motores, sociais, cognitivos, ansiedade e irritabilidade. Eles descrevem, ainda, outras categorias de aspectos que são mensurados nas escalas de ansiedade tais como: humor, cognição, comportamento, estado de hiperalerta e sintomas somáticos.

As escalas mais utilizadas para mensuração de ansiedade e depressão, em nosso meio, são:

- escala DE ANSIEDADE DE HAMILTON (HAMILTON, 1959) - baseia-se em itens de características clínicas e quanto maiores forem os sintomas apresentados pelo paciente, mais grave é a manifestação da patologia (NARDI, 1998). A escala possui 14 itens, que pode levar a um escore total variando entre zero (0) e cinqüenta e seis (56) pontos, sendo que quanto maior for a pontuação, maior será a intensidade da ansiedade.

- INVENTÁRIO DE ANSIEDADE TRAÇO-ESTAdO - IDATE (SPIELBERGER; GORSUCH; LUSHENE 1970) - é composto por dois inventários distintos de autoavaliação, um medindo o estado de ansiedade e outro medindo o traço de ansiedade. $O$ conceito de ansiedade-traço é definido como propensão, inclinação para a ansiedade, ou seja, a tendência do indivíduo perceber as situações como ameaçadoras (SPIELBERGER; GORSUCH; LUSHENE, 1979), sendo considerado 
como uma característica de personalidade influenciada pelas representações que a pessoa traz consigo, ao longo das vivências da sua vida (NARDI, 1998). A ansiedade-estado é a descrição de uma sensação emocional em um determinado momento (NARDI, 1998). É uma ansiedade transitória, sendo uma resposta a uma situação estressante (ANDREATINI; LEITE, 1994). As escalas de ansiedade-estado e ansiedade-traço possuem 20 afirmações cada uma e o indivíduo irá indicar a intensidade da ansiedade naquele momento (estado) ou freqüência com que ocorrem (traço), usando uma medida de quatro pontos (de um a quatro).

- INVENTÁRIO DE DEPRESSÃO DE BECK (BECK, 1961) - é uma escala de auto-avaliação com 21 itens, cuja pontuação pode variar de zero a sessenta e três. Seus itens incluem sintomas e atitudes que se referem a tristeza, pessimismo, sensação de fracasso, falta de satisfação, sensação de culpa, sensação de punição, autodepreciação, auto acusações, idéias suicidas, crises de choro, irritabilidade, retração social, indecisão, distorção da imagem corporal, inibição para o trabalho, distúrbio do sono, fadiga, perda de apetite, perda de peso, preocupação somática e diminuição da libido (ANDRADE; GORESTEIN, 1998).

- ESCALA DE DEPRESSÃO DE HAMILTON (HAMILTON, 1960) - composta por 17 itens que avalia humor depressivo, sentimento de culpa, suicídio, insônia, trabalho e atividades, agitação, retardação (demora), ansiedade (psíquica e somática), sintomas somáticos, sintomas genitais, hipocondria, diminuição de peso e introspecção (FRÁGUAS JUNIOR et al, 2000). O autor da escala considera um escore maior do que seis como sendo indicativo de sintomas depressivos (HAMILTON, 1960).

HOSPITAL ANXIETY DEPRESSION SCALE - HADS (ESCALA HOSPITALAR DE ANSIEDADE E DEPRESSÃO - HAD) (ZIGMOND; SNAITH, 1983) - escala de 
auto avaliação, de fácil rápido preenchimento, usada extensivamente em população hospitalar, incluindo pacientes cardíacos. Composta por catorze itens intercalados, sendo sete para avaliar ansiedade e sete para depressão. A avaliação das respostas pode ser feita com o valor total de cada sub-escala, sendo que quanto maior o valor, maior o transtorno emocional.

\subsubsection{Ansiedade e depressão no período perioperatório de cirurgia cardíaca}

Os pacientes que passam por uma cirurgia cardíaca estão expostos às mais diversas emoções e sentimentos no período que abrange esse acontecimento em suas vidas e que podem interferir diretamente em sua recuperação.

Segundo Duits et al (1999) existe uma forte relação entre ansiedade e depressão no pré-operatório e na evolução pós-operatória de cirurgia cardíaca, pois o traço de ansiedade, explicado anteriormente, pode diferenciar os pacientes que são depressivos no pré e no pós-operatório daqueles que apresentam sintomas depressivos somente em um breve período de tempo após a cirurgia (TIMBERLAKE et al., 1997).

A ansiedade está presente em todas as fases do período perioperatório devido ao receio que os pacientes sentem pelo ato anestésico-cirúrgico. Segundo Black e Matassarin-Jacobs (1998) o receio das pessoas sobre a cirurgia pode variar de acordo com sua personalidade, suas respostas gerais ao estresse, sua saúde mental e os preconceitos que têm sobre a cirurgia e anestesia. $O$ receio do desconhecido é uma das causas mais importantes de ansiedade no pré-operatório, 
além da dor pós-operatória, a perda de um órgão ou membro, a anestesia, a vulnerabilidade pelo estado de inconsciência, a perda dos papéis familiares e sociais, a ruptura do estilo de vida, a perda de um emprego, a separação de pessoas significativas e o risco da morte.

A ansiedade é um dos sintomas mais citados pelo paciente que espera pela cirurgia cardíaca, juntamente com a depressão, a fadiga e a dispnéia, levando a um efeito negativo em sua rotina diária e de trabalho (JÓNSDOTTIR; BALDUSDÓTTIR, 1998), apresentando, também, forte relação com a alteração da pressão arterial, nos períodos pré e pós-operatório (HALLAS et al, 2003). Nelson et al. (1998) verificaram que há uma relação direta entre ansiedade e dor pós-operatória, considerando o segundo dia após a intervenção cirúrgica.

A avaliação do estado emocional no período pré-operatório de cirurgia cardíaca identifica risco de desordens de humor no pós-operatório (BOUDREZ; DE BACKER, 2001; HALLAS et al., 2003; VINGERHOETS, 1998). Burker et al. (1995) verificaram que um distúrbio emocional pode levar ao desenvolvimento de outros distúrbios e demonstraram que elevados níveis de ansiedade podem levar ao desenvolvimento de depressão no pré-operatório.

Estudos têm demonstrado que a ansiedade presente na experiência cirúrgica dos pacientes é influenciada pelos seguintes fatores: sexo (BENGTSON et al., 1996; BENGTSON et al., 2000; LAMOSA; QUADROS; ZAMBON, 1985; PENICHE, 1999), personalidade ansiosa (LAMOSA; QUADROS; ZAMBON, 1985); padrão do sono (BENGTSON et al., 1996; BENGTSON et al, 2000), presença de dor torácica, incapacidade física, medo da cirurgia (FITZSIMONS et al., 2003), tempo de espera pela cirurgia (FITZSIMONS et al., 2003) e pelas diferentes fases do período perioperatório (RYMASZEWSKA; KIEJNA; HADRYS, 2003). 
O prolongamento do tempo de espera para a cirurgia cardíaca pode levar o paciente à perda de controle da ansiedade e a estados de desesperança (PEREIRA, 2002). O nível de ansiedade está associado ao maior tempo de espera para cirurgia cardíaca e maior grau de angina, bem como à diminuição da renda individual. Não há evidências de associação entre o nível de ansiedade e as variáveis demográficas idade e sexo (FITZSIMONS et al., 2003).

Aiub et al. (1995), em estudo realizado com pacientes em pré-operatório de cirurgia cardíaca, verificaram que há um aumento da ansiedade gerada pela necessidade de enfrentar uma intervenção cirúrgica. A ansiedade tem sido associada fortemente à dor torácica no período pré-operatório de revascularização miocárdica (BENGTSON et al., 1996). Ainda, relacionado a esse período, apesar de não haver diferenças consistentes entre os sexos, Bengtson et al. (2000) observaram que as mulheres foram mais freqüentemente tratadas com sedativos e sofreram mais de distúrbios do sono, enquanto que os homens apresentaram maior irritabilidade.

Pacientes cardiopatas cirúrgicos, de ambos os sexos, apresentam uma diminuição no estado de ansiedade no pós-operatório em relação ao período préoperatório. Entretanto, os pacientes do sexo masculino, em relação ao traço de ansiedade, mostraram ser mais ansiosos que a média da população brasileira (LAMOSA; QUADROS; ZAMBON, 1985).

As maiores preocupações do paciente internado estão relacionadas ao tempo de internação, ao trabalho, à família e a cura da doença (GOMES; FRAGA, 1997).

Pessoas que apresentam altos níveis de ansiedade antes da cirurgia cardíaca, também demonstram altos níveis de ansiedade no pós-operatório e podem 
desenvolver também outros distúrbios psicológicos como depressão (RYMASZEWSKA; KIEJNA; HADRYS, 2003).

Ribeiro e Rengel (1992) compararam a ansiedade entre pacientes coronariopatas e valvopatas, nos períodos pré e pós-operatório, e verificaram que não houve diferenças entre esses dois grupos de pacientes. Por outro lado, a ansiedade em pacientes que aguardavam a cirurgia cardíaca de revascularização do miocárdio, após terem sofrido infarto do miocárdio, era mais freqüente que em pacientes que já haviam sido submetidos à cirurgia (HARRISON, 2005). Acreditamos que isso pode ocorrer devido à preocupação com seu estado de saúde.

Com relação à ansiedade no pré-operatório, Kiyohara et al (2004) verificaram que os níveis de ansiedade estado nos homens foram menores quando eles tinham conhecimento sobre sua cirurgia, mesmo sem saber sobre seu diagnóstico, enquanto Koivula et al. (2002) comprovaram que a ansiedade estava relacionada, principalmente, ao estado conjugal do paciente, pois as pessoas que não possuíam parceiro apresentaram mais ansiedade, especialmente no pré-operatório.

No período pós-operatório o tempo de intubação após a cirurgia, o número de dias na unidade de terapia intensiva, bem como o aparecimento de complicações pós-operatórias tem influência no aumento do nível de ansiedade após a cirurgia (RYMASZEWSKA et al., 2003).

Muitos autores propõem a visita pré-operatória como uma ferramenta para diminuir o nível de ansiedade, mas Lynn-Machale et al. (1997) comprovaram, em seu estudo que, mesmo sendo avaliada como benéfica por pacientes e familiares, essa intervenção não foi responsável pela melhora da ansiedade no grupo estudado.

Com relação à depressão, os fatores predisponentes para o surgimento de depressão no pré-operatório de cirurgia cardíaca foram: sexo feminino, elevado 
estado de ansiedade e menor sentimento de apoio (BURKER et al., 1995). As mulheres apresentaram mais sintomas depressivos do que os homens, entretanto, se beneficiaram mais no pós-operatório de revascularização do miocárdio, pois apresentaram maiores índices de diminuição dos sintomas do que os homens (MITCHELL et al., 2005; DUITS et al., 1998). Pirraglia et al. (1999) identificaram alguns fatores que predispõem ao aparecimento de depressão nos períodos pré e pós-operatório de revascularização miocárdica. No pré-operatório, os fatores foram: pouco apoio social, presença de, no mínimo, um fator estressante e dispnéia moderada a grave. No pós-operatório, os fatores identificados foram a longa estadia na UTI e pouco ou nenhum apoio social.

Uma forte relação entre depressão e alterações na pressão arterial e na freqüência cardíaca foi encontrada no estudo de Hallas et al. (2003) em pacientes no período pré-operatório de revascularização do miocárdio.

A recuperação dos pacientes que passaram por cirurgia de revascularização do miocárdio também pode ser afetada pela depressão, pois os pacientes depressivos apresentaram aumento e continuidade da dor (KARLSSON et al., 1999; BURG; BENEDETTO; SOUFER, 2003); maior morbidade, maiores taxas de rehospitalização, dificuldades no retorno às atividades diárias (BURG; BENEDETTO; SOUFER, 2003) e maior presença de eventos cardíacos como angina, infarto agudo do miocárdio, re-operação ou parada cardíaca após doze meses de cirurgia (CONNERNEY et al., 2001).

A depressão é uma das maiores causas de morbi-mortalidade em pacientes coronariopatas. Mattos et al. (2005) verificaram que $88,9 \%$ dos óbitos de pacientes internados com infarto agudo do miocárdio ou angina instável aconteceram em pacientes que apresentavam depressão. A mortalidade, após cirurgia cardíaca, foi 
significantemente maior em pacientes com elevados sintomas depressivos, quando comparados com pacientes que não apresentaram esses sintomas (BAKER et al., 2001; BLUMENTHAL et al., 2003; BURG; BENEDETTO; SOUFER, 2003). A irritabilidade também esteve mais presente em pacientes depressivos, tanto no pré quanto no pós-operatório de revascularização miocárdica (FRÁGUAS JUNIOR et al., 2002).

Silbert et al. (2001) observaram que os pacientes que foram extubados precocemente tiveram menos sintomas depressivos. A depressão apresenta, também, forte associação com sintomas gastrointestinais no pós-operatório de cirurgia cardíaca como diminuição do paladar, náusea e diminuição do apetite (GRAP; SAVAGE; BALL, 1996). Entretanto, a depressão diminui no pós-operatório, podendo desaparecer com o tempo (LINDAL et al., 1996; RYMASZEWSKA; KIEJNA; HADRYS, 2003).

Pessoas deprimidas têm risco maior de desenvolver doença cardíaca isquêmica e/ou hipertensão e o inverso também é verdadeiro. As taxas de comorbidade entre doença cardiovascular e depressão representam sérias dificuldades diagnósticas (MAJ; SARTORIUS, 2005), ou seja, tanto a depressão pode levar a doença cardiovascular, quanto a doença cardiovascular pode levar a depressão.

\subsubsection{Estresse e estressores em unidade de terapia intensiva.}

Como pudemos observar tanto a ansiedade quanto a depressão podem trazer alterações hemodinâmicas para o paciente durante os períodos pré e pós-operatório 
de cirurgias cardíacas e essas alterações, nas primeiras horas de pós-operatório, podem prejudicar sua pronta recuperação. Após submeterem-se a cirurgia cardíaca, os pacientes são levados para a unidade pós-operatória, onde permanecem sob observação e cuidados intensivos, até que possam retornar à unidade de internação. Acrescenta-se a esse quadro a situação de estresse vivenciada pelo indivíduo durante sua internação em uma unidade de terapia intensiva e todas as implicações clínicas envolvidas, as quais que devem ser consideradas no planejamento da assistência de enfermagem.

Os pacientes consideram o centro de terapia intensiva um lugar desconhecido e assustador, relacionado diretamente à piora do estado de saúde e à morte (LEMOS; ROSSI, 2002). Muitos pacientes referem que a chegada ou o acordar na UTI são assustadores e durante o período pós-operatório imediato suas maiores queixas são quanto ao barulho, à presença de tubos e drenos, à dor e à falta da família (VALLE; GUEDES; ALBUQUERQUE, 1990).

Selye (1976) criou um modelo biológico para entender o estresse, no qual esse é uma condição interna do organismo, ou seja, o indivíduo emite uma resposta não específica diante de um evento que exije sua adaptação. As respostas de adaptação, segundo o autor, se dão a partir de fases, cujo processo se denomina Síndrome de Adaptação Geral (SAG):

- Fase de Alarme (corresponde ao estresse agudo) na qual o corpo prepara-se para ação imediata; ativação do sistema nervoso simpático, que libera adrenalina e noradrenalina, na corrente sanguínea. Se o fator agressor permanecer, pode evoluir para a próxima fase;

- Fase de Resistência (estresse crônico) ocorre quando o estresse é prologado. Durante esse estágio, a ativação dos sistemas é menor que na primeira fase, 
mas nossos corpos continuam recrutando forças para lidar com o agente estressor. Se o agente estressor continuar a fase também permanecerá, podendo desencadear a terceira fase;

- Fase de Exaustão: após uma exposição contínua ao agente estressor, ou aparecimento de vários outros estressores, toda energia de nosso organismo é drenada. Nessa fase, nossa resistência cai e ficamos suscetíveis às doenças. Casos severos de estresse físico prolongado podem resultar em doenças ou até mesmo a morte.

O termo estressor define o evento ou estímulo que pode leva ao estresse. (HOUAISS; VILLAR; FRANCO, 2001).

Novaes; Romano; Lage (1996) observaram que houve uma diminuição nos níveis de ansiedade e depressão dos pacientes após o segundo ou terceiro dias de internação na UTI, sugerindo que, após se familiarizarem com a unidade, os pacientes diminuem algumas de suas respostas emocionais frente ao estresse da internação na UTI.

Rothenhausler et al. (2005) demonstraram que as conseqüências em curto prazo da cirurgia cardíaca incluem desordens de ajustamento com fatores depressivos, estresse pós-traumático, depressão e déficits cognitivos, especialmente no momento da alta hospitalar.

As memórias traumáticas mais comuns para os pacientes que recebem alta de uma unidade de terapia intensiva, segundo Schelling et al. (2003) foram: dor, ansiedade, distúrbios respiratórios e pesadelos, uma semana após a alta dessa unidade.

Avaliando pacientes internados em uma unidade coronariana, Marosti e Dantas (2006), observaram que a média de estressores, mensurados por uma 
escala de estressores em terapia intensiva, foi maior em pessoas do sexo feminino, jovens, que não usaram drogas psicotrópicas até 24 horas antes da entrevista e que estavam internados naquele ambiente pela primeira vez.

Alguns estudos têm demonstrado, também, as percepções dos enfermeiros de terapia intensiva com relação ao enfrentamento dos familiares dos pacientes e dos próprios pacientes enquanto permanecem nesse ambiente (CORREA et al, 2002; GÓIS e DANTAS, 2004). A percepção dos enfermeiros com relação aos estressores muitas vezes é diferente da percepção dos pacientes, demonstrando que esses estressores podem ser sub ou superestimados pela equipe (SO e CHAN, 2004).

Algumas pesquisas qualitativas também têm sido desenvolvidas abordando uma outra face deste assunto, demonstrando toda a tensão vivenciada pelo paciente que se encontra no ambiente de uma UTI, mas, por outro lado, exemplificando o significado de se ver acordando nesse local, experimentando a alegria de estar vivo (GUIRARDELLO, 1999).

\subsubsection{Senso de coerência.}

A capacidade de enfrentar situações estressantes tem sido estudada por vários pesquisadores. Há indícios que apontam para o fato de que indivíduos que lidam melhor com o estresse conseguem manter um estado de saúde mais favorável do que os indivíduos que não conseguem lidar com esse estresse (DANTAS, MOTZER, CIOL, 2002).

Um dos constructos que tem sido estudados quando se investiga a capacidade de enfrentamento ao estresse é o senso de coerência (SC), proposto por Antonovsky 
(Antonovsky, 1987). Antonovsky (1987) desenvolveu o Modelo Salutogênico o qual dá ênfase à saúde em vez da doença como o fenômeno de interesse em um novo paradigma pesquisado no campo do stress e coping (SULLIVAN, 1993). O conceito central desse modelo teórico é o Senso de Coerência.

O Senso de Coerência é definido como uma orientação global do indivíduo que expressa um forte sentimento de confiança de uma pessoa em relação a ambientes internos e externos, encarando-os como sendo previsíveis e manejáveis. Considera que mesmo diante de acontecimentos adversos, esse indivíduo consegue dar um significado para sua vida (ANTONOVSKY, 1987).

Antonovsky (1987) propôs investigar como e porque certos indivíduos permanecem bem mesmo após terem vivido situações de estresse intenso, ampliando a discussão sobre a relação entre estresse e estratégias de coping. $\mathrm{O}$ autor propôs o constructo de senso de coerência (SC), composto teoricamente por três componentes: compreensão, manejo e significado que atuam conjuntamente permitindo ao indivíduo enfrentar os estressores presentes na vida cotidiana.

Para Antonovsky (1987) o Senso de Coerência é formado durante a infância e adolescência; é um conceito contínuo que influencia o sentido, maximizando a consistência e estabilidade da pessoa (SULLIVAN, 1993).

Algumas características individuais podem afetar os valores do senso de coerência. Pessoas com maior idade, casadas e nível de escolaridade maior tendem a ter maior SC; enquanto eventos negativos da vida, como a morte de um parente próximo e problemas no trabalho ou com pessoas da família tendem diminuir o SC (VOLANEN, 2007).

Alguns autores têm estudado a relação do senso de coerência de pessoas com diferentes doenças crônicas (BRUSCIA et al., 2008) e sua relação com a 
qualidade de vida (MONNS e NOREKVAL, 2006). Para Monns e Norekval (2006) a qualidade de vida de pacientes que convivem com doenças crônicas pode ser melhor quando eles possuem um maior senso de coerência. O senso de coerência também tem sido associado a sintomas depressivos e ansiedade (KONTINNEN, HAUKKALA, UUTELA, 2008), apoio social e relacionamentos (BAIGl et al, 2008), qualidade de vida e auto-estima em pacientes cardiopatas (DANTAS, MOTZER, CIOL, 2002) e bem estar psicológico (DRORY et al, 2002).

Wolff e Ratner (1999) encontraram uma relação inversa entre senso de coerência e estresse, ou seja, indivíduos que tinham níveis elevados de estresse crônico, estresse pessoal e grande número de eventos traumáticos recentes (como grandes dificuldades financeiras, problemas sérios no trabalho ou escola) apresentavam baixo senso de coerência.

Segundo Karlsson et al (1999) pacientes submetidos à cirurgia de revascularização miocárdica com pior SC no pré-operatório, apresentavam mais dor torácica, no período pós-operatório.

Diante dos resultados obtidos nos estudos anteriormente apresentados e buscando maiores subsídios para avaliar a nossa intervenção e melhorar a assistência prestada aos pacientes, propomos como questões a serem investigadas por este estudo: Quais os níveis de ansiedade e de depressão dos pacientes que estão aguardando a realização de cirurgias cardíacas, na unidade de internação, no período pré-operatório? Há relação entre a ansiedade, depressão e senso de coerência avaliando-os no pré-operatório? Há relação entre ansiedade, depressão, senso de coerência e a percepção dos pacientes quanto aos estressores percebidos durante a internação na unidade de terapia intensiva onde eles permanecerão durante o período do pós-operatório imediato? 


\section{OBJETIVOS}

- Avaliar as relações entre ansiedade, depressão e senso de coerência dos pacientes no pré-operatório de cirurgia cardíaca;

- Avaliar as relações entre ansiedade, depressão e senso de coerência com as variáveis sexo, idade, escolaridade e tempo de espera pela cirurgia;

- Avaliar a relação entre ansiedade, depressão e senso de coerência dos pacientes cardíacos, no período pré-operatório, com os estressores percebidos no pósoperatório imediato. 


\section{CASUÍSTICA E MÉTODO}

\subsection{Delineamento do estudo}

O estudo é de caráter descritivo correlacional.

Segundo Polit; Beck; Hungler (2004), um estudo dessa natureza está interessado em observar, descrever e documentar as associações entre as variáveis, em fenômenos relacionados com o tempo, não procurando estabelecer ou compreender as causas dessas relações, ou seja, não estabelece causa e efeito.

\subsection{Local e casuística}

O estudo foi realizado nas Unidades de Internação da Clínica Cirúrgica e da Clínica Médica e na Unidade Pós Operatória de Cirurgia Torácica e Cardiovascular do Hospital das Clínicas da Faculdade de Medicina de Ribeirão Preto (HCFMRPUSP).

A população potencial deste estudo constituiu-se por pacientes de ambos os sexos, submetidos às cirurgias cardíacas eletivas de revascularização do miocárdio e/ou troca e plastia de válvula, nos períodos pré-operatório e pós-operatório imediato e que atenderam aos critérios de inclusão abaixo:

- concordar em participar do estudo;

- possuir idade acima de 18 anos; 
- estar em condições físicas e psicológicas para participar do estudo;

- estar aguardando cirurgia eletiva de revascularização do miocárdio e/ou cirurgia para correção de valvopatia nas unidades de internação (enfermaria).

Os critérios de exclusão foram:

- ter sido submetido à cirurgia cardíaca anterior.

Entre maio de 2007 e novembro de 2008 foram 225 pacientes submetidos à cirurgia cardíaca em nosso serviço. As cirurgias realizadas foram: 96 (42,6\%) revascularização do miocárdio; 86 (38,2\%) correções de valvopatias; 13 (5,7\%) correções de comunicação interatrial; dez $(4,4 \%)$ cirurgias de revascularização do miocárdio com correção simultânea de valvopatias; seis $(2,6 \%)$ correções de aneurisma de aorta; seis $(2,6 \%)$ correções de dissecção de aorta; quatro $(1,7 \%)$ fechamentos de persistência de canal arterial; três $(1,3 \%)$ correções de coarctação da aorta e uma $(0,4 \%)$ revascularização do miocárdio com aneurismectomia de ventrículo.

Dentre os 225 pacientes, 108 (48,0 \%) preencheram os critérios de inclusão do estudo. Dos 117 pacientes excluídos do estudo, 43 (36,7\%) não eram pacientes em pré-operatório de revascularização do miocárdio ou correção de valvopatias, 31 $(26,4 \%)$ estavam sendo submetidos à reoperação, 15 (12,8\%) se recusaram a participar do estudo, $23(19,6 \%)$ não se encontravam internados na enfermaria, e 5 $(4,2 \%)$ não apresentavam condições de responder aos questionários. Durante o estudo, dez $(9,2 \%)$ pacientes morreram antes de completarem a segunda etapa da coleta dos dados, dois (1,8 \%) não preencheram o questionário de avaliação de estressores (ICUESS) por não estarem em condições clínicas adequadas e seis $(5,5 \%)$ se recusaram a continuar no estudo. Assim, ao término da segunda etapa do 
estudo, contamos com a participação de 91 pacientes $(84,2 \%$ do total de 108 potenciais participantes).

\subsection{Proteção aos sujeitos}

O projeto foi aprovado pelo comitê de ética em Pesquisa do Hospital das Clínicas da Faculdade de Medicina de Ribeirão Preto da Universidade de São Paulo - HCFMRPUSP (ANEXO A).

Ao participante foram explicados os objetivos do estudo e formas de participação e assegurado que ele poderia deixar de participar do estudo sem prejuízo ao seu tratamento de saúde na instituição hospitalar onde estava sendo realizado o estudo. A não identificação dos sujeitos e a manutenção do sigilo dos dados individuais também foram assegurados. Após a aceitação do potencial participante, ele foi convidado a assinar o termo de consentimento livre e esclarecido (APÊNDICE A).

\subsection{Procedimento para coleta dos dados}

A coleta de dados foi realizada nas Unidades de Internação da Clínica Cirúrgica, Clínica Médica e Pós Operatória de Cirurgia Torácica e Cardiovascular do 
Hospital das Clínicas da Faculdade de Medicina de Ribeirão Preto (HCFMRPUSP) por meio de entrevistas individuais e consulta aos prontuários dos participantes.

No período pré-operatório, nas unidades de internação de clínica cirúrgica e de clínica médica, foram coletados dados para a caracterização sócio-demográfica e clínica, avaliação da ansiedade, depressão e senso de coerência dos sujeitos. No pós-operatório, os dados relacionados ao procedimento anestésico-cirúrgico foram coletados na unidade de recuperação pós-operatória (durante as primeiras 24 horas após a cirurgia). Novamente, na unidade de internação de clínica cirúrgica, decorridos no máximo 24 horas da alta da unidade pós-operatória, foram coletados dados para avaliação dos estressores percebidos pelos pacientes relacionados à sua permanência na unidade de tratamento intensivo. Os dados relacionados aos estressores foram coletados por uma enfermeira da própria unidade de internação cirúrgica, para que não houvesse influência nas respostas dos participantes que foram cuidados pela pesquisadora responsável pelo estudo durante o período pósoperatório imediato. A pesquisadora foi responsável pela entrevista no préoperatório e consulta aos prontuários.

Para todos os participantes, as questões foram lidas, mesmo para aqueles que se mostraram aptos à leitura. Essa conduta visou diminuir possíveis vieses na coleta. 


\subsection{Instrumentos de coleta}

\subsubsection{Instrumento de caracterização sócio-demográfica e clínica dos sujeitos}

Para a caracterização dos participantes foi criado um instrumento (APÊNDICE

B) contendo os seguintes dados:

- caracterização sócio-demográfica: iniciais e registro do paciente, data de nascimento, sexo, estado civil, escolaridade e situação profissional;

- caracterização clínica: tempo de internação, diagnóstico principal, patologias associadas, uso de psicofármacos, história pregressa de cirurgia cardíaca, necessidade de remarcação da data da cirurgia, sintomatologia (dor, dispnéia).

O uso de psicofármacos foi investigado por estarmos avaliando, por meio de instrumentos psicométricos, constructos subjetivos como ansiedade, depressão, SC e estressores. Tais avaliações podem ser comprometidas pelo uso de psicofármacos do tipo antidepressivos, ansiolíticos e estabilizadores do humor (como os anticonvulsivantes) (LARAIA, 2001).

Para os períodos trans e pós-operatório foi elaborado um instrumento para coleta de dados referentes ao ato anestésico-cirúrgico, contendo as seguintes informações:

- trans-operatório: data da cirurgia, cirurgia realizada, tempo de cirurgia e de circulação extracorpórea, presença de intercorrências (sangramento, hipertensão, hipotensão, arritmia, parada cárdio-respiratória (PCR), infarto 
agudo do miocárdio (IAM) trans-operatório, complicações relacionadas à saída de CEC);

- pós-operatório imediato: drogas vasoativas instaladas no trans-operatório, drenos torácicos, drogas vasoativas instaladas no pós-operatório, transfusão de hemocomponentes, data e hora de retirada da cânula orotraqueal, presença de intercorrências (arritmias, alterações de pressão arterial, tamponamento, náusea, vômito, hemotórax, pneumotórax, sangramento, PCR, déficit neuro-sensorial, reoperação, dor, agitação, febre, oligúria, hiperglicemia, queda de $\mathrm{Hb}$ e $\mathrm{Ht}$, IAM perioperatório), visitas recebidas na UTI, tempo de estadia na UTI.

Após a elaboração destes instrumentos (APÊNDICE B), eles foram avaliados quanto à validade de conteúdo por um comitê composto por três juízes, com vasta experiência na área de cardiologia e cirurgia cardiovascular, de acordo com o que segue:

- avaliadora 1: Enfermeira da unidade pós-operatória de cirurgia torácica e cardiovascular do HCRP, especialista em Enfermagem Cardiológica e pósgraduanda, nível mestrado, da EERP-USP;

- avaliadora 2: Enfermeira, especialista em Enfermagem Cardiológica e pósgraduanda, nível mestrado, da EERP-USP;

- avaliadora 3: Enfermeira, especialista em Enfermagem Cardiológica e Professora Assistente Nível A no Curso de Enfermagem da Universidade Estadual do Oeste do Paraná (Unioeste), em Cascavel, PR e pós-graduanda, nível doutorado, da EERP-USP.

Às enfermeiras avaliadoras foi solicitada a avaliação referente à clareza (se os itens estavam descritos de forma compreensível) e pertinência (se os itens 
expressavam verdadeira relação com a proposta do estudo) dos itens formulados no instrumento de coleta. Sugestões para modificações ou questionamentos sobre os itens foram pedidas no encaminhamento do instrumento.

As seguintes modificações foram sugeridas e realizadas, após a validação, no que se refere à (APÊNDICE C):

- Adequação da apresentação e ditoração do instrumento: as enfermeiras sugeriram alteração no estilo do instrumento, tornando-o mais funcional para a tabulação dos dados;

- Caracterização sócio-demográfica: foram excluídos os itens iniciais do nome e registro do paciente no hospital, por não ser um dado importante nesse momento, já que esses dados constariam de uma lista de identificação;

- Caracterização Clínica: as questões sobre tempo de internação e se já havia sido operado antes foram retiradas, pois o tempo de internação seria calculado por meio da data de internação e da data da entrevista e a informação de cirurgia cardíaca anterior não era necessária, uma vez que se tratava de um critério de exclusão do estudo.

\subsubsection{Instrumento de avaliação de ansiedade e depressão}

Para a mensuração destas variáveis, optamos pelo instrumento Hospital Anxiety and Depression Scale (HADS) (ZIGMOND; SNAITH, 1983), em sua versão em português validada por Botega et al. (1995), com pacientes internados em uma unidade de clínica médica (ANEXO B). Tal escolha se justifica por ser um 
instrumento de fácil compreensão, de rápida aplicação, com reduzido número de itens e ter se mostrado um instrumento com adequadas propriedades psicométricas. Embora tenha sido inicialmente proposto para pacientes ambulatoriais na detecção de estados depressivos e de ansiedade, pode ser aplicado em diversos contextos (ZIGMOND; SNAITH, 1983; BOWLING, 2005).

Este instrumento possui 14 questões, (sete para ansiedade e sete para depressão), que abordam sintomas somáticos e psicológicos, com escala de resposta de quatro pontos. Os valores das respostas variam de 0 a 3 (zero a três), cuja soma pode variar de zero a 21 (vinte e um) pontos para cada um dos transtornos emocionais pesquisados. Assim, a avaliação das respostas pode ser feita com o valor total de cada sub-escala (HAD-ansiedade e HAD-depressão) sendo que quanto maior o valor, maior o transtorno emocional.

De acordo com os valores obtidos em cada sub-escala, os sujeitos podem ser categorizados em três níveis: não casos (quando a pontuação varia de zero a sete), caso duvidoso ou incerto (pontuação entre oito e dez) e caso (com pontuação de onze a vinte e um).

\subsubsection{Instrumento para avaliação do senso de coerência}

Optamos pela utilização do Questionário de Senso de Coerência de Antonovsky (QSCA) (ANTONOVSKY, 1987) em sua versão traduzida e validada para o português (DANTAS, 2007) (ANEXO C). 
Trata-se de um questionário composto por 29 itens, dividido em três componentes: compreensão, manejo e significado. O componente compreensão, com onze itens, avalia a percepção que a pessoa tem do que está acontecendo com ela, ou seja, o quanto o estímulo faz sentido em sua vida. Manuseio, com dez itens, refere-se a capacidade do indivíduo para lidar com o problema, buscando recursos internos e externos. O terceiro componente é o significado, com oito itens, exprime o sentido que a pessoa dá aos acontecimentos que está vivenciando. As respostas aos itens são obtidas por meio de uma escala de sete pontos, com os valores extremos variando de um (1) a sete (7), no qual o valor um representa o mais fraco SC e o sete o mais forte. Esses números são inseridos nos extremos da escala de resposta e sob eles há duas frases âncoras para informar ao respondente como o item deve ser considerado na sua resposta. Dos 29 itens, 13 são respondidos em uma escala reversa de valores, ou seja, valores maiores indicam menor SC (itens 1 , $4,5,6,7,11,13,14,16,20,23,25$ e 27). Quando os valores são somados para se obter o valor total do SC, esses 13 itens precisam ter seus valores revertidos, ou seja, o valor sete será transformado em um, o seis em dois, o cinco em três e, assim, sucessivamente. Valores elevados sempre significam forte senso de coerência e o intervalo possível de pontuação varia de 29 a 203 (ANTONOVSKY, 1987). 


\subsubsection{Instrumento para avaliação dos estressores percebidos em terapia intensiva}

Para a avaliação dos estressores percebidos no período pós-operatório, utilizamos a "Escala de Estressores em Terapia Intensiva (ICUESS - Intensive Care Unit Environmental Stressor Scale) (BALLARD, 1981), na versão traduzida para o português por Novaes et al., (1997) em pacientes internados em uma UTI geral de um hospital particular (ANEXO D). Os autores da versão traduzida para o português retiraram 2 itens da escala original de 42 questões, alegando uma melhor adaptação da escala à população estudada. No entanto em nosso estudo, usamos os 42 itens originais, uma vez que os dois itens retirados (ter homens e mulheres internados em um mesmo ambiente e assistir aos cuidados médicos e de enfermagem realizados em outros pacientes) fazem parte da realidade vivenciada pelos pacientes em nosso serviço. Outro aspecto que fundamentou essa decisão é o fato da versão completa ter sido usada por outros autores no Brasil com bons resultados (GOIS; DANTAS, 2004; MAROSTI; DANTAS, 2006). É uma escala de quatro pontos, cuja numeração significa: (1) não estressante, (2) pouco estressante, (3) estressante e (4) muito estressante. Os resultados são obtidos pela soma dos valores atribuídos a cada um dos itens. A soma pode variar de 42 ( $1 \times 42$ itens) a 168 ( $4 \times 42$ itens), o que significa quanto maior o valor, maior o estresse percebido na unidade. Podemos, ainda, analisar os resultados através da média dos itens dividindo o valor total da escala pelo número de itens e utilizar a escala de resposta (não estressante até muito estressante) para interpretar o resultado. 


\subsection{Análise semântica e estudo piloto}

Após a análise das respostas dos juizes foi feita a análise semântica dos instrumentos de coleta. Segundo Pasquali (1999), antes de se utilizar um instrumento de medida ele deve ser submetido a um processo de análise semântica que tem como objetivo verificar se todos os itens são compreensíveis para os membros da população à qual o instrumento se destina. Argumento que nessa análise uma das preocupações relevantes era verificar se os itens eram inteligíveis para o estrato mais baixo (de habilidade) da população meta e, por isso, a amostra para essa análise deve ser feita com esse estrato. Diante disso, optamos por realizar as análises semânticas dos instrumentos com um grupo composto por cinco pacientes, internados em pré-operatório, solicitando que eles avaliassem a clareza e pertinência do conjunto de instrumentos a serem usados para a coleta dos dados (o instrumento de dados sócio-demográficos e clínicos, a escala de avaliação de ansiedade e depressão (HAD), o questionário para avaliação do senso de coerência (Questionário de Senso de Coerência de Antonovsky - QSCA) e a escala para avaliação dos estressores percebidos em terapia intensiva (ICUESS). A análise semântica da versão traduzida do ICUESS foi realizada no período pós-operatório pela enfermeira da unidade de internação da clínica cirúrgica, após os pacientes receberem alta da unidade pós-operatória.

Durante a análise semântica foi lido item por item de cada instrumento para cada sujeito participante e questionado sobre a compreensibilidade dos mesmos e solicitado sugestões para facilitar a compreensão, quando necessário. Como resultado dessa análise, realizamos a modificação da questão "Eu perdi o interesse 
em cuidar da minha aparência" (HAD-depressão) porque três dos cinco participantes tiveram dificuldade no entendimento da alternativa "talvez não tanto quanto antes". As sugestões dadas levaram a mudança de sua redação para "talvez não me cuido tanto quanto antes" (APÊNDICE E).

Fizemos uma alteração no instrumento de dados sócio-demográficos e clínicos, codificando cada dado coletado, para que ficasse mais fácil no momento de digitar no banco de dados (APÊNDICE D).

Após essas modificações, realizamos um estudo piloto com outros cinco pacientes. Estudo piloto é um ensaio em pequena escala do estudo a ser desenvolvido, visando à melhoria do projeto. Segundo Polit; Beck; Hungler (2004) quando há qualquer modificação no delineamento da pesquisa, na amostragem ou nos instrumentos de coleta de dados, os dados coletados anteriormente a essas alterações devem ser descartados. Após verificarmos que não houve necessidade de novas alterações, iniciamos a coleta definitiva dos dados e os pacientes do estudo piloto foram inseridos no estudo final.

\subsection{Processamento e análise dos dados}

Os dados foram processados inicialmente em planilhas do Excel versão 2003, com técnica de dupla digitação para a validação dos dados. Após essa conferência, os dados foram transportados para o programa de software Statistical Package for Social Science (SPSS), versão 15.0 para cálculo das análises descritivas e de correlação entre as variáveis. Para a análise descritiva das variáveis foram utilizadas 
medidas de posição (média, mediana) e variabilidade (desvio-padrão) para as variáveis contínuas e de freqüência simples para as variáveis categóricas.

As variáveis escalares foram avaliadas quanto à consistência interna através do alfa de Cronbach. Coeficiente de correlação de Spearman foi calculado entre as medidas das variáveis exploratórias (senso de coerência, depressão, ansiedade e estressores), para avaliarmos se havia correlação entre as variáveis exploratórias do pré-operatório entre si e entre elas e a variável estressores do pós-operatório imediato. As forças das correlações obtidas foram analisadas de acordo com a categorização proposta por Ajzen e Fishbein (1980) a qual classifica que valores abaixo de 0,30, mesmo quando estatisticamente significantes, devem ser considerados de fraca magnitude e sem utilidade na prática clínica; entre 0,30 e 0,50 de moderada magnitude e acima de 0,50 , de forte magnitude.

Os testes de comparação da distribuição das medidas de ansiedade, depressão, senso de coerência e estressores com as variáveis sexo (masculino e feminino) e escolaridade (até nível fundamental e nível médio ou superior) foram avaliadas pelo teste não-paramétrico de Mann-Whitney. O teste de Kruskal-Wallis foi usado para testar essa comparação com idade (até 40, entre 41 e 59 e acima de 60 anos), tempo de pré-operatório (até sete dias, de oito a 14 e acima de 14 dias) e tempo de permanência na UTI (menos de três dias, de três a seis dias e acima de seis dias). Tempo de permanência na UTI foi avaliado somente com a medida de estressores no pós-operatório.

O nível de significância adotado foi de 0,05. 


\section{RESULTADOS}

4.1 Relacionados à caracterização sócio-demográfica e clínica dos participantes do estudo.

Com relação à caracterização sócio-demográfica dos participantes constatamos média de idade 56,9 anos (Desvio-padrão=13,7; mínima de 18 e máxima de 79 anos), tendo $47,3 \%$ dos sujeitos entre 40 e 59 anos e $44 \%$ com 60 anos ou mais. Quanto ao sexo, observamos uma distribuição semelhante entre pacientes do sexo feminino $(48 ; 52,7 \%)$ e masculino (43; 47,3\%). Houve predominância de indivíduos casados $(57 ; 62,6 \%)$, com baixa escolaridade $(81,3 \%$ possuíam até o primeiro grau completo) e sem desempenho de atividades ocupacionais remuneradas $(56 ; 61,5 \%)$ (Tabela 1$)$. 
Tabela 1 - Distribuição dos 91 sujeitos do estudo segundo a caracterização sóciodemográfica. Ribeirão Preto, 2007 - 2008.

\begin{tabular}{|c|c|c|c|c|c|}
\hline Variáveis & n (\%) & Intervalo & Mediana & Média & $\begin{array}{l}\text { Desvio } \\
\text { Padrão }\end{array}$ \\
\hline Idade & & $18-79$ & 57,1 & 56,9 & 13,7 \\
\hline Menor de 40 anos & $8(8,8)$ & & & & \\
\hline Entre 40 e 59 anos & $43(47,3)$ & & & & \\
\hline 60 anos ou mais & $40(44)$ & & & & \\
\hline \multicolumn{6}{|l|}{ Sexo } \\
\hline Feminino & $48(52,7)$ & & & & \\
\hline Masculino & $43(47,3)$ & & & & \\
\hline \multicolumn{6}{|l|}{ Estado civil } \\
\hline Casado/união consensual & $57(62,6)$ & & & & \\
\hline Solteiro & $15(16,5)$ & & & & \\
\hline Viúvo & $15(16,5)$ & & & & \\
\hline Separado & $4(4,4)$ & & & & \\
\hline \multicolumn{6}{|l|}{ Escolaridade } \\
\hline Nível fundamental & $74(81,3)$ & & & & \\
\hline Nível médio e superior & $17(18,7)$ & & & & \\
\hline \multicolumn{6}{|l|}{ Ocupação } \\
\hline Inativos & $56(61,5)$ & & & & \\
\hline Ativos & $35(38,5)$ & & & & \\
\hline
\end{tabular}

Quanto à caracterização clínica dos participantes, os diagnósticos mais freqüentes identificados entre eles foram: hipertensão arterial (74,7\%), doença arterial coronariana $(58,2 \%)$ e valvulopatias $(51,6 \%)$. Com relação aos 47 pacientes com valvulopatias, 23 (48,9\%) tinham disfunção de válvula mitral e 20 (42,6\%) de válvula aórtica. O uso de psicofármacos foi informado por $19(20,9 \%)$ participantes e, desses, 12 (63,2 \%) eram usuários de ansiolíticos, três (15,8 \%) de estabilizadores do humor (anticonvulsivantes), três $(15,7 \%)$ de antidepressivos e um paciente $(5,3 \%)$ associava ansiolítico e estabilizadores do humor (anticonvulsivantes).

Com relação ao período pré-operatório investigamos a presença de sintomas que pudessem interferir no estado emocional dos pacientes. Entre eles, $56(61,5 \%)$ 
referiram dor, sendo a dor torácica a mais relatada $(36 ; 64,28 \%)$. Outro sintoma relatado foi a dispnéia, referida por 48 (52,7\%) entrevistados.

O tempo de internação pré-operatória variou de zero a 59 dias, com uma média de 13 dias. Esse tempo de internação foi calculado entre o dia da internação e o dia da primeira entrevista. Quando os pacientes foram entrevistados no mesmo dia da internação, consideramos o valor zero.

As cirurgias realizadas foram: revascularização do miocárdio (45 pacientes; 49,4\%); correção de disfunção valvar (39; 42,9\%); e a revascularização do miocárdio com simultânea correção de disfunção valvar, por troca ou plastia de válvula $(7 ; 7 \%)$. O tempo médio de duração do procedimento cirúrgico foi de 4,8 horas (mínimo de 3 e máximo de 9,5 horas) (Tabela 2).

Tabela 2 - Caracterização do tratamento cirúrgico entre os 91 participantes do estudo. Ribeirão Preto, 2007 - 2008.

\begin{tabular}{lcccc}
\hline \multicolumn{1}{c}{$\begin{array}{c}\text { Variáveis do } \\
\text { tratamento cirúrgico }\end{array}$} & $\mathbf{n}(\%)$ & $\begin{array}{c}\text { Intervalo } \\
\text { obtido }\end{array}$ & Mediana & $\begin{array}{c}\text { Média } \\
\text { (DP)* }\end{array}$ \\
$\begin{array}{l}\text { Tempo de internação pré- } \\
\text { operatória (em dias) } \\
\text { Cirurgias realizadas } \\
\text { Revascularização do miocárdio }\end{array}$ & $45(49,5)$ & $0-59$ & 8,0 & 13,0 \\
$\begin{array}{l}\text { Troca e/ou plastia de válvula } \\
\text { Revascularização do miocárdio } \\
\text { com troca e/ou plastia de válvula }\end{array}$ & $39(42,9)$ & & & \\
$\begin{array}{l}\text { Tempo de duração da cirurgia } \\
\text { (em horas) }\end{array}$ & $7(7,7)$ & & & \\
*DP= Desvio-padrão & & $3-9,5$ & 4,6 & 4,8 \\
\hline
\end{tabular}




\subsection{Relacionados à avaliação de ansiedade, depressão e senso de coerência, no período pré-operatório.}

A avaliação das variáveis ansiedade, depressão e senso de coerência foi realizada, respectivamente, pelos instrumentos Hospital Anxiety and Depression Scale (HAD) e Questionário de Senso de Coerência de Antonovsky (QSCA). A consistência interna dos instrumentos e a análise estatística descritiva dos resultados obtidos encontram-se na Tabela 3.

Tabela 3 - Estatística descritiva e consistência interna dos instrumentos usados na avaliação pré-operatória dos participantes. Ribeirão Preto, 2007-2008.

\begin{tabular}{|c|c|c|c|c|c|}
\hline Instrumentos & $\mathbf{N}(\%)$ & $\begin{array}{c}\text { Intervalo } \\
\text { Obtido }\end{array}$ & Mediana & Média (DP) & $\begin{array}{c}\alpha \text { de } \\
\text { Cronbach }\end{array}$ \\
\hline $\begin{array}{l}\mathrm{HAD}^{*} \text { - Ansiedade (7 itens) } \\
\text { Não caso } \\
\text { Caso duvidoso } \\
\text { Caso }\end{array}$ & $\begin{array}{l}48(52,2) \\
27(29,3) \\
16(17,4)\end{array}$ & $0-18$ & 7 & $7,3(4,2)$ & 0,72 \\
\hline $\begin{array}{l}\text { HAD - Depressão (7 itens) } \\
\text { Não caso } \\
\text { Caso duvidoso } \\
\text { Caso }\end{array}$ & $\begin{aligned} 64 & (69,6) \\
20 & (21,7) \\
7 & (7,6)\end{aligned}$ & $0-18$ & 5 & $5,3(3,5)$ & 0,61 \\
\hline QSCA $^{* *}$ (29 itens) & & $102-198$ & 158 & $155,6(25,3)$ & 0,77 \\
\hline
\end{tabular}

* $\mathrm{HAD}=$ Escala de Ansiedade e Depressão Hospitalar; ${ }^{* *} \mathrm{QSCA}=$ Questionário de Senso de Coerência de Antonovsky. "DP= Desvio-padrão

No grupo estudado, no que se refere à avaliação da ansiedade, tivemos um valor médio de 7,3 $(\mathrm{DP}=4,2)$, com intervalo entre zero e 18 , em um intervalo possível de zero a 21. O alpha de Cronbach obtido foi de 0,72. De acordo com a categorização da escala HAD, dos 91 participantes, 48 (52,2\%) foram categorizados como não-casos, $27(29,3 \%)$ como casos duvidosos e $16(17,4 \%)$ foram categorizados como casos de ansiedade. 
Na medida da depressão tivemos um valor médio de 5,3 ( $\mathrm{DP}=3,5)$, com intervalo entre zero e 18, em um intervalo possível de zero a 21 . O alpha de Cronbach foi de 0,61 . Em conformidade com a categorização proposta pela escala HAD, dos 91 participantes, 64 (69,6\%) foram categorizados como não-casos para depressão, 20 (21,7\%) foram categorizados como casos duvidosos e $7(7,6 \%)$ como casos.

Para a medida de senso de coerência, obtivemos um valor médio de 155,6 $(\mathrm{DP}=25,3)$, com intervalo entre 102 e 198, sendo que o intervalo possível é de 29 a 203. O intervalo possível para essa medida de SC varia de 29 a 203 (maior o valor, maior SC) e seu ponto médio é o valor 116. Assim, podemos constatar que os pacientes apresentaram valores médios e da mediana acima de 116, indicando melhores avaliações para o SC. O alpha de Cronbach para essa medida foi de 0,77. Os valores dos alphas de Cronbach foram satisfatórios para os instrumentos HAD Ansiedade e QSCA e abaixo de 0,70 para HAD - Depressão (embora não inferior a $0,60)$.

Um dos objetivos do estudo era analisar as relações entre ansiedade, depressão e senso de coerência no pré-operatório. É importante salientar que os instrumentos possuem direções opostas, uma vez que na HAD (Ansiedade e Depressão) maiores valores indicam maior transtorno emocional, enquanto que no instrumento de Antonovsky, maiores valores indicam maior SC, possibilitando uma maior compreensão, manejo e avaliação do significado dessa experiência em suas vidas. Ao analisarmos a presença de possíveis correlações entre essas medidas no grupo estudado, constatamos que a correlação entre as medidas de ansiedade e de depressão foi positiva e de moderada magnitude $(r=0,465 ; p=0,000)$, indicando que pacientes com sintomas de ansiedade também apresentavam sintomas de 
depressão, no geral. Como já era esperado, as correlações da medida de SC com ansiedade e com depressão foram negativas ou inversas. Quanto à magnitude, constatamos correlação moderada com a medida de ansiedade $(r=-0,371 ; p=0,000)$ e forte com a medida de depressão $(r=-0,516 ; p=0,000)$. Tais resultados sugerem que os pacientes com maior senso de coerência apresentavam menores sintomas de ansiedade e depressão, no momento da avaliação (Tabela 4).

Tabela 4 - Coeficientes de correlação de Spearman entre as medidas de SC, ansiedade e depressão no pré-operatório de cirurgias cardíacas. Ribeirão Preto, 2007-2008.

\begin{tabular}{lccc}
\hline \multicolumn{1}{c}{ Medidas } & SC total & HAD ansiedade & HAD depressão \\
\hline $\mathrm{SC}^{*}$ & 1 & $-0,371$ & $-0,516$ \\
$\mathrm{HAD}{ }^{* *}$ Ansiedade & - & 1 & 0,465 \\
$\mathrm{HAD}$ & & & 1 \\
\end{tabular}

${ }^{*} \mathrm{SC}=$ Senso de coerência; HAD**Hospital Anxiety and Depression Scale Todas as correlações com $p=0,000$.

No pré-operatório, também realizamos testes de comparação da distribuição das medidas entre ansiedade e depressão com aquelas variáveis que têm sido apontadas, pelos estudos revisados, como tendo possível efeito preditor para o estado emocional. Assim, foram selecionadas as variáveis sexo, idade, escolaridade e tempo de internação antes da cirurgia.

Primeiramente, verificamos se havia diferenças das variáveis citadas com a medida de ansiedade (Tabela 5). Com relação ao sexo dos pacientes, observamos uma média de 8,1 $(\mathrm{DP}=4,0)$ para as mulheres e 6,5 $(\mathrm{DP}=4,3)$ para os homens, sendo essa diferença estatisticamente significativa $(p=0,03)$ entre os grupos. De 
acordo com a idade obtivemos valores médios de 6,9 $(\mathrm{DP}=3,3)$ para os pacientes com até 40 anos, de 8,1 ( $\mathrm{DP}=4,7)$ para os pacientes entre 41 e 59 anos e uma média de 6,6 $(\mathrm{DP}=3,8)$ para os pacientes com 60 anos ou mais. A diferença entre ansiedade e idade não se mostrou estatisticamente significativa entre os grupos $(p=$ 0,37). Os valores médios da medida de ansiedade segundo a escolaridade foram de 7,6 $(\mathrm{DP}=4,2)$ para os que possuíam até o nível fundamental completo e de 5,9 $(\mathrm{DP}=3,9)$ para os pacientes com nível médio e superior. Não constatamos diferença estatisticamente significativa entre as medidas de ansiedade obtidas nos dois grupos de pacientes, divididos pela escolaridade $(p=0,07)$. Observamos um aumento nos valores médios da ansiedade quando agrupamos os pacientes segundo o tempo de internação. Pacientes com mais de uma semana de internação tiveram maiores valores e essa diferença se mostrou estatisticamente significativa $(p=0,03)$ (Tabela 5).

Tabela 5 - Resultados dos testes de comparação da distribuição entre as medidas de HAD-ansiedade e as variáveis: sexo, idade, escolaridade e tempo de préoperatório. Ribeirão Preto, 2007-2008.

\begin{tabular}{|c|c|c|c|}
\hline \multirow{2}{*}{ Variáveis } & \multicolumn{3}{|c|}{ Medidas de HAD-ansiedade } \\
\hline & Média (DP) & Mediana & $p$ \\
\hline $\begin{array}{l}\text { Sexo } \\
\quad \text { Masculino }(n=43) \\
\text { Feminino }(n=48)\end{array}$ & $\begin{array}{l}6,5(4,3) \\
8,1(4,0)\end{array}$ & $\begin{array}{l}8,0 \\
6,0\end{array}$ & $0,03^{*}$ \\
\hline $\begin{array}{l}\text { Idade } \\
\text { Até } 40 \text { anos }(n=8) \\
\text { Entre } 41 \text { e } 59 \text { anos }(n=43) \\
\text { Acima de } 60 \text { anos }(n=40)\end{array}$ & $\begin{array}{l}6,9(3,4) \\
8,1(4,7) \\
6,6(3,8)\end{array}$ & $\begin{array}{l}6,5 \\
8,0 \\
6,5\end{array}$ & $0,37^{* *}$ \\
\hline $\begin{array}{l}\text { Escolaridade } \\
\quad \text { Até nível fundamental }(n=74) \\
\text { Nível médio ou superior }(n=17)\end{array}$ & $\begin{array}{l}7,6(4,2) \\
5,9(3,9)\end{array}$ & $\begin{array}{l}7,5 \\
5,0\end{array}$ & $0,07^{*}$ \\
\hline $\begin{array}{l}\text { Tempo de pré-operatório } \\
\text { Até } 7 \text { dias }(n=46) \\
\text { De } 8 \text { a } 14 \text { dias }(n=16) \\
\text { Acima de } 14 \text { dias }(n=29)\end{array}$ & $\begin{array}{l}6,2(4,0) \\
8,4(3,8) \\
8,4(4,5)\end{array}$ & $\begin{array}{l}6,0 \\
8,0 \\
8,0\end{array}$ & $0,03^{* *}$ \\
\hline
\end{tabular}

Teste de Mann-Whitney ; ** Teste de Kruskal-Wallis. 
Com relação à comparação da distribuição das medidas destas variáveis sócio-demográficas e o tempo de internação pré-operatório com a medida de depressão, constatamos valores médios de 5,2 $(\mathrm{DP}=3,5)$ para o grupo todo, sendo que as mulheres apresentaram uma média de $5,8(D P=4,0)$ e os homens uma média de 4,7 ( $\mathrm{DP}=2,7)$. Na observação dos testes de comparação da medida de depressão com a idade dos pacientes, tivemos os valores médios de 6,9 $(\mathrm{DP}=3,4)$ para pacientes até 40 anos, 8,1 ( $\mathrm{DP}=4,7)$ para pacientes entre 41 e 59 anos e 6,6 $(\mathrm{DP}=3,8)$ em pacientes acima de 60 anos. Essas diferenças não foram estatisticamente significativas entre os grupos. Segundo o grau de escolaridade, obtivemos valores médios de $5,7(\mathrm{DP}=3,5)$ para a medida de depressão no grupo dos participantes que possuíam até o nível fundamental e de 3,4 (DP=2,7) para os pacientes que possuíam nível médio e/ou nível superior, sendo essa diferença estatisticamente significativa $(p=0,08)$. No que se refere ao tempo de internação no período pré-operatório, os valores de média e desvio-padrão obtidos, respectivamente, foram 4,9 $(3,2)$ para internação até sete dias; $6,4(3,3)$ para pacientes internados entre oito e 14 dias e 5,2 $(4,1)$ para os internados acima de 14 dias. A comparação da distribuição das medidas entre essas duas variáveis, depressão e tempo de internação, não foi confirmado $(p=0,24)$ (Tabela 6). 
Tabela 6 - Resultados dos testes de comparação da distribuição entre as medidas de HAD-depressão e as variáveis: sexo, idade, escolaridade e tempo de préoperatório. Ribeirão Preto, 2007-2008.

\begin{tabular}{|c|c|c|c|}
\hline \multirow{2}{*}{ Variáveis } & \multicolumn{3}{|c|}{ Medidas de HAD-depressão } \\
\hline & Média (DP) & Mediana & $p$ \\
\hline $\begin{array}{l}\text { Sexo } \\
\text { Masculino }(n=43) \\
\text { Feminino }(n=48)\end{array}$ & $\begin{array}{l}4,7(2,7) \\
5,8(4,0)\end{array}$ & $\begin{array}{l}5,0 \\
5,0\end{array}$ & $0,21^{*}$ \\
\hline $\begin{array}{l}\text { Idade } \\
\text { Até } 40 \text { anos }(n=8) \\
\text { Entre } 41 \text { e } 59 \text { anos }(n=43) \\
\text { Acima de } 60 \text { anos }(n=40)\end{array}$ & $\begin{array}{l}5,5(3,5) \\
4,9(3,0) \\
5,7(4,0)\end{array}$ & $\begin{array}{l}6,0 \\
4,0 \\
5,0\end{array}$ & $0,76^{* *}$ \\
\hline $\begin{array}{l}\text { Escolaridade } \\
\text { Até nível fundamental }(n=74) \\
\text { Nível médio ou superior }(n=17)\end{array}$ & $\begin{array}{l}5,7(3,5) \\
3,4(2,7)\end{array}$ & $\begin{array}{l}5,0 \\
2,0\end{array}$ & $0,08^{*}$ \\
\hline $\begin{array}{l}\text { Tempo de pré-operatório } \\
\text { Até } 7 \text { dias }(n=46) \\
\text { De } 8 \text { a } 14 \text { dias }(n=16) \\
\text { Acima de } 14 \text { dias }(n=29)\end{array}$ & $\begin{array}{l}4,9(3,2) \\
6,4(3,3) \\
5,2(4,1)\end{array}$ & $\begin{array}{l}4,5 \\
7,5 \\
4,0\end{array}$ & $0,24^{* *}$ \\
\hline
\end{tabular}

* Teste de Mann-Whitney ; ${ }^{* *}$ Teste de Kruskal-Wallis.

$\mathrm{Na}$ Tabela 7, podemos visualizar a descrição estatística dos testes de comparação entre as medidas de senso de coerência, obtidas pelo QSCA, e as outras variáveis estudadas. No grupo, a média do SC foi de $155,6(D P=25,3)$, sendo que as mulheres apresentaram uma média de 150,8 (DP=26,5) e os homens de 161,0 (DP=23,1).

Com relação à idade dos participantes, pacientes com 60 anos ou mais apresentaram uma média de 157,2 ( $\mathrm{DP}=4,3)$ para a medida de SC, valor maior do que aquele obtido nos grupos de idade até 40 anos e entre 41 e 59 anos (154 e 154,53 respectivamente). De acordo com o grau de escolaridade, obtivemos os seguintes valores médios das medidas de SC: $154(\mathrm{DP}=26,5)$ para os pacientes que possuíam até o nível fundamental e 162,8 ( $\mathrm{DP}=18,3)$ para aqueles com o nível médio ou nível superior. Segundo o tempo de internação, as medidas obtidas foram de 158,9 $(\mathrm{DP}=24,6)$ para os participantes internados até sete dias antes da cirurgia, $153,4(\mathrm{DP}=30,2)$ para aqueles internados de oito a 14 dias e 151,6 $(\mathrm{DP}=23,6)$ para aqueles que estavam internados acima de 14 dias. Nenhuma dessas diferenças nas medidas de SC foi estatisticamente significativa entre os grupos $(p>0,05)$ (Tabela 7). 
Tabela 7 - Resultados dos testes de comparação da distribuição entre as medidas de senso de coerência e as variáveis: sexo, idade, escolaridade e tempo de préoperatório. Ribeirão Preto, 2007-2008.

\begin{tabular}{|c|c|c|c|}
\hline \multirow{2}{*}{ Grupo } & \multicolumn{3}{|c|}{ Medidas de SC } \\
\hline & Média (DP) & Mediana & $p$ \\
\hline Sexo & & & $0,06^{*}$ \\
\hline Masculino $(n=43)$ & $161(23,1)$ & 156,0 & \\
\hline Feminino $\quad(n=48)$ & $150,8(26,5)$ & 164,0 & \\
\hline Idade & & & $0,77^{\star *}$ \\
\hline Até 40 anos $(n=8)$ & $154,0(24,1)$ & 163,0 & \\
\hline Entre 41 e 59 anos $(n=43)$ & $154,5(24,4)$ & 154,0 & \\
\hline Acima de 60 anos $(n=40)$ & $157,2(27,1)$ & 162,5 & \\
\hline Escolaridade & & & $0,31^{*}$ \\
\hline Até nível fundamental $(n=74)$ & $154(26,5)$ & 156,5 & \\
\hline Nível médio ou superior $(n=17)$ & $162,8(18,3)$ & 169,0 & \\
\hline Tempo de pré-operatório & & & $0,38^{* *}$ \\
\hline Até 7 dias $(n=46)$ & $158,9(24,6)$ & 161,5 & \\
\hline De 8 a 14 dias $(n=16)$ & $153,4(30,2)$ & 152,0 & \\
\hline Acima de 14 dias $(n=29)$ & $151,6(23,6)$ & 156,0 & \\
\hline
\end{tabular}

* Teste de Mann-Whitney ; ${ }^{* *}$ Teste de Kruskal-Wallis.

\subsection{Relacionados à avaliação de estressores pelos participantes no pós- operatório imediato.}

A avaliação dos estressores percebidos na unidade pós-operatória foi realizada pela Escala de Estressores em Terapia Intensiva (ICUESS) decorridas, no máximo, 24 horas após o paciente ter recebido alta dessa unidade. Nas medidas obtidas o valor médio do total da escala foi de $87,9(\mathrm{DP}=28,8)$, com intervalo entre 43 a 162, em um intervalo possível de 42 a 168. O alpha de Cronbach foi de 0,90, demonstrando a alta consistência interna entre os itens do instrumento. Na Tabela 8 podemos visualizar a distribuição das médias das respostas dos pacientes para cada um dos 42 itens, bem como o valor médio total das respostas aos 42 itens. 
Tabela 8 - Distribuição das médias das respostas para a Escala de Estressores em Terapia Intensiva (total e dos itens). Ribeirão Preto, 2007-2008.

\begin{tabular}{|c|c|}
\hline ICUESS* & Média (DP) ** \\
\hline Total dos 42 itens & $87,9(28,8)$ \\
\hline Média das respostas aos 42 itens & $2,1(0,7)$ \\
\hline Ter dor & $3,23(1,0)$ \\
\hline Não conseguir dormir & $3,01(1,1)$ \\
\hline Ter tubos no nariz e/ou na boca & $2,77(1,2)$ \\
\hline Ter sede & $2,71(1,2)$ \\
\hline Não conseguir mexer as mãos ou os braços devido às vias intravenosas & $2,70(1,1)$ \\
\hline Não saber onde está & $2,62(1,3)$ \\
\hline Não saber que horas são & $2,56(1,2)$ \\
\hline Sentir falta do marido ou da esposa & $2,53(1,3)$ \\
\hline Não saber que dia é hoje & $2,53(1,3)$ \\
\hline Ser furado por agulhas & $2,45(1,2)$ \\
\hline Estar amarrado por tubos & $2,44(1,1)$ \\
\hline Ter que ficar olhando para os detalhes do teto & $2,43(1,2)$ \\
\hline Ter luzes acesas constantemente & $2,43(1,2)$ \\
\hline Ver a família e os amigos por apenas alguns minutos & $2,32(1,2)$ \\
\hline Não ter controle de si mesmo & $2,29(1,3)$ \\
\hline Ver as bolsas de soros penduradas sobre a cabeça & $2,16(1,2)$ \\
\hline Cama e/ou travesseiros inconfortáveis & $2,14(1,2)$ \\
\hline Não saber quando as coisas vão ser feitas & $2,13(1,1)$ \\
\hline Estar num ambiente muito quente ou muito frio & $2,10(1,2)$ \\
\hline Ter a equipe falando termos incompreensíveis & $2,09(1,2)$ \\
\hline Não ter privacidade & $2,07(1,2)$ \\
\hline Ter que usar oxigênio & $2,04(1,1)$ \\
\hline Sentir cheiros estranhos & $1,98(1,1)$ \\
\hline Escutar o gemido de outros pacientes & $1,93(1,1)$ \\
\hline Não ter explicações sobre o tratamento & $1,91(1,2)$ \\
\hline Ser incomodado & $1,91(1,1)$ \\
\hline Escutar os alarmes do monitor cardíaco despertarem & $1,91(1,1)$ \\
\hline Escutar o barulho e os alarmes dos equipamentos & $1,86(1,1)$ \\
\hline Sentir que a enfermeira está muito apressada & $1,80(1,1)$ \\
\hline Ter homens e mulheres internados no mesmo ambiente & $1,79(1,1)$ \\
\hline Ser acordado pela enfermagem & $1,69(1,0)$ \\
\hline Sentir que a enfermagem esta mais atenta aos equipamentos do que a você & $1,67(1,0)$ \\
\hline Sons e ruídos desconhecidos & $1,67(0,9)$ \\
\hline $\begin{array}{l}\text { Assistir aos cuidados médicos e de enfermagem realizados em outros } \\
\text { pacientes }\end{array}$ & $1,66(1,0)$ \\
\hline Ser cuidado por médicos desconhecidos & $1,65(1,1)$ \\
\hline Escutar o telefone tocar & $1,65(1,0)$ \\
\hline Ter máquinas estranhas ao redor & $1,65(0,9)$ \\
\hline Enfermagem e médicos falando muito alto & $1,60(0,9)$ \\
\hline A enfermeira não se apresentar pelo nome & $1,59(0,9)$ \\
\hline Ter enfermagem constantemente fazendo tarefas ao redor do leito & $1,46(0,8)$ \\
\hline Medir a pressão arterial muitas vezes ao dia & $1,43(0,8)$ \\
\hline Ser examinado por médicos e enfermeiros constantemente & $1,41(0,8)$ \\
\hline
\end{tabular}


Considerando um intervalo possível de 1 (não estressante) a 4 (muito estressante), obtivemos um valor médio de 2,1 ( $\mathrm{DP}=0,7)$ para as respostas aos 42 itens da escala. Tal resultado indica que, em média, os participantes consideraram os itens avaliados entre "pouco estressante" e "estressante". Os dois itens considerados mais estressantes foram: "ter dor" $(M=3,2 ; \mathrm{DP}=1,0)$ e "não conseguir dormir" $(M=3,0 ; D P=1,1)$ e os dois menos estressantes foram: "medir a pressão arterial muitas vezes ao dia" $(M=1,4 ; D P=0,8)$ e "ser examinado por médicos e enfermeiros constantemente" (M=1,4; $\mathrm{DP}=0,8)$ (Tabela 8).

$\mathrm{Na}$ tabela 9 podemos observar a distribuição dos pacientes segundo as suas respostas aos itens da ICUESS. Se agruparmos as opções em apenas duas categorias - "não estressante" e com algum grau de estresse (de pouco a muito) verificamos que, em apenas 16 dos 42 itens, tivemos mais de $50 \%$ dos pacientes classificando-os como "não estressantes" (itens, 2, 3, 5, 7, 8, 9, 10, 12, 15, 17, 21 , $24,25,26,39,41)$. Ou seja, 27 itens da escala pontuaram algum grau de estresse para mais da metade dos sujeitos. Por exemplo, "ter sede" (item quatro) foi avaliado por $42,9 \%$ dos entrevistados como muito estressante e $56 \%$ avaliaram com a mesma opção o item 32, "ter dor". 
Tabela 9 - Distribuição dos pacientes segundo as respostas aos itens da Escala de Estressores em Terapia Intensiva (ICUESS). Ribeirão Preto, 2007-2008 (continua).

\begin{tabular}{|c|c|c|c|c|}
\hline \multirow[t]{2}{*}{ Itens da ICUESS* } & $\begin{array}{l}\text { Não } \\
\text { Estressante }\end{array}$ & $\begin{array}{c}\text { Pouco } \\
\text { Estressante }\end{array}$ & Estressante & $\begin{array}{l}\text { Muito } \\
\text { estressante }\end{array}$ \\
\hline & n (\%) & n (\%) & n (\%) & n (\%) \\
\hline $\begin{array}{l}\text { 1-Estar amarrado por tubos } \\
\text { 2-A enfermeira não se apresentar } \\
\text { pelo nome }\end{array}$ & $\begin{array}{l}23(25,3) \\
58(63,7)\end{array}$ & $\begin{array}{l}30(33) \\
20(22)\end{array}$ & $\begin{array}{c}13(14,3) \\
5(5,5)\end{array}$ & $\begin{aligned} & 25(27,5) \\
& 8(8,8)\end{aligned}$ \\
\hline $\begin{array}{l}\text { 3-Sentir que a enfermeira está muito } \\
\text { apressada }\end{array}$ & $52(57,1)$ & $19(20,9)$ & $6(6,6)$ & $14(15,4)$ \\
\hline $\begin{array}{l}\text { 4-Ter sede } \\
\text { 5-Medir a pressão arterial muitas } \\
\text { vezes ao dia }\end{array}$ & $\begin{array}{c}20(22) \\
64(70,3)\end{array}$ & $\begin{array}{l}25(27,5) \\
19(20,9)\end{array}$ & $\begin{array}{l}7(7,7) \\
4(4,4)\end{array}$ & $\begin{array}{c}39(42,9) \\
4(4,4)\end{array}$ \\
\hline $\begin{array}{l}\text { 6-Cama e/ou travesseiros } \\
\text { inconfortáveis }\end{array}$ & $35(38,5)$ & $27(29,7)$ & $10(11)$ & $19(20,9)$ \\
\hline 7-Escutar o telefone tocar & $57(62,6)$ & $18(19,8)$ & $7(7,7)$ & $9(9,9)$ \\
\hline 8-Ser examinado por médicos e & $67(73,6)$ & $16(17,6)$ & $3(3,3)$ & $5(5,5)$ \\
\hline 9-Ter máquinas estranhas ao redor & $54(59,3)$ & $23(25,3)$ & $6(6,6)$ & $8(8,8)$ \\
\hline $\begin{array}{l}\text { 10-Sentir que a enfermagem esta } \\
\text { mais atenta aos equipamentos do }\end{array}$ & $57(62,6)$ & $17(18,7)$ & $7(7,7)$ & $10(11)$ \\
\hline $\begin{array}{l}\text { 11-Escutar o barulho e os alarmes } \\
\text { dos equipamentos }\end{array}$ & $45(49,5)$ & $26(28,6)$ & $8(8,8)$ & $12(13,2)$ \\
\hline $\begin{array}{l}\text { 12-Enfermagem e médicos falando } \\
\text { muito alto }\end{array}$ & $59(64,8)$ & $16(17,6)$ & $9(9,9)$ & $7(7,7)$ \\
\hline 13-Ter que usar oxigênio & $37(40,7)$ & $29(31,9)$ & $9(9,9)$ & $16(17,6)$ \\
\hline $\begin{array}{l}\text { 14-Sentir falta do marido ou da } \\
\text { esposa }\end{array}$ & $32(35,2)$ & $15(16,5)$ & $8(8,8)$ & $36(39,6)$ \\
\hline $\begin{array}{l}\text { 15-Não ter explicações sobre o } \\
\text { tratamento }\end{array}$ & $51(56)$ & $13(14,3)$ & $11(12,1)$ & $16(17,6)$ \\
\hline $\begin{array}{l}\text { 16-Escutar os alarmes do monitor } \\
\text { cardíaco despertarem }\end{array}$ & $44(48,4)$ & $22(24,2)$ & $14(15,4)$ & $11(12,1)$ \\
\hline $\begin{array}{l}\text { 17-Ter enfermagem constantemente } \\
\text { fazendo tarefas ao redor do leito }\end{array}$ & $62(68,1)$ & $21(23,1)$ & $3(3,3)$ & $5(5,5)$ \\
\hline 18-Ter tubos no nariz e/ou na boca & $18(19,8)$ & $23(25,3)$ & $12(13,2)$ & $38(41,8)$ \\
\hline 19-Não saber que horas são & $28(30,8)$ & $14(15,4)$ & $19(20,9)$ & $30(33)$ \\
\hline $\begin{array}{l}\text { 20-Escutar o gemido de outros } \\
\text { pacientes }\end{array}$ & $42(46,2)$ & $24(26,4)$ & $14(15,4)$ & $11(12,1)$ \\
\hline $\begin{array}{l}\text { 21-Ter homens e mulheres } \\
\text { internados no mesmo ambiente }\end{array}$ & $55(60,4)$ & $13(14,3)$ & $10(11)$ & $13(14,3)$ \\
\hline $\begin{array}{l}\text { 22- Ver a família e os amigos por } \\
\text { apenas alguns minutos }\end{array}$ & $33(36,3)$ & $18(19,8)$ & $18(19,8)$ & $22(24,2)$ \\
\hline $\begin{array}{l}\text { 23-Não saber quando as coisas vão } \\
\text { ser feitas }\end{array}$ & $36(39,6)$ & $25(27,5)$ & $12(13,2)$ & $18(19,8)$ \\
\hline 24-Ser acordado pela enfermagem & $51(56)$ & $25(27,5)$ & $7(7,7)$ & $8(8,8)$ \\
\hline 25-Sons e ruídos desconhecidos & $51(56)$ & $26(28,6)$ & $7(7,7)$ & $7(7,7)$ \\
\hline $\begin{array}{l}\text { 26-Assistir aos cuidados médicos e } \\
\text { de enfermagem realizados em } \\
\text { outros pacientes }\end{array}$ & $56(61,5)$ & $17(18,7)$ & $11(12,1)$ & $7(7,7)$ \\
\hline $\begin{array}{l}\text { 27-Ter que ficar olhando para os } \\
\text { detalhes do teto }\end{array}$ & $30(33)$ & $20(22)$ & $13(14,3)$ & $28(30,8)$ \\
\hline
\end{tabular}


Tabela 9 - Distribuição dos pacientes segundo as respostas aos itens da Escala de Estressores em Terapia Intensiva (ICUESS). Ribeirão Preto, 2007-2008 (continuação).

\begin{tabular}{|c|c|c|c|c|}
\hline \multirow[t]{2}{*}{ Itens da EETI* } & $\begin{array}{c}\text { Não } \\
\text { Estressante }\end{array}$ & $\begin{array}{c}\text { Pouco } \\
\text { Estressante }\end{array}$ & Estressante & $\begin{array}{c}\text { Muito } \\
\text { estressante }\end{array}$ \\
\hline & n (\%) & n (\%) & n (\%) & n (\%) \\
\hline 28-Não conseguir dormir & $15(16,5)$ & $12(13,2)$ & $21(23,1)$ & $43(47,3)$ \\
\hline $\begin{array}{l}\text { 29-Não conseguir mexer as mãos ou } \\
\text { os braços devido às vias } \\
\text { intravenosas }\end{array}$ & $18(19,8)$ & $22(24,2)$ & $20(22)$ & $31(34,1)$ \\
\hline 30-Sentir cheiros estranhos & $44(48,4)$ & $20(22)$ & $12(13,2)$ & $15(16,5)$ \\
\hline 31-Ter luzes acesas constantemente & $31(34,1)$ & $17(18,7)$ & $16(17,6)$ & $27(29,7)$ \\
\hline 32-Ter dor & $6(6,6)$ & $18(19,8)$ & $16(17,6)$ & $51(56)$ \\
\hline $\begin{array}{l}\text { 33-Ver as bolsas de soros } \\
\text { penduradas sobre a cabeça }\end{array}$ & $39(42,9)$ & $19(20,9)$ & $12(13,2)$ & $21(23,1)$ \\
\hline 34-Ser furado por agulhas & $28(30,8)$ & $23(25,3)$ & $11(12,1)$ & $29(31,9)$ \\
\hline 35-Não saber onde está & $25(27,5)$ & $20(22)$ & $11(12,1)$ & $35(38,5)$ \\
\hline $\begin{array}{l}\text { 36-Ter a equipe falando termos } \\
\text { incompreensíveis }\end{array}$ & $41(45,1)$ & $20(22)$ & $11(12,1)$ & $19(20,9)$ \\
\hline 37-Não ter controle de si mesmo & $37(40,7)$ & $19(20,9)$ & $7(7,7)$ & $28(30,8)$ \\
\hline $\begin{array}{l}\text { 38-Não saber que dia é hoje } \\
\text { 39-Ser incomodado }\end{array}$ & $\begin{array}{c}30(33) \\
46(50,5)\end{array}$ & $\begin{array}{l}14(15,4) \\
20(22)\end{array}$ & $\begin{array}{l}16(17,6) \\
12(13,2)\end{array}$ & $\begin{array}{l}31(34,1) \\
13(14,3)\end{array}$ \\
\hline 40-Não ter privacidade & $43(47,3)$ & $18(19,8)$ & $11(12,1)$ & $19(20,9)$ \\
\hline $\begin{array}{l}\text { 41-Ser cuidado por médicos } \\
\text { desconhecidos }\end{array}$ & $61(67)$ & $12(13,2)$ & $7(7,7)$ & $11(12,1)$ \\
\hline $\begin{array}{l}\text { 42-Estar num ambiente muito quente } \\
\text { ou muito frio }\end{array}$ & $41(45,1)$ & $18(19,8)$ & $14(15,4)$ & $18(19,8)$ \\
\hline
\end{tabular}

*ICUESS: Escala de Estressores em Terapia Intensiva.

Um dos nossos objetivos era analisar as possíveis diferenças entre os estressores percebidos no pós-operatório imediato e as variáveis sexo, idade, escolaridade dos pacientes e tempo de permanência na unidade de internação pós-operatória.

Com relação ao sexo, as mulheres apresentaram uma média de 92,4 (DP=29,7) e os homens de $83(\mathrm{DP}=27,2)$, para o valor total da escala de estressores. Os pacientes com menos de 40 anos obtiveram um valor médio menor $(M=89 ; D P=36,1)$, do que aqueles entre 41 e 59 anos ( $M=90,9 ; D P=27,2)$. Esses também pontuaram mais do que os pacientes idosos, cuja média foi de $84,5(\mathrm{DP}=29,3)$. No que se refere à escolaridade, os pacientes com menor escolaridade apresentaram média de $87,4(\mathrm{DP}=29,3)$ e os pacientes com segundo grau ou nível superior apresentaram uma média de 90,3 (DP= 
27,5). Nenhuma dessas diferenças nas medidas dos estressores no POI foi estatisticamente significativa quando comparamos os pacientes segundo o sexo ( $p=$ $0,11)$, a idade $(p=0,53)$ e a escolaridade $(p=0,65)$, assim como o teste de comparação da distribuição entre a medida de estressores e o tempo de permanência na UTI ( $p=$ 0,87). A maior média foi obtida entre os pacientes que permaneceram internados no local entre três a cinco dias $(\mathrm{M}=90 ; \mathrm{DP}=30,4)$ (Tabela 10).

Tabela 10 - Resultados dos testes de comparação da distribuição entre as medidas da Escala de Estressores em Terapia Intensiva com as variáveis: sexo, idade, escolaridade e tempo de permanência na UTI. Ribeirão Preto, 2007-2008.

\begin{tabular}{|c|c|c|c|}
\hline \multirow{2}{*}{ Variáveis } & \multicolumn{3}{|c|}{ Medidas de ICUESS total } \\
\hline & Média (DP) & Mediana & $p$ \\
\hline $\begin{array}{l}\text { Sexo } \\
\text { Masculino }(n=43) \\
\text { Feminino }(n=48\end{array}$ & $\begin{array}{l}92,4(29,7) \\
83(27,2)\end{array}$ & $\begin{array}{c}89,5 \\
77\end{array}$ & $0,11^{*}$ \\
\hline $\begin{array}{l}\text { Idade } \\
\text { Até } 40 \text { anos }(n=8) \\
\text { Entre } 40 \text { e } 59 \text { anos }(n=43) \\
\text { Acima de } 60 \text { anos }(n=40)\end{array}$ & $\begin{array}{c}89(36,1) \\
90,9(27,3) \\
84,6(29,4)\end{array}$ & $\begin{array}{l}86,5 \\
89,0 \\
76,5\end{array}$ & $0,53^{* *}$ \\
\hline $\begin{array}{l}\text { Escolaridade } \\
\text { Até nível fundamental }(n=74) \\
\text { Nível médio e superior }(n=17)\end{array}$ & $\begin{array}{l}87,4(29,3) \\
90,3(27,5)\end{array}$ & $\begin{array}{l}83,0 \\
87,0\end{array}$ & $0,65^{*}$ \\
\hline $\begin{array}{l}\text { Tempo de permanência na UTI } \\
\text { Menos de } 3 \text { dias }(n=70) \\
\text { De } 3 \text { a } 6 \text { dias }(n=19) \\
\text { Acima de } 6 \text { dias }(n=2)\end{array}$ & $\begin{array}{l}87,5(28,7) \\
90,4(30,4) \\
80,0(29,7)\end{array}$ & $\begin{array}{l}83,0 \\
89,0 \\
80,0\end{array}$ & $0,87^{* *}$ \\
\hline
\end{tabular}

* Teste de Mann-Whitney ; ** Teste de Kruskal-Wallis.

Após a cirurgia, no pós-operatório imediato, constatamos que todos os pacientes apresentaram algum tipo de intercorrência no período, sendo que as complicações mais freqüentes foram: dor $(84,6 \%)$, oligúria $(63,7 \%)$, hiperglicemia $(52,7 \%)$ e hipotensão $(50,5 \%)$. Tais complicações aumentam o tempo de permanência dos pacientes na UTI e podem influenciar às percepções dos estressores pelos pacientes estudados. 


\subsection{Relacionados à correlação entre as variáveis ansiedade, depressão e senso de coerência com o estresse percebido pelos pacientes no pós- operatório da cirurgia cardíaca.}

Para avaliar a relação das medidas de ansiedade, depressão e senso de coerência dos pacientes cardíacos, no período pré-operatório, com o estresse percebido no pós-operatório imediato, outro objetivo deste trabalho, fizemos a análise estatística utilizando o coeficiente de correlação de Spearman.

Constatamos que houve correlação positiva significativa de moderada magnitude entre a medidas de estressores e a medida de HAD-depressão $(r=0,307 ; p<0,05)$, bem como correlação de fraca magnitude e, portanto, de pouco significado clínico com a medida de HAD-ansiedade $(r=0,257 ; p<0,05)$. Foi constatada ainda correlação negativa de fraca magnitude entre a medida de estressores a de senso de Coerência $(r=-0,178$; $\mathrm{p}<0,05)$, como apresentado na Tabela 11.

Podemos observar que as correlações entre as medidas para ansiedade, depressão e estressores percebidos foram estatisticamente significativas.

Tabela 11 - Coeficientes de correlação de Spearman entre as medidas de SC (QSCA), ansiedade (HAD ansiedade) e depressão (HAD-depressão) e estressores (ICUESS). Ribeirão Preto, 2007-2008.

\begin{tabular}{|c|c|c|c|c|}
\hline Medidas & 1 & 2 & 3 & 4 \\
\hline 1- ICUESS* & 1,0 & $-0,178$ & $0,257^{\#}$ & $0,307^{\#}$ \\
\hline 2- QSCA ${ }^{\star *}$ & - & 1,0 & $-0,371^{\#}$ & $-0,516^{\#}$ \\
\hline 3- $H A D^{* \star *}$ ansiedade & - & - & 1,0 & $0,465^{\#}$ \\
\hline 4- HAD ${ }^{* * *}$ depressão & - & - & - & 1,0 \\
\hline
\end{tabular}




\section{DISCUSSÃO}

A finalidade de nosso estudo foi avaliar a ansiedade, a depressão e o senso de coerência dos pacientes submetidos à cirurgia cardíaca e relacionar essas variáveis com a percepção dos estressores durante a sua estadia na unidade pósoperatória.

O grupo estudado foi caracterizado por ser predominantemente feminino (52,7\%), com idade entre 41 e 59 anos (47,3\%), casado (62,6\%), possuir escolaridade em nível fundamental $(81,3 \%)$ e inativos $(61,5 \%)$.

$\mathrm{Na}$ avaliação da ansiedade obtivemos valor médio de 7,3 caracterizando os pacientes como não casos, de acordo com Zigmond e Snaith (1983). Resultados semelhantes foram obtidos por Davies (2000), que obteve uma média de 6,56, utilizando a HAD e categorizando os pacientes, em pré-operatório de cirurgias cardíacas, como não-casos. Outros autores também encontraram resultados que categorizavam os pacientes como não-casos de acordo com a HAD. No estudo de Gallagher et al (2007), os pacientes em pré-operatório de cirurgia de revascularização do miocárdio obtiveram média menor do que a obtida em nosso estudo ( $M=6,54 ; D P=4,54)$ e Harrison (2005) verificou, em seu estudo, que $75 \%$ dos pacientes em programa de reabilitação pós cirurgia cardíaca estavam incluídos nessa categoria.

Ao investigarmos possíveis associações entre a medida de ansiedade e o sexo, idade e escolaridade dos pacientes constatamos que pacientes do sexo feminino, na faixa dos 41 a 59 anos e com menor escolaridade apresentaram maiores escores na avaliação. Entretanto, essa associação só se mostrou 
estatisticamente significativa para a variável sexo. Alguns autores não encontraram diferenças significativas entre os sexos, quando avaliaram pacientes que estavam em lista de espera para revascularização do miocárdio (FITZSIMONS et al, 2003; BENGTSON et al, 2000) enquanto outros autores verificaram que as mulheres foram mais ansiosas do que os homens no perioperatório de cirurgias cardíacas (VINGERHOETS, 1998).

Com relação à associação entre ansiedade e a idade dos sujeitos, nossos resultados não foram estatisticamente significativos, corroborando com os resultados encontrados por Fitzsimons et al (2003) e Vingerhoets (1998).

Outra associação foi entre ansiedade e tempo de internação pré-operatória. Pacientes internados acima de oito dias apresentaram maiores valores na HADansiedade do que aqueles com menor tempo de internação, sendo a diferença entre os grupos estatisticamente significante. Esse resultado vai de encontro ao apresentado por Fitzsimons (2003) no qual os pacientes que esperavam pela cirurgia de revascularização miocárdica há mais tempo, em lista de espera, apresentaram um aumento nos níveis de ansiedade, porém não significativa.

Com relação à depressão o valor médio obtido foi de 5,2, categorizando os pacientes como não-casos de acordo com a HAD. No estudo de Harrison (2005) os pacientes também foram incluídos na categoria de não-casos por apresentarem, em sua maioria, pontuação menor do que oito. No entanto, eles já se encontravam em programas de reabilitação pós cirurgia cardíaca.

Os resultados do nosso estudo indicam que pacientes do sexo feminino apresentaram uma média maior do que os homens para depressão, resultados que corroboram com aqueles obtidos por outros investigadores (RYMASZEWSKA et al, 2003), ressaltando, ainda que os valores para depressão foram maiores do que para 
ansiedade nas mulheres. Pacientes do sexo feminino têm sido apontadas como mais depressivas do que os homens em outros estudos (MALLIK et al, 2005; PINTON et al, 2006).

Os participantes idosos, em nosso estudo, apresentaram um nível de depressão maior, resultado não compatível com os achados de alguns autores, que identificaram que quanto mais idosos eram os sujeitos, menor era o nível de depressão (BLUMENTHAL et al, 2003; MALLIK et al, 2005).

Com relação ao grau de escolaridade, os pacientes com nível maior apresentaram uma média menor para depressão, resultado não consistente com o estudo de Mallik et al (2005) quando avaliou pacientes que haviam sido submetidos a primeira revascularização miocárdica.

Quanto ao tempo de internação, os pacientes que apresentaram maiores níveis de depressão foram aqueles que estavam internados entre oito e 14 dias, entretanto essa diferença não foi estatisticamente significante. Não encontramos outros estudos que tenham investigado essa relação para compararmos com os resultados obtidos.

Neste estudo, houve uma correlação moderada entre as medidas de ansiedade e de depressão, sugerindo que pacientes mais ansiosos também se apresentaram mais deprimidos. Rymaszewska et al (2003) encontraram resultados que indicavam que o aumento nos níveis de ansiedade era interdependente com o aumento nos níveis de depressão. Essa associação também se manteve no perioperatório, como demonstra o estudo de Murphy et al (2008) no qual verificaram uma correlação entre ansiedade e depressão no período perioperatório de cirurgia de revascularização do miocárdio. 
A capacidade de enfrentamento aos problemas é outro fator que está diretamente ligado à recuperação dos pacientes após cirurgia cardíaca, pois a forma como o paciente nfrenta as situações estressantes pelas quais está passando poderá levar a um aumento no tempo de internação decorrente de complicações. Em nosso estudo, utilizamos o Questionário de Senso de Coerência de Antonovsky (QSCA) para avaliarmos o constructo senso de coerência que tem sido utilizado como uma medida de coping.

No grupo estudado, a média obtida para o SC foi de 155,6. Esse resultado foi maior do que a média obtida por outros autores em estudo brasileiro (DANTAS, 2007) e americano (DANTAS, MOTZER e CIOL, 2002), que abordaram, respectivamente, pacientes internados para tratamento clínico e pacientes com média de dois anos após cirurgia de revascularização do miocárdio.

Não houve diferença estatisticamente significante entre as médias do SC com relação ao sexo e à idade dos sujeitos, entretanto as mulheres apresentaram um valor menor para o SC do que os homens. Tal resultado vem ao encontro de estudos realizados tanto com pacientes cardíacos (DANTAS, 2007; KATTAINEN, 2006; KONTTINNEN, HAUKKALA e UUTELA, 2008; BERGMAN et al., 2009) quanto com outras populações de pacientes (CEDERFJALL et al., 2001). Os valores médios para homens e mulheres na população geral têm sido similares (VOLANEN, 2004).

Em nosso estudo, os pacientes mais idosos apresentaram uma média maior do que os mais novos, porém essa diferença não foi estatisticamente significativa. Esses achados são consistentes com os resultados encontrados por outros autores que observaram que o SC tende a aumentar com a idade (EKMAN, FAGERBERG, 
LUNDMAN, 2002), entretanto contradiz a idéia defendida por Antonovsky (1987) de que não há mudanças no SC após a sua completa formação, em torno dos 30 anos.

Os participantes com maior escolaridade apresentaram pontuação maior para o SC, porém não estatisticamente significante, corroborando com o achado de Konttinen, Haukkala e Uutela (2008) em uma pesquisa para identificar fatores de risco cardiovascular, realizada na Finlândia. No estudo de Volanen et al (2004), desenvolvido em população geral, os participantes com maior escolaridade também apresentaram maior SC.

Com relação ao tempo de internação no período pré-operatório e a associação com o SC, não encontramos estudos abordando essa relação.

Devido à influência que as variáveis ansiedade, depressão e senso de coerência podem ter sobre a recuperação dos pacientes submetidos à cirurgia cardíaca, as possíveis correlações entre elas também foram avaliadas. Essas correlações entre ansiedade, depressão e SC foram de moderada magnitude e negativas, ou seja, quanto maiores eram os valores para o senso de coerência, menores eram os valores para ansiedade e para depressão. Com relação à ansiedade, estudos com pacientes submetidos a outros tipos de cirurgia têm demonstrado que altos níveis de ansiedade foram obtidos entre pessoas com pontuações menores para o SC (BADURA-BRZOZA et al, 2009). No estudo de Eriksson, Lindstrom e Lilja (2008) a relação entre SC e depressão foi significante e negativa, como encontrado em nosso estudo. Konttinnen, Haukkala e Uutela (2008) verificaram que existe uma forte correlação entre depressão, ansiedade e senso de coerência, sendo que essa correlação é maior para depressão do que para ansiedade. Outros autores têm apresentado resultados semelhantes como, por exemplo, no estudo de Drory et al (2002) cujos autores identificaram uma correlação 
significante entre SC e bem-estar psicológico, mensurado pelo nível de depressão em pacientes cardiopatas que haviam sofrido o primeiro infarto agudo do miocárdio.

Outra variável de interesse em nosso estudo foi a percepção dos estressores na unidade pós-operatória. Para avaliar essa variável foi utilizada a Escala de Estressores em Unidade de Terapia Intensiva, com a qual pudemos observar que os pacientes entrevistados avaliaram a maioria dos itens da escala como tendo algum grau de estresse, sendo que os itens com maior média foram "ter dor" e "não conseguir dormir" e os dois itens menos estressantes foram "medir a pressão arterial muitas vezes ao dia" e "ser examinado por médicos e enfermeiros constantemente". Com relação ao item "ter dor", considerado mais estressante pelos participantes de nosso estudo, esse resultado é consistente com o estudo de Novaes et al (1999) no qual esse item foi avaliado como mais estressante tanto pelos pacientes quanto pelos familiares e pela equipe de trabalho. No estudo de Hweidi (2007), realizado em uma UTI geral, os participantes apontaram o mesmo item como sendo o segundo mais estressante. Em outro estudo os itens com maior pontuação foram "estar amarrado por tubos" e "não ter controle sobre si mesmo" (SO e CHAN, 2004). Observamos também que, em nosso estudo, as médias para os itens foram maiores do que no estudo de So e Chan (2004).

Os pacientes admitidos em uma UTI de cirurgia cardíaca estão expostos a muitos procedimentos invasivos para monitorização e diagnóstico que causam dor quando são realizados em si mesmos ou aumentam o estresse quando são realizados em outros pacientes e percebidos por eles.

No estudo de So e Chan (2004), no Japão, eles verificaram que as respostas mais comuns dos pacientes para os itens foram não estressantes e pouco estressantes, enquanto que as enfermeiras avaliaram os itens como estressante e 
muito estressante, demonstrando que a equipe muitas vezes superestima a percepção do próprio paciente.

Outros pesquisadores realizaram outro estudo no mesmo serviço de recuperação pós-cirurgia cardíaca, onde desenvolvemos a presente investigação. Eles constataram que os enfermeiros avaliaram os itens da escala como mais estressantes do que os pacientes do nosso estudo e que o item mais estressante para os profissionais era "estar amarrado por tubos" (GOIS e DANTAS, 2004).

O valor médio total para os 42 itens obtidos em nosso estudo $(87,9)$, bem como o valor médio para cada um dos 42 itens foi maior do que o apresentado por Marosti e Dantas (2006) quando avaliaram o estresse percebido pelos pacientes internados em uma unidade coronariana. Esses resultados sugerem que os pacientes internados na unidade pós-operatória estão expostos a mais eventos geradores de estresse devido às particularidades da própria unidade, como procedimentos e equipamentos.

As mulheres apresentaram uma média menor para as medidas de estressores do que os homens, apesar dessa diferença não ser estatisticamente significativa. No estudo de Hweidi (2007) em uma UTI geral e no estudo de Marosti e Dantas (2006) em uma UTI coronariana os resultados demonstraram também maior média para as mulheres.

Com relação à idade, os pacientes mais idosos tiveram uma percepção menor dos estressores na unidade pós-operatória, porém não estatisticamente significante. Entretanto a menor média encontrada não foi na população mais jovem (menos de 40 anos) e sim na população de meia idade (entre 41 e 59 anos). A associação entre idade e estressores em terapia intensiva tem se mostrado controversa. Por exemplo, no estudo de Marosti e Dantas (2006), a percepção dos estressores foi maior nos 
pacientes mais jovens enquanto no de Hweidi (2007), os resultados obtidos demonstraram que quanto maior era a idade dos pacientes, maior era a percepção dos estressores.

Para os pacientes com maior nível de escolaridade a percepção dos estressores na unidade pós-operatória foi maior, resultados que contradizem aqueles encontrados no estudo de Hweidi (2007). O resultado do nosso estudo pode ser explicado pela maior compreensão das informações detalhadas sobre a cirurgia e o período de internação na unidade pós-operatória que os pacientes recebem no pré-operatório e que são vivenciadas após a cirurgia.

Os pacientes com mais dias de internação na UTI, acima de seis dias, tiveram uma pontuação menor para os estressores. Na literatura estudada, não encontramos a avaliação da associação entre essas duas variáveis. Entretanto, no estudo de Novaes; Romano e Lage (1996) os pacientes apresentaram uma diminuição nos níveis de ansiedade após o segundo ou terceiro dias de internação na UTI. Esses achados podem sugerir que houve uma diminuição na percepção dos estressores quando os pacientes se familiarizaram com o ambiente e com a equipe.

Avaliar a correlação entre as medidas de ICUESS com as medidas de ansiedade e depressão e senso de coerência foi um dos objetivos do nosso trabalho. Essa correlação foi de moderada magnitude e positiva, indicando que a percepção dos estressores é maior quanto maiores são os níveis de ansiedade e depressão. Esses achados vão de encontro aos do estudo de Samuelson et al (2007) no qual foram avaliadas as memórias de pacientes dois meses após a alta de uma internação em UTI. Os autores verificaram que os pacientes que apresentavam maiores valores para ansiedade e depressão também apresentavam maiores valores para estresse pós-traumático. 
A correlação entre estressores e SC apesar de negativa, foi baixa, demonstrando que quanto maior o senso de coerência menor a percepção dos estressores, entretanto não encontramos estudos na literatura que abordassem esse tema com pacientes cardíacos. Esses resultados sugerem que o senso de coerência tem menor influência sobre a percepção dos estressores em UTI do que a ansiedade e a depressão, no grupo estudado. 


\section{CONCLUSÕES}

Os resultados deste estudo nos permitem constatar que entre os participantes, no período pré-operatório:

- Houve correlação positiva e moderada entre as medidas de ansiedade e depressão; negativa e moderada entre ansiedade e senso de coerência e negativa e de forte magnitude entre depressão e senso de coerência;

- As medidas de ansiedade apresentaram diferenças estatisticamente significativas quando consideramos o sexo, a escolaridade e o tempo de internação préoperatório. Pacientes do sexo feminino, com menor escolaridade e tempo de internação acima de sete dias tiveram maiores valores na HAD-ansiedade (maior ansiedade);

- Constatamos associação entre as medidas de depressão e escolaridade e entre senso de coerência e sexo. Pacientes com menor escolaridade tiveram maior pontuação na HAD-depressão enquanto os homens tiveram maiores pontuações na avaliação do senso de coerência;

No pós-operatório, a medida dos estressores percebidos na unidade de terapia intensiva teve correlação moderada e positiva com a medida de ansiedade. Não constatamos correlações clinicamente importantes ente a medida de estressores e a avaliação de depressão e senso de coerência realizada no préoperatório. 


\section{CONSIDERAÇÕES FINAIS}

Nosso estudo tem algumas limitações, como, por exemplo, o número reduzido de sujeitos e o curto espaço de tempo para a coleta de dados. Acreditamos que uma amostra maior poderia levar a uma diferença mais significativa e confirmação de nossos questionamentos entre as variáveis investigadas.

Embora a maioria das correlações, em nosso estudo, não tenha apresentado significância estatística, elas existem e demonstram a importância da assistência de qualidade aos pacientes frente a uma cirurgia cardíaca e do conhecimento dos sentimentos e preocupações daqueles que estão sob nossos cuidados para que possamos atuar na orientação e minimizar a ansiedade, a depressão e o estresse no período perioperatório dessas cirurgias.

Trabalhos futuros sobre uma abordagem mais humanizada, com orientação sistematizada no período pré-operatório e humanização do ambiente na UTI, poderiam ser de grande ajuda na assistência a esses pacientes. 


\section{REFERÊNCIAS BIBLIOGRÁFICAS}

AIUB, A. L. C.; WIEHE, M. H.; ROTERT, R.; BARRAZ, A. C. G.; RUSCHEL, P. P. Ansiedade em pacientes cardíacos pré-cirúrgicos. Revista Sociedade Cardiologia Estado São Paulo, São Paulo, v. 5, n. 6, (supl. A), p. 6-8, Nov-Dez. 1995.

AJZEN, I.; FISHBEIN, M. Understanding attitudes and predicting social behavior, 1980.

ANDRADE, L. H. S. G.; GORESTEIN, C. Aspectos gerais das escalas de avaliação de ansiedade. Revista de Psiquiatria Clínica, São Paulo, v. 6, n. 25, Nov.-Dez. 1998. Edição especial.

ANDREATINI, R.; LEITE, J. R. IDATE-traço: adaptação para avaliação da ansiedade durante sete dias. Jornal Brasileiro de Psiquiatria, v. 43, n. 5, p. 25965, 1994.

ANTONOVSKY, A. Unraveling the mystery of health. São Franscisco: JosseyBass. 1987.

BADURA-BRZOZA, K.; ZAJAC, P.; BRZOZA, Z.; KASPERSKA-ZAJAC, A.; MATYSIAKIEWICZ, J.; PIEQZA, M.; HESE, R. T.; ROGALA, B.; SEMENOWICZ, J.; KOCZY, B. Psychological and psychiatric factors related to health-related quality of life after total hip replacement - preliminary report. European Psychiatry, v. 24, n. 2, p. 119-124, Mar. 2009.

BAIGI, A.; HILDINGH, C.; VIRDHALL, H.; FRIDLUND, B. Sense of coherence as well as social support and network as perceived by patients with a suspected or manifest myocardial infarction: a short-term follow-up study. Clinical Rehabilitation, v. 22, p. 646-652, Inglaterra, 2008.

BAKER, R. A.; ANDREW, M. J.; SCHRADER, G.; KNIGHT, J. L. Preoperative depression and mortality in coronary artery bypass surgery: preliminary findings. ANZ Journal Surgery, Australia, v. 3, n.71, p.139-42. Mar. 2001.

BALLARD, K. S. Identification of environmental stressors for patients in a surgical intensive care unit. Issues in Mental Health Nursing, v. 1, n. 3, p. 89-108, 1981. 
BECK, A. T.; WARD, C. H.; MENDELSON, M.; MOCK, J.; ERBAUGH, J. An inventory for measuring depression. Archives of General Psychiatry, USA, n. 4, p. 561-71, Jun. 1961.

BENGTSON, A.; HERLITZ, J.; KARLSSON, T.; HJALMARSON, A. Distress correlates with the degree of chest pain: a description of patients awaiting revascularisation. Heart, Inglaterra, v. 3, n. 75p. 257-260, Mar. 1996.

BENGTSON, A.; KARLSSON, T.; HERLITZ, J. Differences between men and women on the waiting list for coronary revascularization. Journal of Advanced Nursing, Inglaterra, v. 6, n. 31, p. 1361-1367, Jun. 2000.

BERGMAN, E.; MALM, D.; KARLSSON, J-E.; BERTERÖ, C. Longitudinal study of patients after myocardial infarction: Sense of coherence, quality of life, and symptoms. Heart Lung, v. 38, n. 2, p. 129-140, Mar. 2009.

BLACK, J. M.; MATASSARIN-JACOBS, E. LUCKMANN \& SORENSEN Enfermagem médico-cirúrgica : uma abordagem psicofisiológica. Tradução de Carlos Henrique de Araújo Cosendey et al. v. 2, 4${ }^{a}$ edição, editora Guanabara Koogan, Rio de Janeiro, 1996.

BLUMENTHAL, J. A.; LETT, H. S.; BABYAK, M. A.; WHITE, W.; SMITH, P. K.; MARK, D. B.; JONES, R.; MATHEW, J. P.; NEWMAN, M. F.; NORG Investigators. Depression as a risk factor for mortality after coronary artery bypass surgery. Lancet, Inglaterra, v. 9384, n. 362, p. 604-609, Ago. 2003.

BOJAR, R. M. Manual of perioeperative care in cardiac surgery. Blackwell Science, 1999. 624 p.

BOTEGA, N. J.; PONDÉ, M. P.; MEDEIROS, P.; LIMA, M. G.; GUERREIRO, C. A. M. Validacäo da escala hospitalar de ansiedade e depressäo (HAD) em pacientes epiléticos ambulatoriais. Jornal Brasileiro de Psiquiatria, Rio de Janeiro, v. 6, n. 47, p. 285-289, Jun. 1998.

BOUDREZ, H.; DE BACKER, G. Psychological status and the role of coping style after coronary artery bypass graft surgery. Results of a prospective study. Quality of Life Research. Holanda, v. 1, n. 10, p. 37-47, 2001. 
BOWLING, A.; EBRAHIM, S. Handbook of health research methods: investigation, measurement and analysis. Maidenhead, England, Open University Press, 2005. $625 \mathrm{p}$

BRAILE, D. M.; GODOY, M.F. História da cirurgia cardíaca. Arquivos Brasileiros de Cardiologia, v. 66, n. 6, p. 329-370, 1996.

BRICK, A. V.; BRAILE, D. S. R. S.; BRAILE, D. M.; BUFFOLO, E.; LUCCHESE, F. A.; SILVA, F. P. V.; BRANCO, J. N.; LOBO FILHO, BUFFOLO, E.; LUCCHESE, F. A.; SILVA, F. P. V.; BRANCO, J. N.; LOBO FILHO, J. G.; MENDONÇA, J. T.; WANDERLEY NETO, J.; GUIMÃS, J. A. N.; MARANHÃO, M. V. M.; MARIA DO SOCORRO DUARTE LEITE; MARIO GESTEIRA COSTA; MAURÍLIO ONOFRE DEININGER; MAURO BARBOSA ARRUDA MAURO ARRUDA FILHO; MOZART AUGUSTO SOARES DE ESCOBAR; NILSON AUGUSTO MENDES RIBEIRO; PAULO SLUD BROFMAN; PEDRO RAFAEL SALERNO; SÉRGIO TAVARES MONTENEGRO. Diretrizes da cirúrgia de revascularização miocárdica valvopatias e doenças da aorta. Arquivos Brasileiros de Cardiologia, vol.82, suppl. 5, p.1-20, Mar. 2004.

BRUSCIA, K.; SHULTIS, C.; DENNERY, K.; DILEO, C. The sense of coherence in hospitalized cardiac and cancer patients. Journal of Holistic Nursing, v. 20, n. 10, p. 1-8, USA, 2008.

BURG, M. M.; BENEDETTO, M. C.; SOUFER, R. Depressive symptoms and mortality two years after coronary artery bypass graft surgery (CABG) in men. Psychosomatic Medicine, USA, v. 4, n. 65, p. 508-510, Jul-Ago. 2003.

BURKER, E. J.; BLUMENTHAL, J. A.; FELDMAN, M.; BURNETT, R.; WHITE, W.; SMITH, L. R.; CROUGHWELL, N.; SCHELL, R.; NEWMAN, M.; REVES, J. G. Depression in male and female patients undergoing cardiac surgery. British Journal of Clinical Psychology, Inglaterra, n. 34, p. 119-128, Fev. 1995.

CEDERFJALL, C.; LANGIUS-EKLOF, A.; LIDMAN, K.; WREDLING, R. Gender differences in perceived health-related quality of life among patients with HIV infection. AIDS Patient Care, v. 15, n. 1, p. 31-39, 2001.

CONNERNEY, I.; SHAPIRO, P. A.; MCLAUGHLIN, J. S.; BAGIELLA, E.; SLOAN, R. $P$. Relation between depression after coronary artery bypass surgery and 12-month outcome: a prospective study. Lancet, Inglaterra, v. 9295, n. 358, p. 1766-1771, Nov. 2001. 
CORRÊA, A. K.; SALES, C. A.; SOARES, L. A família do paciente internado em terapia intensiva: concepções do enfermeiro. Acta Scientiarum. Maringá, v. 4, n. 3, p. 811-818, 2002.

COSTA, I. A. História da cirurgia cardíaca brasileira. Revista Brasileira de Cirurgia Cardiovascular, São José do Rio Preto, v. 13 n. 1, Jan-Mar. 1998.

DALGALARRONDO, P. Psicopatologia e Semiologia dos Transtornos Mentais. Porto Alegre, Artes Médicas, 2000. 257 p.

DANTAS, R. A. S. Adaptação cultural e validação do Questionário de Senso de Coerência de Antonovsky em uma amostra de pacientes cardíacos brasileiros. 2007, 183p. Tese de Livre-Docência, Escola de Enfermagem de Ribeirão Preto, Universidade de São Paulo, Ribeirão Preto, 2007.

DANTAS, R. A. S.; MOTZER, S. A.; CIOL, M. A. The relationship between quality of life, sense of coherence and self-esteem in persons after coronary artery bypass graft surgery. International Journal of Nursing Studies, v. 39, USA, p.745-755, 2002.

DAVIES, N. Patients' and carers' perceptions of factors influencing recovery after cardiac surgery. Journal of Advanced Nursing, v. 32, n. 2, p. 318-326, 2000.

DRORY, Y.; KRAVETZ, S.; HIRSCHBERGER, G.; ISRAELI STUDY GROUP ON FIRST ACUTE MYOCARDICAL INFARCTION. Long-term mental health of men after a first acute myocardial infarction. Archives of Phisical Medicine and Rehabilitation, v. 83, n. 3, p. 352-359, Mar. 2002.

DUITS, A. A.; DUIVENVOORDEN, H. J.; BOEKE, S.; TAAMS, M. A.; MOCHTAR, B.; KRAUSS, X. H.; PASSCHIER, J.; ERDMAN, R. A. The course of anxiety and depression in patients undergoing coronary artery bypass graft surgery. Journal of Psychosomatic Research, Inglaterra, v. 2, n. 45, p. 127-138, Ago. 1998.

A structural modeling analysis of anxiety and depression in patients undergoing coronary artery bypass graft surgery: a model generating approach. Journal of Psychosomatic Research, Inglaterra, v. 2, n. 46, p. 187-200, Fev. 1999.

EKMAN, I.; FAGERBERG, B.; LUNDMAN, B. Health-related quality of life and sense of coherence among elderly patients with severe chronic heart failure in comparison with healthy controls. Heart Lung, v. 31, p. 94-101, 2002. 
ERIKSSON, M.; LINDSTROM, B. Validity of Antonovsky's sense of coherence scale: a systematic review. Journal of Epidemiology Community Health, v. 59, n. 6, p. 460-466, Jun. 2007.

FINKELMEIER, B. A. Valvular heart disease. In: FINKELMEIER, B. A. Cardiothoracic surgical nursing. Pennsylvania, Ed. J. B. Lippincott Company. Cap. 2 (p. 21-31).

FITZSIMONS, D.; PARAHOO, K.; RICHARDSON, S. G.; STRINGER, M. Patient anxiety while on a waiting list for coronary artery bypass surgery: a qualitative an quantitative analysis. Heart Lung, USA, v. 1, n. 32, p. 23-31, Jan-Fev. 2003.

FRÁGUAS JÚNIOR, R.; ALVES, T.C.T.F. Depressão no Hospital Geral: estudo de 136 casos. Revista Associação Médica Brasileira, v. 48, n.3, Set. 2002.

GALLAGHER, R.; MCKINLEY, S. Surgery stressors and anxiety in patients undergoing coronary artery bypass. American Journal of Critical Care, v. 16, p. 248-257, 2007.

GOIS, C.F.L.; DANTAS, R.A.S. Estressores em uma unidade pós-operatória de cirurgia torácica: avaliação da enfermagem. Revista Latino-Americana Enfermagem, v.12, n.1, p.22-27, Fev. 2004.

GOMES, L.C.; FRAGA, M. DE N. DE O. Doenças, Hospitalização e Ansiedade: uma abordagem em saúde mental. Revista Brasileira de Enfermagem, Brasília, v. 50, n. 3, p. 425-40. 1997.

GORESTEIN, C.; ANDRADE, L. Inventário de Depressão de Beck: propriedades psicométricas da versão em português. Revista Psiquiatria Clínica. V. 5, n. 5, p. 245-250, 1998.

GORENSTEIN, C.; ANDRADE, L. H. S. G.; ZUARDI, A. W. Escalas de avaliação clínica em psiquiatria e psicofarmacologia. Lemos, São Paulo, 2000. 438 p.

GRAP, M. J.; SAVAGE, L.; BALL, G. B. The incidence of gastrointestinal symptoms in cardiac surgery patients through six weeks after discharge. Heart Lung, USA, , v. 6, n. 25p. 444-450, Nov-Dez. 1996. 
GUIRARDELLO, E. B.; ROMERO-GABRIEL, C. A. A.; PEREIRA, I. C.; MIRANDA, A. F. A percepção do paciente sobre sua permanência na unidade de terapia intensiva. Revista da Escola de Enfermagem, São Paulo, v. 33, p. 123-129, 1999.

HALLAS, C. N.; THORNTON, E. W.; FABRI, B. M ; FOX, M. A.; JACKSON, M. Predicting blood pressure reactivity and heart rate variability from mood state following coronary artery bypass surgery. International Journal of Psychophysiology, USA, v. 1, n. 47, p. 43-55, Jan. 2003.

HAMILTON, M. A rating scale for depression. Journal of Neurology, Neurosurgery and Psychiatric, USA, n. 23, p. 56-62. 1960.

. The assessment of anxiety states by rating. The British Journal of Medical Psychology, n. 32, p. 50-55, 1959.

HWEIDI, I.M. Jordanian patients' perception of stressors in critical care units: A questionnaire survey. International Journal of Nursing Studies, v. 44, p. 227-235, 2007.

HARRISON, R. Psychological assessment during cardiac rehabilitation. Nursing Standard, Inglaterra, v. 27, n. 19, p. 33-36, Mar. 2005.

HOUAISS, A.; VILLAR, M. S.; FRANCO, F. M. Dicionário da Língua Portuguesa. Rio de Janeiro, 1를 edição, 2001, p 1264.

JONSDOTTIR, H.; BALDUSDOTTIR, L. The experience of people awaiting coronary artery bypass graft surgery: the Icelandic experience. Journal of Advanced Nursing, Inglaterra, v. 27, n. 1, p. 68-74, Jan. 1998.

KARLSSON, I.; BERGLIN, E.; PETTERSSON, G.; LARSSON, P. A. Predictors of chest pain after coronary artery bypass grafting. Scandinavian Cardiovascular Journal, n. 33, p. 289-294. 1999.

KATTAINEN, E.; MERILANINEN, P.; SINTONEN, H. Sense of Coherence and health-related quality of life among patients undergoing coronary artery bypass grafting or angioplasty. European Journal of Cardiovascular Nursing, v. 5, n. 1, p. 21-30, Mar. 2006. 
KOIVULA, M.; TARKKA, M. T.; TARKKA, M.; LAIPPALA, P.; PAUNONEN-ILMONEN, M. Fear and anxiety in patients at different time-points in the coronary artery bypass process. International Journal of Nursing Studies, Inglaterra, v. 8, n. 39, p. 811822, Nov. 2002.

KONTINNEN, H.; HAUKKALA, A.; UUTELA, A. Comparing sense of coherence, depressive symptoms and anxiety, and their relationships with health ina populationbased study. Social Science \& Medicine, v. 66, p. 2401-2412, Finlandia, 2008.

KIYOHARA, L.Y., KAYANO L. K., OLIVEIRA, L.M., YAMAMOTO, M. U., INAGAKI, M. M., OGAWA, N. Y., GONZALES, P. E. S. M., MANDELBAUM, R., OKUBO, S. T., WATANUKI, T., VIEIRA, J. E. Surgery information reduces anxiety in the preoperative period. Revista Hospital das Clínicas Faculdade Medicina Universidade São Paulo, v. 59, n. 2, p. 51-56, 2004.

LAMOSA, B. W. R.; QUADROS, C. S. O.; ZAMBON, E. Ansiedade em cardiopatas cirúrgicos: um estudo da variação do pré e pós-operatório. RBM Cardiologia, Brasil, v. 2, n. 4, p. 63-68, Abr. 1985.

LARAIA, M. T. Psicofarmacologia. IN: Stuart GW, Laraia MT. Enfermagem Psiquiátrica: Princípios e prática. Porto Alegre: Artmed. 6 ed., 2001. Cap, 27. p. 607-639.

LEMOS, R. C. A.; ROSSI, L. A. O significado cultural atribuído ao centro de terapia intensiva por clientes e seus familiares: um elo entre a beira do abismo e a liberdade. Revista Latino-Americana Enfermagem, Ribeirão Preto, v.10, n. 3, p. 345-357, Jun. 2002.

LINDAL, E.; HARTHARSON, P.; MAGNUSSON, J.; ALFRETHSSON, H. A 5-year psycho-medical follow-up study of coronaru by-pass artery graft patients. Scandinavian Journal of Rehabilitation Medicine, Suecia, v. 1, n. 28, p. 27-31, Mar. 1996.

LOBO FILHO, J.G.; LEITÃO, M. C. A.; LOBO FILHO, H. G.; SOARES, J. P. H.; MAGALHÃES, G. A.; LEÃO FILHO, C. S. C.; FEITOSA, J.A.; OLIVEIRA, F. M.; LAVOR, A.; SOARES FILHO, O.; BORGES, E.; ABREU, J. S.; DIÓGENES, T. C. P.; BARRETO, J. E. F.; PAES JUNIOR, J. N. Cirurgia de revascularização coronariana esquerda sem CEC e sem manuseio da aorta em pacientes acima de 75 anos: Análise das mortalidades imediata e a médio prazo e das complicações neurológicas no pós-operatório imediato. Revista Brasileira Cirurgia Cardiovascular, v. 17, n. 3 , p. 208-214, 2002. 
LYNN-MCHALE, D.; CORSETTI, A.; BRADY-AVIS, E.; SHAFFER, R.; MCGROY, J.; ROTHENBERGER, C. Preoperative ICU tours: are they helpful? American Journal Critical Care, USA, v. 2, n. 6, p. 106-115, Mar. 1997.

MAJ, M.; SARTORIUS, N. Transtornos depressivos. Tradução Claudia Dornelles. Porto alegre: Artmed, 2005. 392 p.

MALLIK, S.; KRUMHOLZ, H. M.; LIN, O.; KASL, S. V.; MATTERA, J. A.; ROUMAINS, S. A.; VACCARINO, V. Coronary artery bypass surgery patients with depressive symptoms have lower health status benefits after. Circulation, v. 111, p. 271-277, Jan. 2005.

MAROSTI, C.A.; DANTAS, R.A.S. Relation between stressors and sociodemographic and clinical characteristics of patients hospitalized at a coronary unit. Revista LatinoAmericana Enfermagem, Ribeirão Preto, v.14, n.5, p.713-719, Oct. 2006.

MATTOS, M. A.; LOUGON, M.; TURA, B. R.; PEREIRA, B. B. Depressão e síndrome isquêmica coronariana aguda. Revista da SOCERJ, Rio de Janeiro, vol. 18, n. 4, p. 288-294, Jul-Ago. 2005.

MITCHELL, R. H.; ROBERTSON, E.; HARVEY, P. J.; NOLAN, R.; RODIN, G.; ROMANS, S. ; ABRAMSON, B. L.; BRISTER, S. J.; IVANOV, J.; STEWART, D. E. Sex differences in depression after coronary artery bypass graft surgery. American Heart Journal, USA, v. 5, n. 150, p. 1017-1025, Nov. 2005.

MOONS, P.; NOREKVAL, T. M. Is sense of coherence a pathway for improving the quality of life of patients who grow up with chronic diseases? A hypothesis. European Journal of Cardiovascular Nursing, v. 5, p. 16-20, 2006.

MURPHY, B. M.; ELLIOTT, P.C.; HIGGINS, R. O.; LE GRANDE, M. R.; WORCESTER, > U. C.; GOBLE, A. J.; TATOULIS, J. Anxiety and depression after coronary artery bypass graft surgery: most get better, some get worse. European Journal Cardiovascular Prevention and Rehabilitation, v. 15, p. 434-440, 2008.

NARDI, A.E. Comentários do debatedor: escalas de avaliação de ansiedade. Revista Psiquiatria Clinica. v. 6, n. 25, p. 331-333, 1998. Edição Especial.

NELSON, F. V.; ZIMMERMAN, L.; BARNASON, S.; NIEVEEN, J.; SCHMADERER, $M$. The relationship and influence of anxiety on postoperative pain in the coronary 
artery bypass graft patient. Journal of Pain and Symptom Management, USA, v. 15, n. 2, p. 102-109, Fev. 1998.

NOVAES, M. A. F.; ROMANO, B. W.; LAGE, S. G. Internação em UTI. Variáveis que Interferem na Resposta Emocional, Arquivos Brasileiros de Cardiologia, São Paulo, v. 2, n.67, 1996.

NOVAES, M. A.; ARONOVICH, A.; FERRAZ, M.; KNOBEL, E. Stressors in ICU: patients' evaluation. Intensive Care Medicine, v. 23, 1282-1285, 1997.

NOVAES, M. A.; KNOBEL, E.; BORK, A. M. Estressores em UTI: Percepção do paciente, família e equipe de saúde. Intensive Care Medicine, v. 25, p.1421-1426, Dec. 1999.

ORGANIZAÇÃO MUNDIAL DA SAÚDE. CID-10: classificação estatística internacional de doenças e problemas relacionados à saúde, Ed. 8, EDUSP, 2000.

PASQUALI, L. Instrumentos psicológicos: Manual prático de elaboração. 1. ed, Brasília, DF: LabPAM/IBAPP, 1999. v. 1. 306 p.

PENICHE, A. C. G. A influência da ansiedade na resposta do paciente no período pós-operatório imediato. 1998. $81 \mathrm{f}$. Tese (Doutorado). Escola de Enfermagem, Universidade de São Paulo, São Paulo, 1998.

PEREIRA, A. A. M. Efeitos psicológicos do prolongamento do tempo de espera para cirurgia cardíaca. Revista Sociedade de Cardiologia Estado de São Paulo, São Paulo, v. 12 (supl.5), p. 1-9, Set.-Out. 2002.

PINTON, F. A.; CARVALHO, C. F.; MIYAZAKI, M. C. O. S.; GODOY, M. F. Depressão como fator de risco de morbidade imediata e tardia pós-revascularização cirúrgica do miocárdio. Revista Brasileira de Cirurgia Cardiovascular, v. 21, n. 1, p. 68-74, 2006.

PIRRAGLIA, P. A.; PETERSON, J. C.; WILLIAMS-RUSSO, P.; GORKIN, L.; CHARLSON, M. E. Depressive symptomatology in coronary artery bypass graft surgery patients. International Journal of Geriatric Psychiatry, Inglaterra, n. 14, vol. 8, p. 668-680, Ago. 1999. 
POLIT, D. F.; BECK, C. T.; HUNGLER, B. P. Fundamentos de pesquisa em enfermagem: métodos, avaliação e utilização. Tradução Ana Thorell. Porto Alegre Artmed, 2004. $487 \mathrm{p}$.

PRATES, P. R. Pequena história da cirurgia cardíaca: e tudo aconteceu diante de nossos olhos... Revista Brasileira Cirurgia Cardiovascular, v. 14, n. 3, p. 177-184, 1999.

RIBEIRO, A. S.; RENGEL, D. H. P. Estudo comparativo sobre a ansiedade frente a cirurgia cardíaca entre paciente coronarianos e valvopatas. Revista Sociedade Cardiologia Estado de Säo Paulo, São Paulo, n. 2, supl. 1, p. 9-12. Jan.-Fev, 1992.

ROTHENHAUSLER, H. B.; GRIESER, B.; NOLLERT, B.; REICHART, B.; SCHELLING, G.; KAPFHAMMER, H. P. Psychiatric and psychosocial outcome of cardiac surgery with cardiopulmonary bypass: a prospective 12-month follow-up study. General Hospital Psychiatry, USA, v. 27, n. 1, p. 18-28, Jan-Feb. 2005.

RYMASZEWSKA, J.; KIEJNA, A.; HADRYS, T. Depression and anxiety in coronary artery bypass grafting patients. European Psychiatry, França, v. 4, n. 18, p. 155160, Jun. 2003.

SAMUELSON, K. A.; LUNDBERG, D.; FRIDLUND, B. Stressful memories and psychological distress in adult mechanically ventilated intensive care patients - a 2month follow-up study. Acta Anaesthesiologica Scandinavica, v. 51, n. 6, p. 671678, Jul. 2007.

SCHELLING, G.; RICHTER, M.; ROOSENDAAL, B.; ROTHENHÄUSLER, H.B.; KRAUSENECK, T.; STOLL, C.; NOLLERT, G.; SCHIMIDT, M.; KAPFHAMMER, H.P. Exposure to high stress in the intensive care unit may have negative effects on health-related quality-of-life outcomes after cardiac surgery. Critical Care Medicine, v. 31, n. 7, p. $1971-1980,2003$

SELYE, H. The stress of life. Nova York: McGraw-Hill. 1956.

SILBERT, B. S.; SANTAMARIA, J. D.; KELLY, W. J.; O’BRIEN J. L.; BLYTH, C. M.; WONG, M. Y.; ALLEN, N. B.; FAST TRACK CARDIAC CARE TEAM. Early extubation after cardiac surgery: emotional status in the early postoperative period. Journal Cardiothoracic and Vascular Anesthesia, v. 15, n. 4, p. 439-444, Aug. 2001. 
SO, H. M.; CHAN, D. S. K. Perception of stressors by patients and nurses of critical care units in Hong Kong. International Journal of Nursing Studies, v. 41, p. 77-84, 2004.

SPIELBERGER, C. D.; GORSUCH, R. L.; LUSHENE, R. E. State-Trait Anxiety Inventory manual. Palo Alto: Consulting Psychologists Press, 1970.

Inventário de ansiedade traço-estado. Tradução: A. M. B. Biaggio; L. Natalicio. Rio de Janeiro: CEPA, 1979.

SPIELBERGER, C. D. Tensão e ansiedade. São Paulo: Harper \& Row do Brasil, 1981. $128 \mathrm{p}$.

SULLIVAN, G.C. Towards clarification of convergent concepts: sense of coherence, will to meaning, locus of control, learned helplessness and hardiness. Journal of Advanced Nursing, v. 18, 1772-1778, 1993.

TIMBERLAKE, N.; KLINGER, L.; SMITH, P.; VENN, G.; TREASURE, T.; HARRISON, M.; NEWMAN, S. P. Incidence and patterns of depression following coronary artery bypass graft surgery. Journal of Psychosomatic Research, Inglaterra, v. 2, n. 43, p. 197-207, Ago. 1997.

TSUSHIMA, W. T.; JOHNSON, D. B.; LEE, J. D.; MATSUKAWA, J. M.; FAST, K. M.S. Depression, anxiety and neuropsychological test scores of candidates for coronary artery bypass graft surgery. Archives of Clinical Neuropsychology, v. 20 p. 667-673, 2005.

VALLE, E. G.; GUEDES, M. V. C.; ALBUQUERQUE, M. T. Pós-operatório de cirurgia cardíaca: o que pensam e verbalizam os pacientes. Revista Brasileira de Enfermagem, Brasília, vol. 1, n. 43, 2, p. 79-84, Jan-Dez. 1990.

VINGERHOETS, G. Perioperative anxiety and depression in open-heart surgery. Psychosomatics, USA, vol. 1, n. 39, p. 30-37, Jan-Fev. 1998.

VOLANEN, S.M.; SUOMINEN, S.; LAHELMA, E.; KOSKENVUO, M.; SILVENTOINEN, K. Negative life events and stability of sense of coherence: a fiveyear follow-up study of Finnish women and men. Scandinavian Journal of Psychology, v. 48, p. 433-441, 2007. 
WOLFF, A.C., RATNER, P.A. Stress, Social Support and Sense of Coherence. West Journal of Nursing Research, v. 21, n. 2, p. 182-197, 1999.

WOODS, S.L., FROELICHER, E.S.S., MOTZER, S.U. Enfermagem em Cardiologia. Tradução: Shizuka Ishii. São Paulo: Manole, 2005. 1077 p.

ZIGMOND, A. S.; SNAITH, R. P. The hospital anxiety and depression scale. Acta Psychiatrica Scandinavica, n. 67, p. 361-370, 1983. 


\section{APÊNDICES}

\section{APÊNDICE A \\ HOSPITAL DAS CLÍNICAS DA FACULDADE DE MEDICINA DE RIBEIRÃO PRETO DA UNIVERSIDADE DE SÃO PAULO \\ -ESCLARECIMENTO AO SUJEITO DA PESQUISA}

Nome da pesquisa: Ansiedade e depressão entre pacientes e cônjuges no perioperatório de revascularização do miocárdio: subsídios para a assistência de enfermagem.

Pesquisador responsável: Enf. Fernanda Gaspar Torrati (COREN 72.807)

Prof. Dra. Rosana Ap. Spadoti Dantas (COREN 44148)

Promotora da pesquisa: Escola de Enfermagem de Ribeirão Preto - USP

Enquanto enfermeiras, cuidamos de pacientes que sofreram uma cirurgia cardíaca e podemos observar em nosso dia a dia que muitas vezes essas pessoas referem mudanças no seu estado emocional. Algumas dizem estarem muito ansiosas e preocupadas com a cirurgia e a sua recuperação e também verbalizam estarem deprimidas com a sua situação de saúde. Diante disso, estamos realizando um estudo para conhecer o quanto os sentimentos de ansiedade e de depressão estão presentes durante a internação, ou seja, antes e depois da cirurgia cardíaca.

A sua participação neste estudo é voluntária. Caso decida participar, você irá responder a perguntas sobre a sua pessoa, a doença cardíaca e dos seus sentimentos sobre a cirurgia. O tempo da entrevista é de, aproximadamente, 30 minutos. Este estudo não oferece qualquer risco ou desconforto e asseguramos que você não será identificado. Embora sua participação não Ihe traga nenhum benefício diretamente, os resultados deste estudo nos ajudarão a conhecer como vivem e são ajudados os pacientes que sofrem do coração e que são atendidos neste hospital. Futuramente poderemos propor um atendimento que cada vez mais ajude o paciente a enfrentar a sua cirurgia cardíaca de uma maneira mais tranquila. Se decidir não participar da nossa pesquisa, ou resolver parar no meio da entrevista, sua decisão não acarretará nenhuma mudança no seu atendimento pelos profissionais do $\mathrm{HC}$.

Profa. Dra. Rosana A Spadoti Dantas

Telefone para contato: 602-3402

\section{Pesquisador responsável Fernanda Gaspar Torrati \\ Enfermeira da Unidade Pós Operatória de Cirurgia Torácica e Cardiovascular}

EU

$\mathrm{RG}$,abaixo assinado, tendo recebido as informações acima, e ciente dos meus direitos abaixo relacionados, concordo em participar.

1. A garantia de receber a resposta a qualquer pergunta ou esclarecimento de qualquer dúvida a respeito dos procedimentos, riscos, benefícios e de outras situações relacionadas com a pesquisa e o tratamento a que serei submetido.

2. A liberdade de retirar o meu consentimento e deixar de participar do estudo, a qualquer momento, sem que isso traga prejuízo à continuidade do meu tratamento.

3. A segurança de que não serei identificado e que será mantido o caráter confidencial da informação relacionada a minha privacidade.

4. O compromisso de que me será prestada informação atualizada durante o estudo, ainda que esta possa afetar a minha vontade de continuar dele participando.

5. O compromisso de que serei devidamente acompanhado e assistido durante todo o período de minha participação no projeto, bem como de que será garantida a continuidade do meu tratamento, após a conclusão dos trabalhos da pesquisa.

Ribeirão Preto, de de 


\section{APÊNDICE B}

\section{Instrumento de caracterização sócio-demográfica e clínica Versão 1}

1. Iniciais:

2. Registro HCRP :

3. Data do nascimento:

4. Data da entrevista:

5. Data da internação no HCRP:

6. Data da cirurgia:

7. Freqüentou até que série escolar:

8. Você faz uso de algum medicamento controlado, que precise de receita azul? ( ) sim ( ) não Se sim, qual (is)?

Há quanto tempo?

Com que freqüência?

9. Já esteve internado antes? ( ) sim ( ) não

Por quê?

10. Você já foi operado antes? ( ) sim （） não

Por quê?

11. Há quanto tempo você está esperando para ser operado do coração?

12. Sua cirurgia já foi remarcada alguma vez? ( ) sim （）não

Quantas?

13. Você sente dor com freqüência? ( ) sim （）não

14. Em que local?

15.Usa remédios para dor? ( ) sim （）não

16. Qual?

17. Você sente falta de ar? ( ) sim （） não

18. Em que situação (coes)? 


\section{APÊNDICE C}

Instrumento de caracterização sócio demográfica e clínica - versão após análise dos juízes e anterior ao estudo piloto

ID:

\section{Ansiedade e depressão do paciente no perioperatório de cirurgia cardíaca}

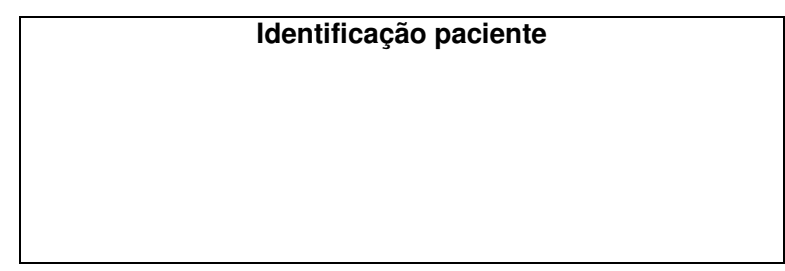

\section{Coleta de dados sociodemográficos e clínicos}

\section{Pré Operatório}

1. Data da entrevista:

Data nascimento:

2. Data internação:

3. Sexo: ( ) fem.

( ) mas.

4. Estado civil: ( ) solteiro ( ) casado/união consensual ( ) separado ( ) viúvo

5. Escolaridade (anos que freqüentou a escola)

( ) analfabeto ( ) $1^{\circ}$ grau incompleto ( ) $1^{\circ}$ grau completo ( ) $2^{\circ}$ grau incompleto

( ) $2^{\circ}$ grau completo ( ) superior incompleto ( ) superior completo

6. Situação profissional:

7. Diagnóstico principal:

8. Patologias associadas:

9. Uso de medicamentos controlados (com receita azul): ( ) sim ( ) não Quais?

Freqüência:

10. Cirurgia remarcada

( ) $\operatorname{sim}$

( ) não Quantas vezes?

11. Dor ( ) sim ( ) não Onde?

12. Dispnéia ( ) sim ( ) não

13. Observações: 


\section{Intra Operatório}

1. Data da cirurgia:

2. Cirurgia realizada:

3. Entrada em SO:

h Saída: h

4. Tempo de CEC:

5. Intercorrências:
( ) Sangramento
( ) Arritmia
( ) Hipertensão
( ) Hipotensão
( ) PCR
( ) Saída CEC difícil
( ) Outros

\section{Observações:}

\section{Pós operatório imediato \\ UPOTV}

1. Hora chegada: h

2. Drogas vindas de SO:

3. Drenos:

4. Drogas instaladas na UPOTV:

5. Transfusão hemocomponentes:

6. Retirada da COT: data hora h

7. Intercorrências:

( ) Arritmias ( ) Hipertensão

( ) Hipotensão ( ) Tamponamento 
( ) Náusea/vômito ( ) Hemotórax

( ) Sangramento

( ) Pneumotórax

( ) PCR ( ) Déficit neuro-sensorial

( ) Reoperação ( ) Dor

( ) Febre

( ) Outros

8. Alta Data:

Hora:

h Enfermaria:

9. Observações:

\section{Na enfermaria}

Durante sua internação na recuperação, o sr.(a) recebeu visita de seus familiares? ( ) sim ( ) não

\section{DOR}

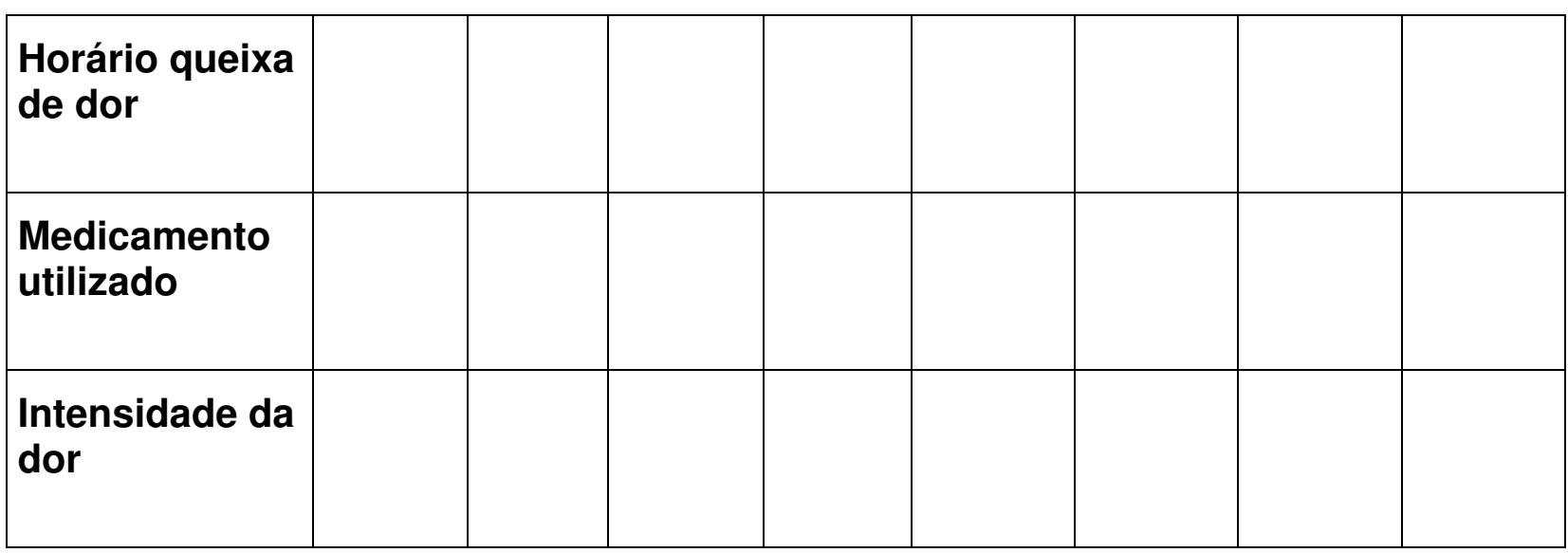




\section{APÊNDICE D}

\section{Versão final do instrumento de caracterização sócio-demográfica e clínica}

ID:

Ansiedade e depressão do paciente no perioperatório de cirurgia cardíaca

Identificação paciente

\section{Coleta de dados sociodemográficos e clínicos}

\section{Pré Operatório}

1. Data da entrevista:

Data nascimento:

Data internação:

2. Sexo:

1. ( ) fem.

2. ( ) mas.

3. Estado civil: 1. ( ) solteiro

2. ( ) casado/união consensual

3. ( ) separado

4. ( ) viúvo

4. Escolaridade: 1. ( ) analfabeto

2. ( ) $1^{\circ}$ grau incompleto

3. ( ) $1^{\circ}$ grau completo

4. ( ) $2^{\circ}$ grau incompleto

5. ( ) $2^{\circ}$ grau completo

6. ( ) superior incompleto

7. ( ) superior completo

5. Situação profissional

1. ativo

2. aposentado

3. aguardando aposentadoria

4. aposentado devido à cardiopatia

5. aposentado + trabalho

6. desempregado

7. desempenha atividades em casa (dona casa, auxilia casa

8. do lar

9. aposentadoria do marido ou esposa

6. Diagnóstico principal: Coronariopatia 1 1. ( ) sim $\quad 2$. ( ) não
Valvopatia
1. ( ) $\operatorname{sim}$
2. ( ) não

7. Tipo de

1. mitral

valvopatia:

2. aórtica

3. tricúspide

4. pulmonar

5. mitral + aórtica

6. mitral + tricúspide

7. mitral + aórtica + tricúspide

-88 não se aplica 
8. Patologias

Diabetes mellitus

1. ( ) $\operatorname{sim}$

2. ( ) não

associadas:

Hipertensão arterial sistêmica

1. ( ) $\operatorname{sim}$

2. ( ) não

Obesidade

1. ( ) $\operatorname{sim}$

2. ( ) não

Dislipidemia

1. ( ) sim

2. ( ) não

Hipotireoidismo

1. ( ) $\operatorname{sim}$

2. ( ) não

Problemas neurológicos

1. ( ) sim

2. ( ) não

Insuficiência renal crônica

1. ( ) $\operatorname{sim}$

2. ( ) não

Outras patologias associadas

1. ( ) sim

2. ( ) não

9. Uso de medicamentos controlados (com receita azul): 1. ( ) sim

2. ( ) não

$\begin{array}{ll}\begin{array}{ll}\text { 10. Quais? (Tipos } \\ \text { de medicamentos): }\end{array} & \begin{array}{l}\text { Ansiolíticos } \\ \text { Antidepressivos } \\ \text { Anticonvulsivantes }\end{array} \\ & 1 . \\ \text { 11. Frequência } & \text { 1. } 1 \text { vez } \\ \text { (vezes por dia): } & \text { 2. } 2 \text { vezes } \\ & \begin{array}{l}\text { 3. mais vezes } \\ \text { 4. esporadicamente }\end{array} \\ & -88 \text { não se aplica }\end{array}$

12. Cirurgia

1. 1 vez

2. 2 vezes

3. mais vezes

-88 não se aplica

13. Presença de dor

1. tórax

2. dor em outro local

3. tórax e em outro local

-88 não se aplica

13. Dispnéia: 1. ( ) sim

2. ( ) não

14. Observações: 
ID:

\section{Intra Operatório}

1. Data da cirurgia:

2. Cirurgia realizada:

1. Revascularização Miocárdio

2. Troca Valvar

3. Plastia Valvar

4. Revascularização Miocárdio com Troca Valvar

5. Revascularização Miocárdio com Plastia Valvar

6. Troca valvar com plastia valvar

7. Troca valvar + troca valvar

3. Entrada em So: h Saída: h Tempo de CEC:

4. Intercorrências em SO: 1. ( ) sim 2. ( ) não

Sangramento
Hipertensão
Hipotensão
Arritmia
PCR

1. ( ) sim

2. ( ) não

IAM trans.

1. ( ) sim

2. ( ) não

Saída CEC difícil

1. ( ) sim

2. ( ) não

Outras

1. ( ) $\operatorname{sim}$

2. ( ) não

1. ( ) $\operatorname{sim}$

2. ( ) não

1. ( ) $\operatorname{sim}$

2. ( ) não

1. ( ) $\operatorname{sim}$

2. ( ) não

2. ( ) não

5. Observações:

1. Hora chegada:

Pós operatório imediato - UPOTV

1. Horachegada: $\mathrm{h}$

2. Drogas vindas de 1. vasodilatador coronariano SO:

2. hipotensor

3. hipertensor

4. vasodilatador coronariano + hipotensor

5. vasodilatador coronariano + hipertensor

6. hipotensor + hipertensor

7. hipertensor + hipertensor -88 não se aplica

3. Drenos:
1. mediastinal
2. pleural direito
3. pleural esquerdo
4. mediastinal + pleural direito
5. mediastinal + pleural esquerdo
6. mediastinal + pleurais direito e esquerdo

4. Drogas instaladas 1. vasodilatador coronariano na UPOTV:

2. hipotensor

3. hipertensor

4. vasodilatador coronariano + hipotensor

5. vasodilatador coronariano + hipertensor

6. hipotensor + hipertensor

7. hipertensor + hipertensor

-88 não se aplica 
5. Transfusão de hemocomponentes na UPOTV:
1. concentrado hemáceas

2. plasma

3. plaquetas

4. crioprecipitado

5. concentrado hemáceas + plasma

6. concentrado hemáceas + plaquetas

7. concentrado hemáceas + crio

8. concentrado hemáceas + plaquetas + crio -88 não se aplica

Retirada da COT: data

6. Intercorrências na UPOTV: 1. ( ) sim 2. ( ) não

hora

\begin{tabular}{|c|c|c|}
\hline Arritmia & 1. ( ) sim & 2. ( ) nã-o \\
\hline Hipertensão & 1. ( ) sim & 2. ( ) não \\
\hline Hipotensão & 1. ( ) sim & 2. ( ) não \\
\hline Tamponamento & 1. ( ) sim & 2. ( ) não \\
\hline Náusea & 1. ( ) sim & 2. ( ) não \\
\hline Vômito & 1. ( ) sim & 2. ( ) não \\
\hline Hemotórax & 1. ( ) sim & 2. ( ) não \\
\hline Pneumotórax & 1. ( ) sim & 2. ( ) não \\
\hline Sangramento & 1. ( ) sim & 2. ( ) não \\
\hline PCR & 1. ( ) sim & 2. ( ) não \\
\hline Déficit neuro-sensorial & 1. ( ) sim & 2. ( ) não \\
\hline Reoperação & 1. ( ) sim & 2. ( ) não \\
\hline Dor & 1. ( ) sim & 2. ( ) não \\
\hline Número queixas & 1. ( ) sim & 2. ( ) não \\
\hline Agitação & 1. ( ) sim & 2. ( ) não \\
\hline Febre & 1. ( ) sim & 2. ( ) não \\
\hline Oligúria & 1. ( ) sim & 2. ( ) não \\
\hline Hiperglicemia & 1. ( ) sim & 2. ( ) não \\
\hline Queda $\mathrm{Hb}$ e Ht & 1. ( ) sim & 2. ( ) não \\
\hline IAM & 1. ( ) sim & 2. ( ) não \\
\hline Outras intercorrências & 1. ( ) sim & 2. ( ) não \\
\hline
\end{tabular}

6. Alta Data: Hora: h Enfermaria:

7. Observações:

8. Durante sua internação na recuperação, o sr.(a) recebeu visita de seus familiares?1. ( ) sim2. ( ) não DOR

\begin{tabular}{|l|l|l|l|l|l|}
\hline Horário queixa de dor & & & & & \\
\hline Medicamento utilizado & & & & & \\
\hline Intensidade da dor & & & & & \\
\hline
\end{tabular}




\section{APÊNDICE E \\ Escala de Ansiedade e Depressão Hospitalar (HAD) - Versão após análise semântica realizada no estudo piloto}

Marque com um $X$ a resposta que melhor corresponder a como você se sente agora, nesse momento da entrevista. Marque apenas uma resposta para cada pergunta.

Você não deve ficar pensando muito em cada questão. Neste questionário as respostas espontâneas e rápidas têm mais valor do que aquelas em que se pensa muito.

A Eu me sinto tenso ou contraído:

3 ( ) A maior parte do tempo

2 ( ) Boa parte do tempo

1 ( ) De vez em quando

0 ( ) Nunca

D Eu ainda sinto gosto pelas mesmas coisas de antes:

0 ( ) Sim, do mesmo jeito que antes

1 ( ) Não tanto quanto antes

2 ( ) Só um pouco

3 ( ) Já não sinto mais prazer em nada

A Eu sinto uma espécie de medo, como se alguma coisa ruim fosse acontecer:

3 ( ) Sim, e de um jeito muito forte

2 ( ) Sim, mas não tão forte

1 ( ) Um pouco, mas isso não me preocupa

0 ( ) Não sinto nada disso

D Dou risada e me divirto quando vejo coisas engraçadas:

0 ( ) Do mesmo jeito que antes

1 ( ) Atualmente um pouco menos

2 ( ) Atualmente bem menos

3 ( ) Não consigo mais

A Estou com a cabeça cheia de preocupações:

3 ( ) A maior parte do tempo

2 ( ) Boa parte do tempo

1 ( ) De vez em quando

0 ( ) Raramente

D Eu me sinto alegre:

3 ( ) Nunca

2 ( ) Poucas vezes

1 ( ) Muitas vezes

0 ( ) A maior parte do tempo 
A Consigo ficar sentado à vontade e me sentir relaxado:

0 ( ) Sim, quase sempre

1 ( ) Muitas vezes

2 ( ) Poucas vezes

3 ( ) Nunca

D Eu estou lento para pensar e fazer as coisas:

3 ( ) Quase sempre

2 ( ) Muitas vezes

1 ( ) De vez em quando

0 ( ) Nunca

A Eu tenho uma sensação ruim de medo, como um frio na barriga ou um aperto no estômago:

0 ( ) Nunca

1 ( ) De vez em quando

2 ( ) Muitas vezes

3 ( ) Quase sempre

D Eu perdi o interesse em cuidar da minha aparência:

3 ( ) Completamente

2 ( ) Não estou mais me cuidando como eu deveria

1 ( ) Talvez não me cuido tanto quanto antes

0 ( ) Me cuido do mesmo jeito que antes

A Eu me sinto inquieto, como se eu não pudesse ficar parado em lugar nenhum:

3 ( ) Sim, demais

2 ( ) Bastante

1 ( ) Um pouco

0 ( ) Não me sinto assim

D Fico esperando animado as coisas boas que estão por vir:

0 ( ) Do mesmo jeito que antes

1 ( ) Um pouco menos do que antes

2 ( ) Bem menos do que antes

3 ( ) Quase nunca

A De repente, tenho a sensação de entrar em pânico:

3 ( ) A quase todo momento

2 ( ) Várias vezes

1 ( ) De vez em quando

0 ( ) Não sinto isso

D Consigo sentir prazer quando assisto um bom programa de televisão, de rádio, ou quando leio alguma coisa:

0 ( ) Quase sempre

1 ( ) Várias vezes

2 ( ) Poucas vezes

3 ( ) Quase nunca 


\section{ANEXOS}

\section{ANEXO A}

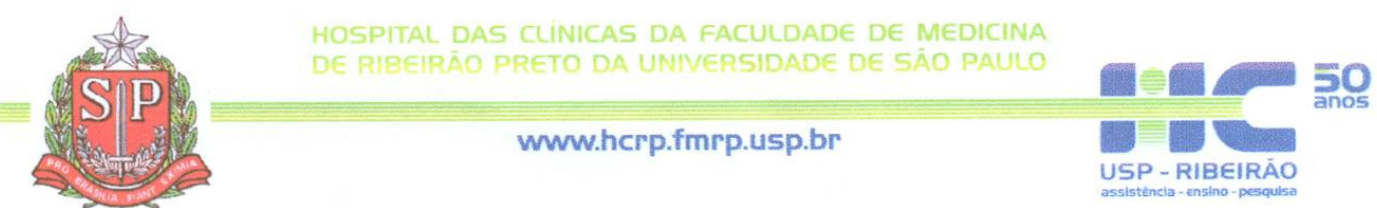

Ribeirão Preto, 20 de dezembro de 2006

Ofício $\mathrm{n}^{\circ} 3687 / 2006$

$\mathrm{CEP} / \mathrm{SPC}$

Prezada Senhora,

O trabalho intitulado “ANSIEDADE E DEPRESSÃO ENTRE PACIENTES E CÔNJUGES NO PERIOPERATÓRIO DE REVASCULARIZAÇÃO DO MIOCÁRDIO: SUBSÍDIOS PARA A ASSISTÊNCIA DE ENFERMAGEM", foi analisado pelo Comitê de Ética em Pesquisa, em sua $239^{a}$ Reunião Ordinária realizada em 18/12/2006, e enquadrado na categoria: APROVADO, bem como o Termo de Consentimento Livre e Esclarecido, de acordo com o Processo HCRP $\mathrm{n}^{\circ}$ $13521 / 2006$.

Atenciosamente.

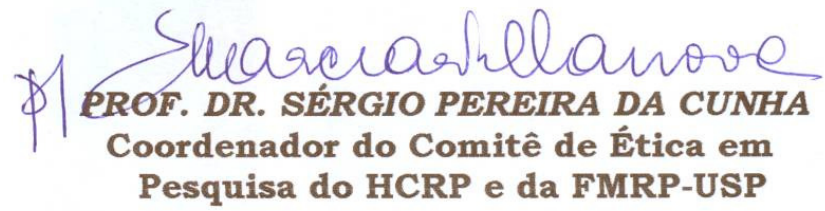

Ilustríssima Senhora

FERNANDA GASPAR TORRATI

PROF $^{a}$ DR $^{\text {a }}$ ROSANA APARECIDA SPADOTI DANTAS (Orientadora)

Escola de Enfermagem de Ribeirão Preto-USP 


\section{ANEXO B \\ Escala de Ansiedade e Depressão Hospitalar (HAD) ${ }^{1}$}

Marque com um X a resposta que melhor corresponder a como você se sente agora. Não é preciso ficar pensando muito em cada questão. Neste questionário as respostas espontâneas têm mais valor do que aquelas em que se pensa muito. Marque apenas uma resposta para cada pergunta.

A Eu me sinto tenso ou contraído:

3 ( ) A maior parte do tempo

2 ( ) Boa parte do tempo

1 ( ) De vez em quando

0 ( ) Nunca

D Eu ainda sinto gosto pelas mesmas coisas de antes:

0 ( ) Sim, do mesmo jeito que antes

1 ( ) Não tanto quanto antes

2 ( ) Só um pouco

3 ( ) Já não sinto mais prazer em nada

A Eu sinto uma espécie de medo, como se alguma coisa ruim fosse acontecer:

3 ( ) Sim, e de um jeito muito forte

2 ( ) Sim, mas não tão forte

1 ( ) Um pouco, mas isso não me preocupa

0 ( ) Não sinto nada disso

D Dou risada e me divirto quando vejo coisas engraçadas:

0 ( ) Do mesmo jeito que antes

1 ( ) Atualmente um pouco menos

2 ( ) Atualmente bem menos

3 ( ) Não consigo mais

A Estou com a cabeça cheia de preocupações:

3 ( ) A maior parte do tempo

2 ( ) Boa parte do tempo

1 ( ) De vez em quando

0 ( ) Raramente

D Eu me sinto alegre:

3 ( ) Nunca

2 ( ) Poucas vezes

1 ( ) Muitas vezes

0 ( ) A maior parte do tempo

A Consigo ficar sentado à vontade e me sentir relaxado:

1 ( ) Sim, quase sempre

2 ( ) Muitas vezes

3 ( ) Poucas vezes

4 ( ) Nunca

'ZIGMOND, A. S.; SNAITH, R. P. The hospital anxiety and depression scale. Acta Psychiatrica Scandinavica, n. 67, p. 361-370, 1983. Adaptado por Botega et al. (1998) 
D Eu estou lento para pensar e fazer as coisas:
3 ( ) Quase sempre
2 ( ) Muitas vezes
5 ( ) De vez em quando
$0 \quad$ ( ) Nunca

A Eu tenho uma sensação ruim de medo, como um frio na barriga ou um aperto no estômago:

$\begin{array}{ll}0 & \text { ( ) Nunca } \\ 1 & \text { ( ) De vez em quando } \\ 2 & \text { ( ) Muitas vezes } \\ 3 & \text { ( ) Quase sempre }\end{array}$

D Eu perdi o interesse em cuidar da minha aparência:

3 ( ) Completamente

2 ( ) Não estou mais me cuidando como eu deveria

1 ( ) Talvez não tanto quanto antes

0 ( ) Me cuido do mesmo jeito que antes

A Eu me sinto inquieto, como se eu não pudesse ficar parado em lugar nenhum:

3 ( ) Sim, demais

2 ( ) Bastante

1 ( ) Um pouco

0 ( ) Não me sinto assim

D Fico esperando animado as coisas boas que estão por vir:

0 ( ) Do mesmo jeito que antes

1 ( ) Um pouco menos do que antes

2 ( ) Bem menos do que antes

3 ( ) Quase nunca

A De repente, tenho a sensação de entrar em pânico:

3 ( ) A quase todo momento

2 ( ) Várias vezes

1 ( ) De vez em quando

0 ( ) Não sinto isso

D Consigo sentir prazer quando assisto um bom programa de televisão, de rádio, ou quando leio alguma coisa:
0 ( ) Quase sempre
1 ( ) Várias vezes
2 ( ) Poucas vezes
3 ( ) Quase nunca 


\section{ANEXO C \\ Questionário de Senso de Coerência de Antonovsky²}

Aqui está uma série de questões relacionadas a vários aspectos de nossas vidas. Cada questão tem sete respostas possíveis. Por favor, marque o número que expressa sua resposta, com números de 1 a 7. Se você estiver de acordo com as palavras abaixo do número 1, circule o número 1 . Se você estiver de acordo com as palavras abaixo do número 7 , circule o número 7 . Se sua resposta for diferente, circule o número que melhor expressa seus sentimentos. Por favor, marque só uma resposta para cada questão (Mostrar exemplo de preenchimento de acordo com o sexo do paciente).

1. Quando você conversa com outras pessoas tem a sensação de que elas não te entendem?
1
2
3
4
5
6
7

Nunca tenho

essa

sensação

Sempre tenho essa sensação

2. Quando você precisou fazer algo que dependia da colaboração de outros, você teve a sensação de que:

1

2

3
4

5
6
7

Com certeza seria feito

Com certeza

não seria feito

3. Pense nas pessoas com quem você tem contato diariamente e das quais não se sente muito próximo, pois não são seus familiares e amigos íntimos. Como você acha que conhece a maioria dessas pessoas?
1
2
3
4
5
6
7

Você sente

que não as

Você as

conhece

conhece muito bem

4. Com que freqüência você tem a sensação de que não se importa com o que está se acontecendo ao seu redor:

$$
1
$$

2

3

4

5

6

7

Raramente ou nunca

Com muita freqüência

5. Alguma vez já aconteceu de você se surpreender com o comportamento de pessoas que você achava que conhecia bem?

1

23

4

5

6

7

Nunca

aconteceu

6. Já aconteceu das pessoas com quem você contava te decepcionarem?

1

2

3

4

5

6

7

Nunca

aconteceu

Sempre

aconteceu

\footnotetext{
2 ANTONOVSKY, A. Unraveling the mystery of health. São Franscisco: Jossey-Bass. 1987.
} Adaptado por Dantas (2007). 
7. A vida é:

1

Muito

interessante
2

3

4

5

6

7

Muito rotineira

8. Até agora, sua vida tem sido:

$$
1
$$

2

3

4

5

6

7

Sem qualquer

objetivo ou

finalidade
Com finalidade e objetivos claros

9. Com que freqüência você tem a sensação de que está sendo tratado injustamente?

1

2

Com muita freqüência

4

5

6

Raramente ou nunca

10. Nos últimos dez anos sua vida tem sido:

$$
1
$$

2

3

4

5

6
Completamente previsível (esperada)$$
\text { mudanças sem }
$$

$$
\begin{aligned}
& \text { que você } \\
& \text { soubesse o que } \\
& \text { iria acontecer } \\
& \text { em seguida }
\end{aligned}
$$

11. A maior parte das coisas que você fará no futuro provavelmente será:
1
2
3
4
5

6

7

Completamente

fascinante

Extremamente chata

12. Com que freqüência você tem a sensação de que está numa situação desconhecida e não sabe o que fazer?
1
2

3

4

5

6

7

Com muita

freqüência

Raramente ou nunca

13. Como você vê a vida?

1

2

3

4

5

6

7

Sempre se pode achar uma

solução para os

sofrimentos da

vida

Não há solução para os sofrimentos da vida

14. Quando você pensa na sua vida, freqüentemente você:

1

2

3

4

5

6

7

Sente o quanto

é bom estar vivo

Pergunta a si mesmo por que você existe

\footnotetext{
${ }^{2}$ ANTONOVSKY, A. Unraveling the mystery of health. São Franscisco: Jossey-Bass. 1987.
} Adaptado por Dantas (2007). 
15. Quando você enfrenta um problema difícil, a escolha de uma solução é:

1

2

3 7

Sempre

confusa e

difícil de

encontrar
6

$4 \quad 5$

Sempre

completamente clara e fácil de encontrar

16. Fazer as coisas que você faz todos os dias é:

1

2

3

4

5

6

7

Uma fonte

de grande

prazer e

satisfação

17. Sua vida no futuro provavelmente será:

2

3

4

5

6

Cheia de

mudanças

sem que

você saiba 0

que

acontecerá

em seguida
7

Uma fonte de sofrimento e chatice

Completamente previsível (esperada)

18. Quando algo desagradável aconteceu, sua tendência foi:

1

2

3

4

5

Ficar se

"remoendo

de raiva"

sobre o

acontecido
19. Com que freqüência você tem sentimentos e idéias bastante confusas?
1

2

3

Com muita

freqüência
4

4

6

6

6

7

Dizer "está tudo bem, tenho que viver com isso" e seguir em frente

20. Quando você faz algo que the dá uma sensação boa, o que você sente:

$$
1
$$

2

3

4

5

6

7

Com certeza

você

continuará

sentindo-se

bem
Com certeza algo acontecerá para estragar essa sensação

\footnotetext{
2 ANTONOVSKY, A. Unraveling the mystery of health. São Franscisco: Jossey-Bass. 1987.
} Adaptado por Dantas (2007). 
21. Com que freqüência acontece de você ter sentimentos que você preferiria não sentir?
1
2
3
4
5
6

7

Com muita

freqüência

Raramente ou nunca

22. Você acha que sua vida pessoal no futuro será:
1
2
3
4
5
6
7
sem
Cheia de significado e finalidade

Totalmente

significado e

finalidade

23. Você acha que sempre existirão pessoas com quem você poderá contar no futuro?
1
2
3
4
5
6

7

Você está certo

de que essas

pessoas

existirão

Você duvida que essas pessoas

existirão

24. Com que freqüência você tem a sensação de que não sabe exatamente o que está para acontecer?
1
2
3
4
5
6

Com muita

freqüência

Raramente ou nunca

25. Muitas pessoas - mesmo aquelas muito fortes - algumas vezes se sentem como fracassadas em certas situações. Com que freqüência você já se sentiu dessa maneira?
1
2
3
4
5
6
7

Nunca

Com muita freqüência

26. Quando alguma coisa acontece a você, em geral você acha que:

1

2

$$
\begin{gathered}
\text { Você deu } \\
\text { muita ou } \\
\text { pouca } \\
\text { importância } \\
\text { para o que } \\
\text { aconteceu }
\end{gathered}
$$

$4 \quad 5$

3
5
6

7

Você viu as coisas na medida certa

27. Quando você pensa nas dificuldades que provavelmente terá que enfrentar em aspectos importantes de sua vida, você tem a sensação de que:

1

2

3

4

5

6

7

Sempre terá sucesso em superar as dificuldades

Não terá sucesso em superar as dificuldades

\footnotetext{
${ }^{2}$ ANTONOVSKY, A. Unraveling the mystery of health. São Franscisco: Jossey-Bass. 1987.
} Adaptado por Dantas (2007). 
28. Com que freqüência você tem a sensação de que há pouco significado nas coisas que faz na sua vida diária?

1

2

3

4

5

6

7

Com muita freqüência

29. Com que freqüência você tem a sensação de que você não consegue manter seu auto-controle?

1

Com muita

freqüência
2

3

4

5

6

7

Raramente ou nunca

2 ANTONOVSKY, A. Unraveling the mystery of health. São Franscisco: Jossey-Bass. 1987. Adaptado por Dantas (2007). 


\section{ANEXO D}

\section{Escala de Estressores em Terapia Intensiva- ICUESS ${ }^{3}$}

Por favor, marque o número que melhor expressa sua resposta. Não existe resposta certa ou errada. Marque apenas uma das opções.

\begin{tabular}{|c|c|c|c|}
\hline Não & Pouco & Estressante & Muito \\
Estressante & Estressante & & Estressante \\
1 & 2 & 3 & 4 \\
\hline
\end{tabular}

1

1-Estar amarrado por tubos

2-A enfermeira não se apresentar pelo nome

3-Sentir que a enfermeira está muito apressada

4-Ter sede

5-Medir a pressão arterial muitas vezes ao dia

6-Cama e/ou travesseiros inconfortáveis

7-Escutar o telefone tocar

8-Ser examinado por médicos e enfermeiros constantemente

9-Ter máquinas estranhas ao redor

10-Sentir que a enfermagem esta mais atenta aos equipamentos do que a você

11-Escutar o barulho e os alarmes dos equipamentos

12-Enfermagem e médicos falando muito alto

13-Ter que usar oxigênio

14-Sentir falta do marido ou da esposa

15-Não ter explicações sobre o tratamento
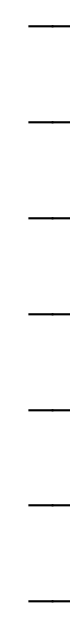

2 3
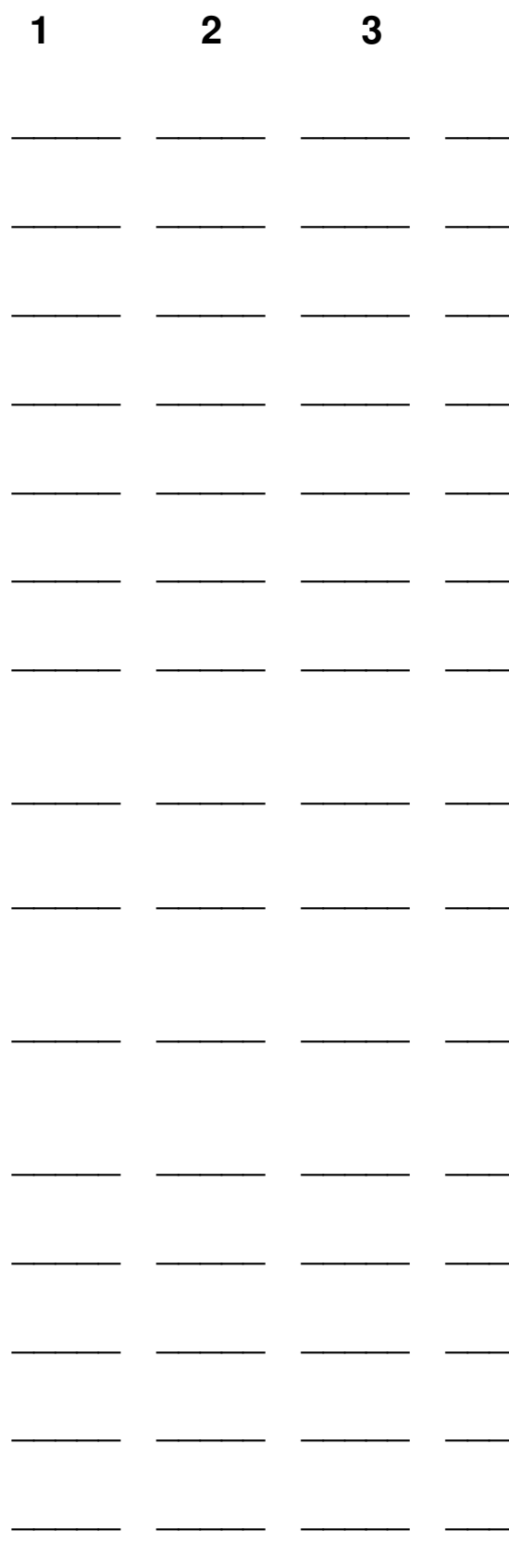

\footnotetext{
${ }^{3}$ BALLARD, K. S. Identification of environmental stressors for patients in a surgical intensive care unit. Issues in Mental Health Nursing, v. 1, n. 3, p. 89-108, 1981. Traduzido por Novaes et al (1997).
} 


\section{Escala de Estressores em Terapia Intensiva - ICUESS}

Por favor, marque o número que melhor expressa sua resposta. Não existe resposta certa ou errada. Marque apenas uma das opções.

\begin{tabular}{|c|c|c|c|c|}
\hline $\begin{array}{c}\text { Não } \\
\text { Estressante } \\
1\end{array}$ & $\begin{array}{c}\text { Pouco } \\
\text { Estressante } \\
2\end{array}$ & Estressante & $\begin{array}{c}\text { Muito } \\
\text { Estressante } \\
4\end{array}$ \\
\hline \multicolumn{1}{|r}{} & 3 & 3 & 4 \\
\hline
\end{tabular}

16-Escutar os alarmes do monitor cardíaco despertarem.

17-Ter enfermagem constantemente fazendo tarefas ao redor do leito

18-Ter tubos no nariz e/ou na boca

19-Não saber que horas são

20-Escutar o gemido de outros pacientes

21-Ter homens e mulheres internados no mesmo ambiente

22- Ver a família e os amigos por apenas alguns minutos

23-Não saber quando as coisas vão ser feitas

24-Ser acordado pela enfermagem

25-Sons e ruídos desconhecidos

26-Assistir aos cuidados médicos e de enfermagem realizados em outros pacientes

27-Ter que ficar olhando para os detalhes do teto

28-Não conseguir dormir

29-Não conseguir mexer as mãos ou os braços devido às vias intravenosas

\footnotetext{
${ }^{3}$ BALLARD, K. S. Identification of environmental stressors for patients in a surgical intensive care unit. Issues in Mental Health Nursing, v. 1, n. 3, p. 89-108, 1981. Traduzido por Novaes et al (1997).
} 


\section{Escala de Estressores em Terapia Intensiva - ICUESS}

Por favor, marque o número que melhor expressa sua resposta. Não existe resposta certa ou errada. Marque apenas uma das opções.

\begin{tabular}{|c|c|c|c|}
\hline Não & Pouco & Estressante & Muito \\
Estressante & Estressante & 3 & Estressante \\
1 & 2 & 3 & 4 \\
\hline
\end{tabular}

30-Sentir cheiros estranhos

31-Ter luzes acesas constantemente

32-Ter dor

33-Ver as bolsas de soros penduradas sobre a cabeça

34-Ser furado por agulhas

35-Não saber onde está

36-Ter a equipe falando termos

incompreensíveis

37-Não ter controle de si mesmo

38-Não saber que dia é hoje

39-Ser incomodado

40-Não ter privacidade

41-Ser cuidado por médicos desconhecidos

42-Estar num ambiente muito quente ou muito frio
1

2

3

4
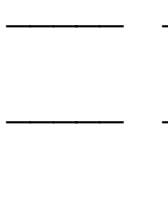

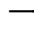
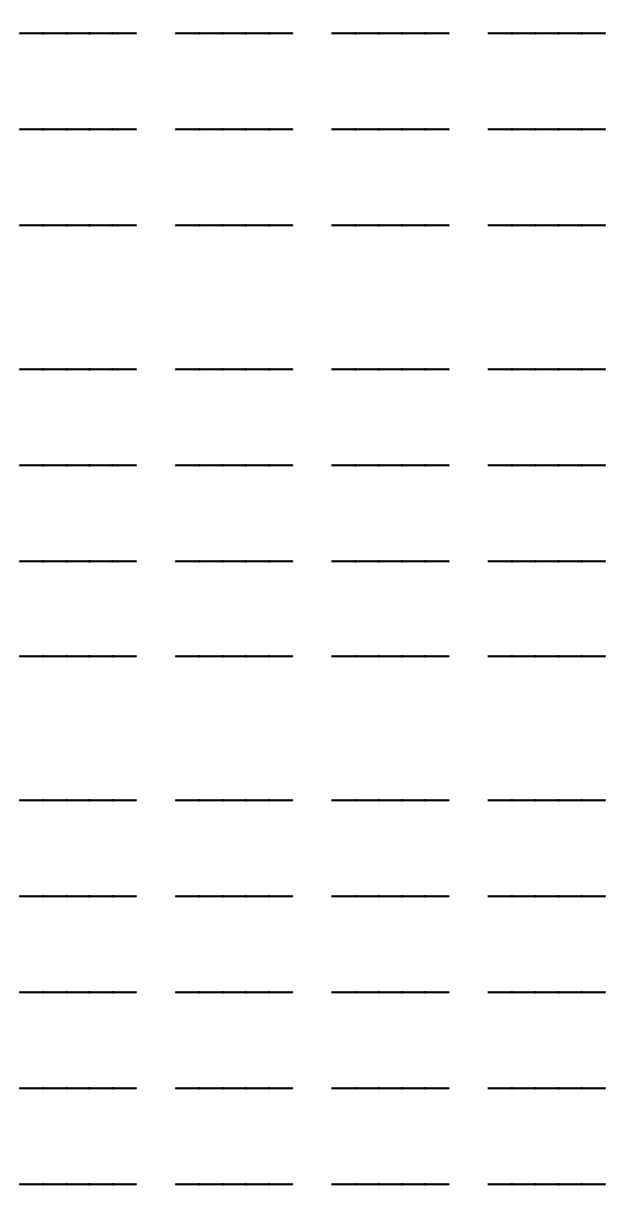